\title{
Feasibility Study on Machining Super-dimensioned Aviation Deep-hole Ti6Al4V Part With Axial Ultrasonic Vibration-assisted Boring
}

He Sui ( $\sim$ hsui@cauc.edu.cn )

College of Aeronautical Engineering, Civil Aviation University of China, Tianjin 300300, China

Lifeng Zhang

College of Aeronautical Engineering, Civil Aviation University of China, Tianjin 300300, China

\section{Shuang Wang}

Information Security Evaluation Center of Civil Aviation, Civil Aviation University of China, Tianjin 300300, China

\section{Zhaojun Gu}

Information Security Evaluation Center of Civil Aviation, Civil Aviation University of China, Tianjin 300300, China

\section{Research Article}

Keywords: Aviation deep-hole part, Titanium alloy Ti6Al4V, Ultrasonic vibration-assisted cutting, Boring

Posted Date: May 29th, 2021

DOI: https://doi.org/10.21203/rs.3.rs-544711/v1

License: (c) (i) This work is licensed under a Creative Commons Attribution 4.0 International License. Read Full License 


\title{
Feasibility study on machining super-dimensioned aviation deep-hole Ti6Al4V part with axial ultrasonic vibration-assisted boring
}

\author{
He Sui ${ }^{a}{ }^{*}$, Lifeng Zhang ${ }^{a}$, Shuang Wang ${ }^{\mathrm{b}}$, Zhaojun $\mathrm{Gu}^{\mathrm{b}}$ \\ ${ }^{a}$ College of Aeronautical Engineering, Civil Aviation University of China, Tianjin 300300, China \\ ${ }^{\mathrm{b}}$ Information Security Evaluation Center of Civil Aviation, Civil Aviation University of China, Tianjin 300300, China \\ * Corresponding author. Tel. /fax: +86022 24092294. E-mail address: hsui@cauc.edu.cn (H. Sui)
}

\section{Abstract}

Deep-holes are typical super-dimensioned parts of aircraft structures, with associated machining technology which is recognized as challenging due to the difficult-to-machine material, the narrow and enclosed machining environment, and the weak rigidity and large deformation of the boring bar. Axial ultrasonic vibration-assisted cutting has been proved to greatly enhance machining performance, especially in the precision machining of aviation alloy. This paper focuses on the machining of a super-dimensioned titanium alloy Ti6Al4V aviation deep-hole part (aspect ratio exceeding 20) with the axial ultrasonic vibration-assisted boring (AUVB) method. First, the kinetics of the AUVB process is analyzed and a retrospective of its separation cutting feature is provided. Subsequently, a multistep cantilever beam model of the boring bar is established to analyze its static rigidity and dynamic stability. The aperture error of bored hole is deduced, and it is found to be mainly determined by the diameter of the basic hole, the cutting depth, the boring force and the length, diameter, elastic modulus, and rotational inertia of each step. Size coefficient, rather than aspect ratio, is then put forward to represent the static rigidity of the boring bar, which is proportional to the third power of the diameter and inversely proportional to the fourth power of the diameter. In addition, two different vibration cases, namely modal-coupling vibration and regenerative vibration are considered for dynamic stability analysis. The actual dynamic rigidity of AUVB in both of these cases is larger than that of conventional boring (CB), resulting from the lower actual boing force and the larger actual cutting depth. Next, the morphology of bored surface is analyzed, and the geometric height of peaks formed by AUVB and CB are calculated. Phase shift $\varphi=\pi$ is suggested for obtaining a better surface in AUVB. Finally, the feasibility of AUVB on machining a super-dimensioned titanium alloy Ti6Al4V aviation deep-hole part with three different sizes of boring bar (size coefficients are 7473, 4076 and 2718, respectively) is verified through systematic experiments, and compared with CB. Results demonstrate that AUVB has obvious advantages in reducing the boring force, improving boring accuracy, suppressing vibration and promoting surface quality. Furthermore, the aperture error decreases to $50 \%$ and 
vibration amplitudes decrease to only $20 \%-25 \%$. The overall surface roughness of the deep-hole part stays below $\mathrm{Ra}=0.8 \mu \mathrm{m}$ with rotational speeds of $60 \mathrm{r} / \mathrm{min}$ and $80 \mathrm{r} / \mathrm{min}$, and the surface residual stress state is transferred from the tensile state to a compressive one. As a result, not only AUVB can provide better boring accuracy and surface finish, but it also can enhance the surface fatigue properties.

Key words: Aviation deep-hole part; Titanium alloy Ti6Al4V; Ultrasonic vibration-assisted cutting; Boring

\section{Introduction}

With the trend to lightweight materials in the aerospace industry, super-dimensioned parts are becoming increasingly abundant in aircraft structures, and deep-hole parts are a typical representative among them. Chern and Liang [1] pointed that machining of deep-hole has been acknowledged as difficult technology due to both the difficult-to-machine aeronautical material and the narrow and enclosed machining environment. Li et al. [2] found that boring was an effective method to manufacture deep-hole part for achieving lower machining force. Zhang et al. [3] showed that boring could also obtain better surface integrity, which meant better machining accuracy and fatigue property of the deep-hole part. However, with the increasing aspect ratio of deep-hole parts, the deformation and vibration of the boring bar caused by the acting forces has become an imminent problem. A vibration-absorbing boring bar, active control, and ultrasonic vibration-assisted cutting are the three main approaches to suppress chatter and improve accuracy in the deep-hole part boring process.

Considerable research have been carried out on designing and manufacturing boring bars with vibration absorber function. Dai et al. [4] reported that the dynamic rigidity was increased by $30 \%$ and chatter was significantly suppressed by using a high rigidity and damping composite boring bar. Zhou and Jiang [5] proposed an identification method of the variation source during the deep-hole machining process based on the Dempster-Shafter theory, which notably improved the boring accuracy. Zhang et al. [6] designed and analyzed a tapered carbon composite boring bar to match the need for high-speed cutting, and their boring bar model based on the Adomian modified decomposition method (AMDM) provided guidelines to improve the surface finish. Ghorbani et al. [7] designed a composite boring bar with enhanced damping 
capacity, which improved the logarithmic decrement from 0.1 to 0.4 , the eigenfrequency to $15 \%$, and the surface quality up to $30 \%$. Sastry et al. [8] undertook an experimental investigation of the process of boring HSLA ASTM A36 steel with a transmogrified boring bar, resulting in $16.1-59.8 \%$ reduction in cutting force, $53.38-78.36 \%$ in cutting temperature and 27.76-70.23\% in surface roughness. Moreover, Song et al. [9] designed a boring bar with constrained layer damper, which improved the capability of chatter suppression by 5 -fold.

Active control acts on the boring bar by a feed forward or a feedback system. Chen et al. [10] studied on the active control which depended on the detection of relative vibration or cutting force between the bar and workpiece through magnetic actuators. Matsubara et al. [11] realized this detection with another way through piezoelectric actuators. Chen et al. [12] also presented an active damping method with a self-designed magnetic actuator, and experimentally tested it on a CNC lathe. Results demonstrated that the dynamic rigidity of the boring bar considerably improved, leading to a significant increase in the chatter-free material removal rate. Som et al. [13] developed a new semi-active damper for a high aspect ratio boring bar, and showed good damper attenuation capability for wide-frequency band by applying various cutting conditions corresponding to chatter frequencies. Vashisht and Peng [14] proposed an optimal fractional order PD lambda controller to achieve sufficiently active chatter mitigation for boring operation through an electromagnetic actuator, and reported the increase of critical cut depth from $0.2 \mathrm{~mm}$ (open loop) to $0.6 \mathrm{~mm}$ (closed loop) with a limited actuator size. Fallah and Moetakef-Imani [15] described a novel adaptive direct velocity feedback (DVF) controller on the basis of integrated electronics piezoelectric (IEPE) accelerometer, and observed that the adaptive DVF controller enhanced the dynamic rigidity of the boring bar by 11.4-fold in the internal turning of aluminum alloy 6063-T6. In addition, the stable cutting process was successfully performed with a maximum cutting depth of $2 \mathrm{~mm}$, however, the critical cutting depth was anticipated as only $0.2 \mathrm{~mm}$ for a conventional slender boring bar. The active control method has addressed the shortcomings of the limited applicability of the vibration absorber boring bar. Nonetheless, the large brake and complex control system prevents its wide application in actual mechanical processing; at present, deep-hole boring remains a process with high cost. 
The ultrasonic vibration-assisted machining technology has been widely used in precision machining in recent years. Several studies have demonstrated that weak rigidity processing can obtain satisfactory machining performance, which is similar to deep-hole boring. Ma et al. [16] experimentally and theoretically proved that the regenerative chatter occurring in ordinary cutting process can be effectively suppressed by adding ultrasonic elliptical vibration on the cutting tool, as an effect of reduction of cutting force and energy input into the cutting system. The dynamical equation was presented by Gao and Altintas [17] in order to analyze the stability of ultrasonic elliptical vibration-assisted milling operation. They used a semi-discrete timedomain method to solve the stability equation of the system, and experimentally validated the result in milling Aluminum Al-7050 and AISI-1045 steel. Experimental results showed that ultrasonic vibration can notably increase the stable cutting depth. Gao et al. [18] performed experiments on the ultrasonic vibration-assisted cutting of stainless steel, and results showed that ultrasonic vibration could suppress chatter, increase cutting stability and decrease surface roughness. Dong et al. [19] proposed a rotary ultrasonic drilling technology for machining deep holes, and reported that it could reduce the cutting force and suppress lateral chatter. The author [20] established a coupling chatter model for the deep-hole boring system, and they analyzed and verified the reduction of boring bar vibration and the improvement of bored surface due to the ultrasonic vibration-assisted machining method. Zhang et al. [21] demonstrated that ultrasonic vibration-assisted boring can effectively overcome the chip block problem, reduce the aperture error and surface roughness, suppress the chatter at the same time, and thus improve the deep-hole boring machining quality. Dong et al. [22] designed an ultrasonic elliptical vibration boring device for deep-hole parts, and experimentally confirmed that it can significantly reduce the boring force, surface roughness, cutting chip length, and vibration during the machining of high-strength steel $18 \mathrm{Cr} 2 \mathrm{Ni} 4 \mathrm{WA}$.

Saoubi et al. [23] pointed that titanium alloy has attracted tremendous attention, and has been extensively applied for structural components in the aerospace industries. However, Zheng et al. [24] regarded titanium alloy as a typical difficult-to-machine material due to its low thermal conductivity and high heat capacity. Therefore, Ti6Al4V was chosen as subject for the current research. For Ti6Al4V, the machining performance of the traditional ultrasonic vibration-assisted cutting method cannot be guaranteed with the increase of cutting speed. All 
of the advantages achieved by the vibration-assisted cutting method result from its separation cutting feature, which disappear if the cutting speed exceeds the critical value. Therefore, the author [25] proposed a kind of axial ultrasonic vibration-assisted cutting method, where a tool vibrates along the axial direction, which results in better performance in machining titanium alloy. Then the author [26] revealed the transient separation cutting feature and force reduction mechanism of this method. Zhang et al. [27] theoretically analyzed and experimentally verified the influence of flank interference and tool wear on the separation cutting feature. A partial separation state and the existence of a flank face interference, which was observed to alter the duty ratio from 1 to a value less than 1, were proposed. In addition, an analytical micro transient cutting force mode was also developed and verified [28]. Liu et al. [29, 30] successfully applied this method in the high-speed milling of Ti6Al4V, and obtained a positive impact on extending the tool lifespan by up to 6.4-fold, lowering the cutting force, shortening the chips, elevating compressive residual stresses, and achieving a greater plastic deformation. This method was used by $\mathrm{Li}$ et al. [31] for machining $\mathrm{SiC}$ sensor diaphragms of $20.3 \mu \mathrm{m}$ thickness by mill grinding, where the axial grinding force was consequently reduced by $60 \%-70 \%$. Geng et al. [32] also applied the technique for drilling a small diameter carbon-reinforced polymer hole. As a result, both the thrust and transverse forces were remarkably reduced with maximum decrements of $71.3 \%$ and $61.5 \%$, respectively. It is therefore evident that this technology is effective for difficult-to-machine material due to the separation cutting feature, which is closely related to machining performance. Therefore, the application of the axial ultrasonic vibrationassisted method has great potential in deep-hole processing, especially of Ti6Al4V materials.

This paper focuses on a feasibility study of machining titanium alloy Ti6Al4V superdimensioned aviation deep-hole parts by the axial ultrasonic vibration-assisted boring (AUVB) method. First, the separation cutting feature in the AUVB process is demonstrated, and the static rigidity and dynamic stability of the boring bar are analyzed. Next, the surface morphology model is established, and the height of peaks in a morphology unit formed by AUVB and CB are calculated theoretically. Finally, the performance of AUVB on boring force, processing vibration, aperture accuracy and surface quality are all investigated experimentally. 


\section{Theoretical analysis}

\subsection{Kinetics analysis}

An axial ultrasonic vibration-assisted deep-hole boring system is established for further analysis, as shown in Fig. 1(a). The ultrasonic vibration is added in the axial direction of the deep hole, which is also the feed direction of the boring bar:

$$
\left\{\begin{array}{l}
x=\frac{d}{2}-a_{\mathrm{p}} \\
y=n \pi d \cdot t \\
\left.z=A \sin \left(2 \pi F_{u} t+\phi\right)+\frac{n f}{60} \cdot t\right]
\end{array}\right.
$$

where $d$ represents the diameter of the basic hole to be bored; $\mathrm{a}_{\mathrm{p}}$ is the nominal cutting depth; $n$ indicates rotational speed; $A$ is the ultrasonic vibration amplitude; $F_{u}$ denotes the ultrasonic vibration frequency; $\phi$ is the phase shift; $f$ stands for feed rate.

The trajectory of the tool tip is exhibited in Fig. 1(b). The cutting trajectory of the CB process is a helical line in the $X-Y-Z$ coordinate space. However, the trajectory of the AUVB process is a sinusoidal curve spiraling upward, and the center line of the sinusoidal curve is the helix line described above in the CB process. With the effective control of feed rate, the adjacent cutting trajectories may cross each other in the Z-axial direction for AUVB.
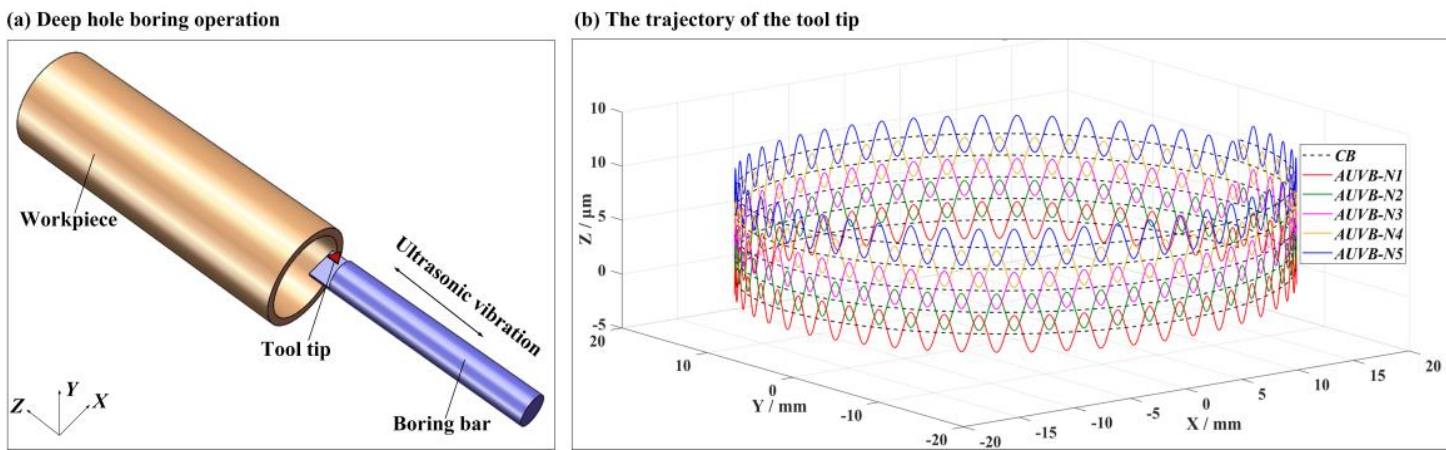

Fig. 1 Schematic of axial ultrasonic vibration-assisted boring

The crossing of the cutting trajectories within several adjacent rotations form a cutting duration and a separation duration, which constitutes the separation cutting feature, as exhibited by the extended plane of the workpiece in Fig. 2(a). The two adjacent cutting trajectories clearly 
intersect each other, creating the embodiment of the separation cutting feature. The distance between two adjacent trajectories in the $Z$-axial direction constitutes the feed rate. The amplitude and frequency of the sinusoidal curves for two adjacent trajectories are the same, however, there is a difference in the initial phases of the curves, namely phase shift. The critical conditions of the separation cutting feature in the two adjacent trajectories are tangent, as shown in Fig. 2(b). Subsequently, the separation cutting conditions, including feed rate $f$, amplitude $A$ and phase shift $\phi$ for AUVB, can be established as given in the literature [25].

$2 \arcsin \left(\frac{f}{2 A}\right) \leq \phi \leq 2 \pi-2 \arcsin \left(\frac{f}{2 A}\right) \quad(f \leq 2 A)$

(a) The extended plane of the workpiece

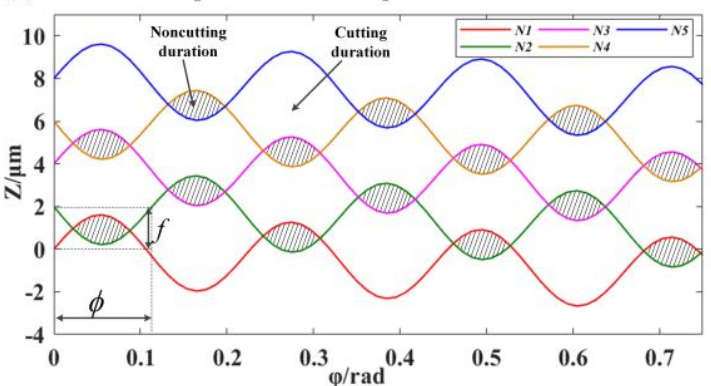

(b) The critical condition of separating cutting

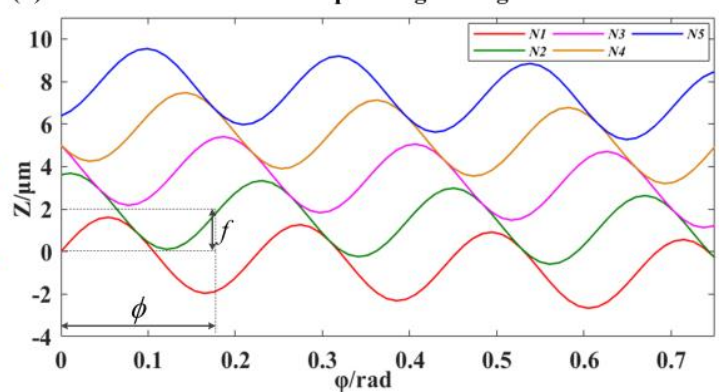

Fig. 2 Separation cutting feature of axial ultrasonic vibration-assisted boring

\subsection{Static rigidity analysis}

In order to analyze static rigidity, the boring bar can be simplified to the cantilever beam model. When the cantilever beam is deformed by the cutting force, this will lead to cutter relieving, resulting in a reduced actual diameter of the bored hole compared with the theoretical value. According to the statics analysis, the deflection and deformation angles are as follows:

$$
\left\{\begin{array}{l}
\delta=\frac{F L^{3}}{3 E I} \\
\theta=\frac{F L^{2}}{2 E I}
\end{array}\right.
$$

where $F$ is the cutting force; $L$ denotes the length of cantilever beam; $E$ is the elastic modulus of the cantilever beam material; and $I$ indicates the moment of inertia of the cantilever beam section, which is generally a cylinder and can be calculated as: 
$I=\frac{\pi D^{4}}{64}$

where $D$ is the diameter of cantilever beam. Subsequently, the deflection is:

$\delta=\frac{64 F l^{3}}{3 \pi E D^{4}}=\frac{D_{l}}{E} F$

where $D_{l}=\frac{64 l^{3}}{3 \pi D^{4}}$ can be defined as a size coefficient of the boring bar, representing the influence of size (both diameter and length, synthetically) on the static deformation of the boring bar; this seems more reasonable than the conventional aspect ratio of the bar. In the deep-hole boring process, the static deformation measured at the end of the boring bar is determined by bar's material and size, in addition to the force subjected to it. As a result, the deformation is proportional to the cutting force and the size coefficient, and is inversely proportional to the elastic modulus of the bar's material.

In practice, the ultrasonic vibration boring bar consists of three parts: a carbide rod, an ultrasonic transducer, and a fixture. The carbide rod is matched with the center hole of the transducer by means of hot loading, and is clamped into the fixture to form a special bar for ultrasonic vibration-assisted boring. The rear of the fixture has a handle for positioning it onto the machine tool, and the tool tip is mounted on the front of the carbide rod. The actual boring bar can be simplified into a circular cross section cantilever beam structure in three steps, as illustrated in Fig. 3(a).

The deflection and deformation angles of each step are shown in Fig. 3(b). Subsequently, the deflection at the tool tip is calculated as:

$\delta=\delta_{1}+\phi_{1} L_{2}+\delta_{2}+\phi_{2} L_{3}+\delta_{3}$

where $\delta_{1}, \delta_{2}, \delta_{3}$ are the deflections of the carbide rod, the ultrasonic transducer and the fixture, respectively; and $\phi_{1}, \phi_{2}$ denote the deformation angle of the carbide rod and the ultrasonic transducer, respectively. Subsequently, the overall deformation of the bar is: 
$\delta=\frac{F L_{1}^{3}}{3 E_{1} I_{1}}+\frac{F L_{1}^{2} L_{2}}{2 E_{1} I_{1}}+\frac{F L_{2}^{3}}{3 E_{2} I_{2}}+\frac{F L_{2}{ }^{2}\left(L_{3}-L_{4}\right)}{2 E_{2} I_{2}}+\frac{F\left(L_{3}-L_{4}\right)^{3}}{3 E_{3} I_{3}}$

where $I_{1}, I_{2}, I_{3}$ indicate the moment of inertia of the fixture, the ultrasonic transduce and the carbide rod, respectively; $D_{1}, D_{2}, D_{3}$ are their diameter values; $L_{1}, L_{2}, L_{3}$ denote their length; $L_{4}$ is the length between tool tip and the end of the carbide rod; and $E_{1}, E_{2}, E_{3}$ are their elastic modulus values.

(a) The boring bar model

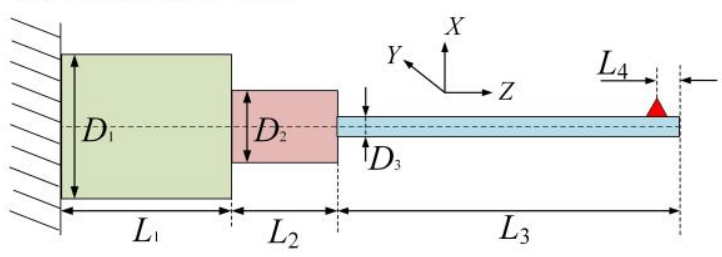

(c) The hole diameter error

(b) Ladder rod stiffness model of the boring bar
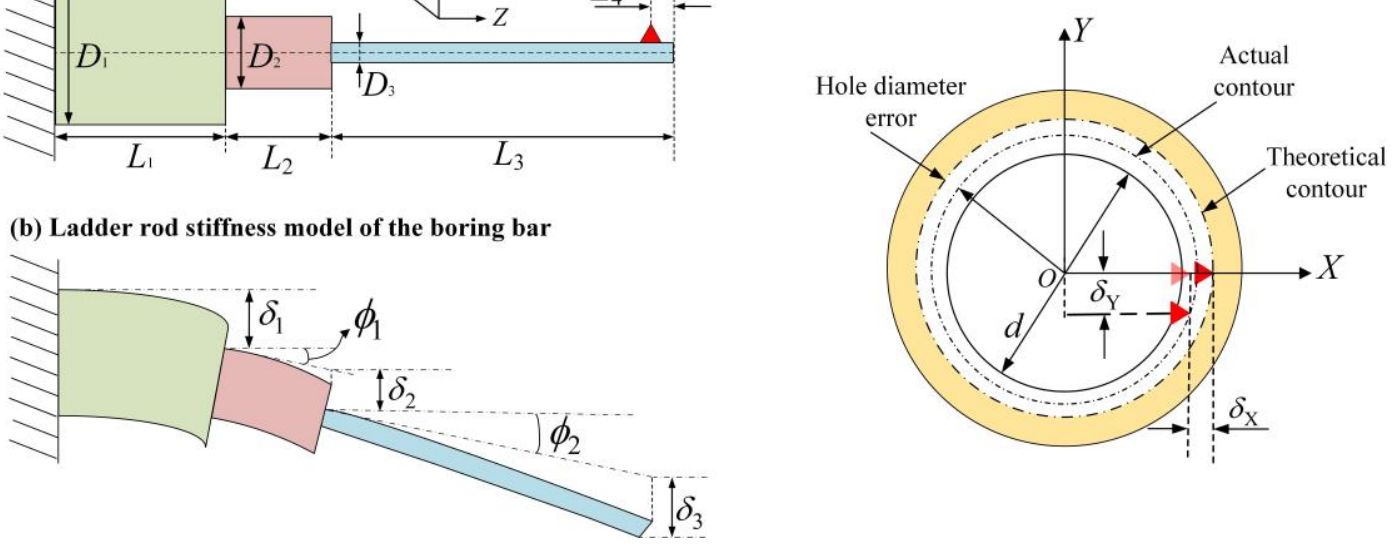

Fig. 3 Static rigidity model and aperture error of ultrasonic vibration-assisted boring bar

In the actual boring process, the bar bears cutting forces both on the $X$-axis and the $Y$-axis, thus deflection will occur on both axes, leading to the cutter relieving of $\delta_{X}, \delta_{Y}$, as shown in Fig. 3(c). Consequently, the actual aperture of bored hole is smaller than the theoretical value, and the error is determined by the value of the cutter relieving. The actual aperture error is defined as:

$\Delta d=\frac{d}{2}+a_{\mathrm{p}}-\sqrt{\left(\frac{d}{2}+a_{\mathrm{p}}-\delta_{\mathrm{X}}\right)^{2}+\delta_{\mathrm{Y}}^{2}}$

\subsection{Dynamic stability analysis}

In addition to static rigidity, the dynamic stability of the boring system should also be evaluated. The boring bar is a typical structure with weak rigidity, whose aspect ratio is larger than 20. Therefore, the boring bar is prone to chatter during the machining process. As 
presented in Fig. 4, two different vibration scenarios should be considered, with one being the model-coupling vibration in the $(X, Y)$ plane, and the other is the regenerative vibration in the $Z$-axis. The static deformation of the boring bar, and the cutting force it is subjected to, are associated. When the cutting force increases, the static deformation rises accordingly, leading to elevated aperture error. This in turn causes a reduction of the actual cutting depth and cutting force. Subsequently, the static deformation of the boring bar decreases and the actual cutting depth and cutting force increases. This interaction between the boring bar's deformation and the actual cutting force easily causes chatter. Therefore, the $(X, Y)$ plane is characterized by weak rigidity spindles, hence the model-coupling vibration should be considered. The main factors affecting dynamic stability in the $Z$-axis are the variation of feed rate and feed resistance force at ultrasonic frequency, thus the regenerative vibration seems more suitable.

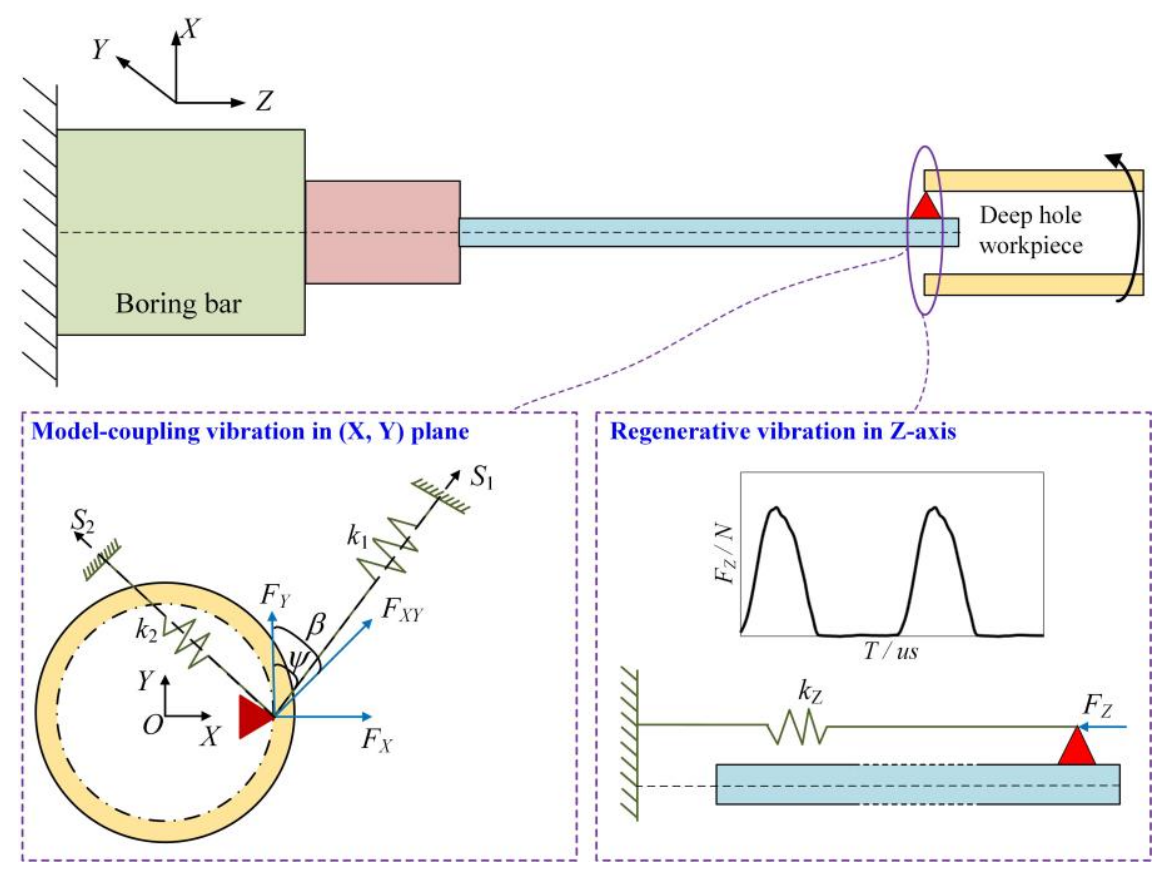

Fig. 5 Vibration model in deep-hole boring

Assuming that $S_{1}$ and $S_{2}$ are the two mutually perpendicular weak rigidity spindles in the $(X, Y)$ plane, and $k_{1}, k_{2}\left(k_{1}<k_{2}\right)$ are their static elastic coefficient, $F_{X Y}$ is the resultant force in the $(X, Y)$ plane; $\psi$ is the angle between $S_{1}$ and $Y$, and $\beta$ is the angle between $F_{X Y}$ and $Y$. Subsequently, the differential equation of the bar is:

$M S^{\prime \prime}+\boldsymbol{K} S+\boldsymbol{F}=\boldsymbol{M} S^{\prime \prime}+\boldsymbol{K}^{\prime} S=\boldsymbol{O}$ 
where $\boldsymbol{M}=\left[\begin{array}{cc}m & 0 \\ 0 & m\end{array}\right], \boldsymbol{K}=\left[\begin{array}{cc}k_{1} & 0 \\ 0 & k_{2}\end{array}\right], S=\left[\begin{array}{l}s_{1} \\ s_{2}\end{array}\right]$ and $\boldsymbol{F}=\left[\begin{array}{l}F_{s 1} \\ F_{s 2}\end{array}\right]=\left[\begin{array}{c}\cos (\beta-\psi) \\ \sin (\beta-\psi)\end{array}\right] F_{X Y}$ are the mass matrix, rigidity matrix, rigid displacement matrix and force matrix, respectively. $F_{X Y}$ is approximately proportional to the cutting depth, and the cutting depth can be expressed as:

$a_{\mathrm{p}}=s_{1} \sin \psi-s_{2} \cos \psi=[\sin \psi, \cos \psi] S$

Consequently, the equivalent rigidity matrix of the bar $\boldsymbol{K}^{\prime}$ can be expressed as:

$$
\boldsymbol{K}^{\prime}=\left[\begin{array}{cc}
k_{1}+q \sin \psi \cos (\beta-\psi) & q \cos \psi \cos (\beta-\psi) \\
-q \sin \psi \sin (\beta-\psi) & k_{2}-q \cos \psi \sin (\beta-\psi)
\end{array}\right]
$$

where $q$ is the proportionality coefficient of $F_{X Y}$ and the cutting depth, namely dynamic elastic coefficient.

It is clearly seen that a particular solution of Eq. (7) is $\boldsymbol{X}_{0}=e^{s t}\left[\begin{array}{l}A_{s 1} \\ A_{s 2}\end{array}\right]=e^{s t} \boldsymbol{A}, A_{\mathrm{s} 1}$ and $A_{\mathrm{s} 2}$ are conjugates. Therefore, $\boldsymbol{X}_{0}{ }^{\prime}=e^{s t} s^{2} \boldsymbol{A}$, and $\left(\boldsymbol{M}^{2}+\boldsymbol{K}^{\prime}\right) \boldsymbol{A}=\boldsymbol{O}$ according to Eq. (7). However, $\boldsymbol{A}$ is not identically equal to $\boldsymbol{O}$, hence the precondition for $\left(\boldsymbol{M} s^{2}+\boldsymbol{K}^{\prime}\right) \boldsymbol{A}=\boldsymbol{O}$ having a solution is:

$$
\left|\boldsymbol{M} s^{2}+K^{\prime}\right|=0
$$

Subsequently, the critical stability condition of the boring bar is :

$$
q_{\lim }=\frac{k_{2}-k_{1}}{\cos (2 \alpha-\beta) \pm \sqrt{\cos ^{2}(2 \alpha-\beta)-\cos ^{2} \beta}}
$$

If the actual dynamic elastic coefficient $q$ satisfies the condition of $q<q_{\mathrm{lim}}$, no modelcoupling chatter occurs in the system. For AUVB, the actual cutting force is lower and the actual cutting depth is larger than CB due to the reduction of cutter relieving, as analyzed above. Therefore, the dynamic elastic coefficient for AUVB $q_{\mathrm{AUVB}}$ is lower than that for $\mathrm{CB} q_{\mathrm{CB}}$, which means that its dynamic rigidity is larger. According to the above analysis, this can significantly improve the dynamic stability of the boring bar. In the Z-axis direction, the motion equation of the bar can be expressed as: 


$$
m z^{\prime \prime}+k_{z}=\Delta F_{z}
$$

where $k_{z}$ is the static elastic coefficient in $Z$-axis direction, and $\Delta F_{z}$ indicates the fluctuation of feed resistance force $F_{f}$. Ma et al. [33] found that the vibration amplitude was proportional to the dynamic elastic coefficient. So the vibration amplitude in the $Z$-axis direction is:

$$
A_{z}=\Delta z(t)=\frac{q_{z} f}{k_{z}}
$$

where $q_{\mathrm{z}}$ is the dynamic elastic coefficient in the Z-axis direction. Shamoto and Moriwaki [34] has pointed that the dynamic elastic coefficient for ultrasonic vibration cutting method was proportional to its duty ratio, the relationship of the dynamic elastic coefficient for AUVB and $\mathrm{CB}$ is:

$q_{z-A U V B}=D_{c} q_{z-C B}<q_{z-C B}$

where $D_{c}<1$ is the duty ratio of AUVB. Therefore, the vibration is smaller in the $Z$-axis direction for AUVB than for CB.

\subsection{Surface morphology analysis}

According to whether the cutting process is continuous or separation, the surface morphology of the bored hole will present two types of different micromorphology, as illustrated in Fig. 5. If it is a separation cutting process, the surface topography will be primarily determined by the rake face profile and the tool trajectories. Therefore, some overlap between the tool cutting trajectories will be present, and the morphology will be diverse based on lots of differently shaped pieces (Fig. 5(a)). Some of these pieces form a regular morphology unit in both the $Y$-axis and the $Z$-axis. Meanwhile, in a continuous cutting process, the micromorphology of the bored surface fluctuates in a sinusoidal pattern (Fig. 6(b)). Obviously, the former of these two conditions is considered more important. 
(a) Separation cutting

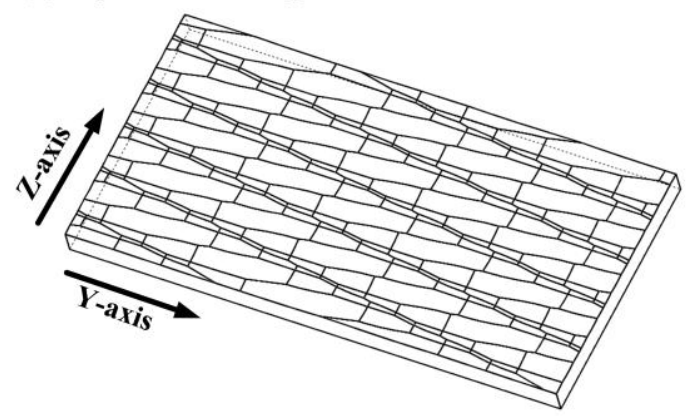

(b) Continuous cutting

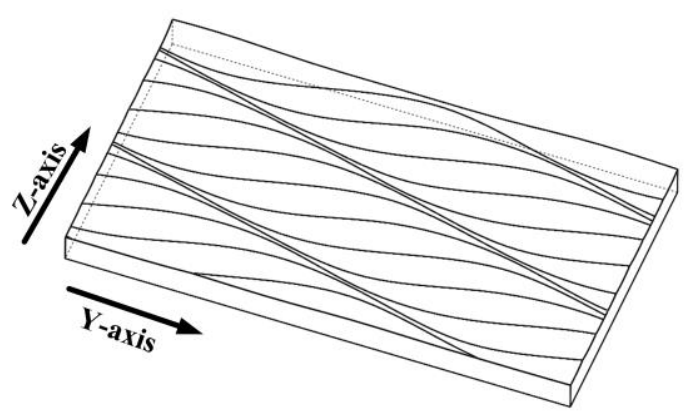

Fig. 5 Simulation results of surface micromorphology in AUVB

A typical bored surface microtopography unit in the separation cutting process is demonstrated in Fig. 6(a). A topography unit can be defined as the minimum-sized rectangle, which is periodically arrayed. Thus, surface roughness for AUVB should be considered in this unit including the $Z$-axis (feed direction) and the $Y$-axis (cutting directing).

The surface forming mechanism in AUVB is different from that in $\mathrm{CB}$, where surface roughness is mainly determined by the intersection of the major tool edge in this rotation and the minor tool edge in the next rotation only in the feed direction. However, since the tool has reciprocating motion in the feed direction and sinusoidal trajectory in the cutting direction, the ridges are formed by several adjacent rotations, and the peaks should be taken into consideration, as shown in Fig. 6(b). In addition, intersections are also different along the cutting direction, hence the peaks of different positions in the cutting direction should be considered as a whole. Consequently, the maximum peak value in a topography unit representing the surface roughness level in AUVB can be given as follows:

$$
\begin{aligned}
& R_{\mathrm{th}}=\max _{\varphi=0} \max _{p=1}^{m} \min _{g=1}^{m} \Delta z \\
& \Delta z=\left\{\begin{array}{lc}
r_{\varepsilon}-\sqrt{r_{\varepsilon}^{2}-\left(\frac{z_{\mathrm{N}+p}-z_{\mathrm{N}}}{2}\right)^{2}} z_{\mathrm{N}+p}-z_{\mathrm{N}+g}>0 \\
a_{\mathrm{p}} & z_{\mathrm{N}+p}-z_{\mathrm{N}+g}<0
\end{array}(0 \leq g \leq \mathrm{m}, 1 \leq p \leq \mathrm{m}, p \neq g)\right. \\
& z_{\mathrm{N}}(\theta)=(N-1) f+A \sin \left[\frac{60 F}{n} \theta+(N-1) \phi\right]
\end{aligned}
$$

where $Z_{\mathrm{N}}$ is the motion trajectory equation of the tool in the $N_{\text {th }}$ rotation; $\varphi$ indicates the rotation angle of the machine tool spindle; $r_{\varepsilon}$ indicates the corner radius; $m$ is the minimum number of 
required to form a morphology unit; and $p$ and $g$ are the rotation number affecting a morphology unit in the $Z$-axis and the $Y$-axis, respectively. The author [35] has given the detailed derivation process in the previous research.

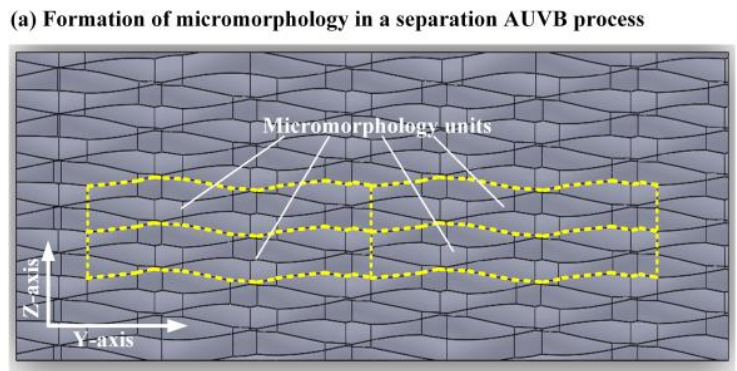

(b) Formation of the ridges and peaks in the micromorphology unit

Fig.6 Schematics of the formation of ridges and peaks formed in a separation AUVB process

According to Eq. (17) to Eq. (19), the relationship between the maximum peak and the phase shift / feed rate is shown in Fig. 8. For both AUVB and CB, the roughness value increases with the feed rate. In addition, the geometry value of the surface roughness for $\mathrm{CB}$ is smaller than that for AUVB. For the latter, the surface roughness in a continuous cutting process is always smaller than that in a separation cutting process. However, under the separation cutting condition, the phase shift $\varphi=\pi$ provides the minimum surface roughness. It should be noted that, in addition to geometric factors, physical factors, such as cutting force, tool wear and chip extraction, should also be taken into account for measuring surface roughness in the actual process, which may be more important for surface integrity. Based on this result, however, more appropriate parameters can be selected, and the phase shift $\varphi=\pi$ is an appropriate choice for AUVB.

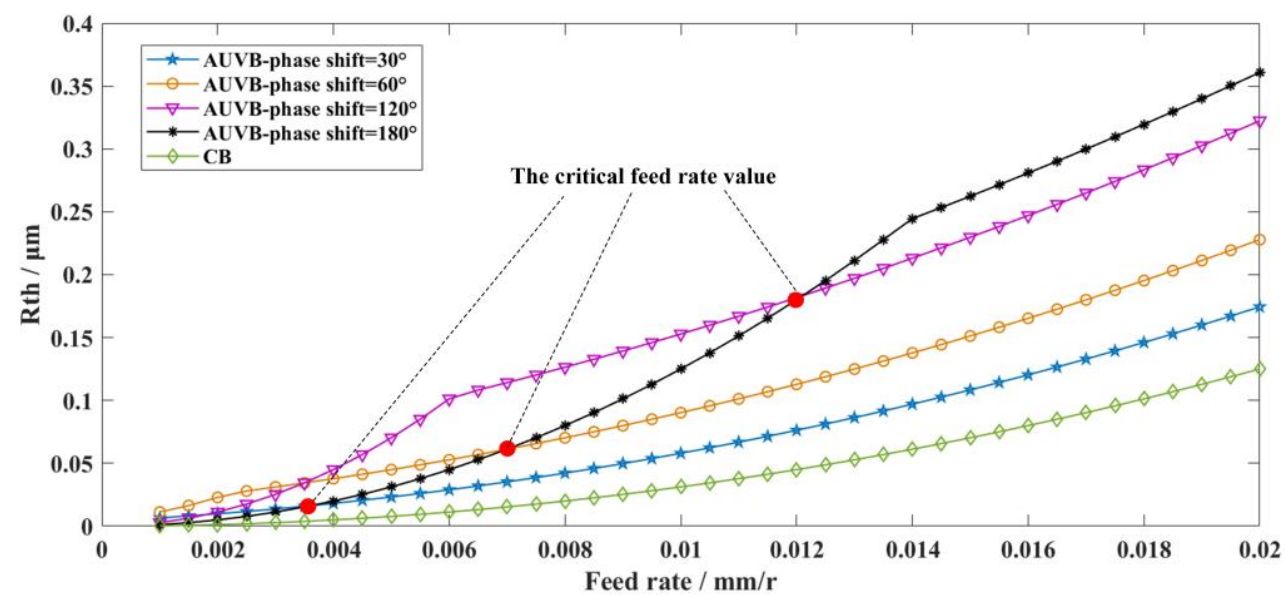

Fig. 7 The height of peaks as formed in the AUVB and the CB process 


\section{Experiment setup and procedures}

The device for ultrasonic vibration boring consists of a tool bit, a carbide rod, a front cover, a piezoelectric ceramic reactor, a back cover and bolt, as shown in Fig. 8(a). The boring device is connected to the dynamometer by an external fixture, and the dynamometer if fixed on the machine tool. The piezoelectric patches are separated by bronze electrodes with $0.2 \mathrm{~mm}$ thickness, which facilitates the application of an electric field. The carbide rod and front cover are connected in an interference fit. The product of the boring bar is shown in Fig. 8(b), and a test on its resonant frequency and amplitude is conducted. The excitation frequency by ultrasonic power is $17,768 \mathrm{~Hz}$, and the vibration amplitude measured at the end of the bar is $7 \mu \mathrm{m}$.
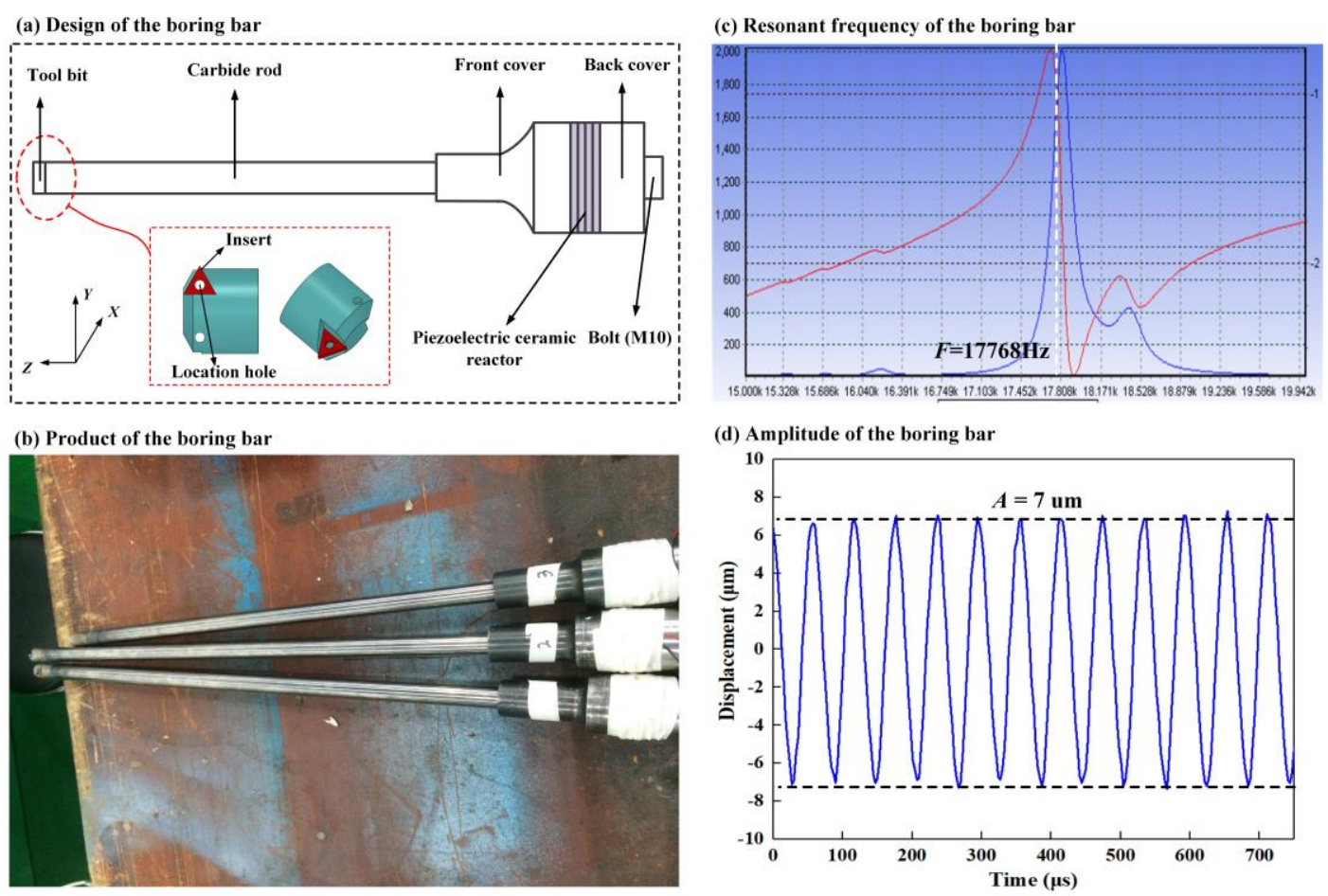

Fig. 8 Design and implementation of the boring bar

The detailed dimensions (diameter and length of each step) of the boring bar shown in Fig. 3 are listed in Table 1. Considering several common part dimensions in engineering practice, three different sizes of carbide rod were selected as the boring execution terminal. Accordingly, the size coefficients of these three boring bars are 7473, 4076 and 2718, respectively. The selected cutting tool insert was a cermet tool (TCMT 060302) produced by Sandvik Co., Ltd with $0^{\circ}$ rake angle, $7^{\circ}$ clearance angle, and $0.2 \mathrm{~mm}$ corner radius. 
Table 1 Detailed parameters of the boring bar

\begin{tabular}{ccccccc}
\hline $\boldsymbol{D}_{\mathbf{1}} / \mathbf{m m}$ & $\boldsymbol{D}_{\mathbf{2}} / \mathbf{m m}$ & $\boldsymbol{D}_{\mathbf{3}} / \mathbf{m m}$ & $\boldsymbol{L}_{\mathbf{1}} / \mathbf{m m}$ & $\boldsymbol{L}_{\mathbf{2}} / \mathbf{m m}$ & $\boldsymbol{L}_{\mathbf{3}} / \mathbf{m m}$ & $\boldsymbol{L}_{\mathbf{4}} / \mathbf{m m}$ \\
\hline 90 & 30 & $14 / 18 / 22$ & 80 & 50 & $350 / 400 / 450$ & 3.3 \\
\hline
\end{tabular}

The boring experiments were performed using a high-precision machine tool (HASS SL40, produced by Haas Automation, Inc.), and the spindle speed was varied from 10 to 2,400rpm. A three-dimensional dynamometer (Kistler 9254) was employed to measure the boring force with an accuracy of $0.05 \mathrm{~N}$. No coolant was used during the boring process. The vibration signals of the boring bar were measured via a laser micrometer (LK-H020, KEYENCE) with an accuracy of $0.01 \mu \mathrm{m}$. The roughness of the bored surface was measured by a rough-meter (Tylor Hobson) with an accuracy of $0.001 \mu \mathrm{m}$. The bored surface residual stress was detected using a stress instrument (X-stress 3000, Stresstech Oy) with an accuracy of 0.1MPa. The experimental setup schematics are shown in Fig. 9.

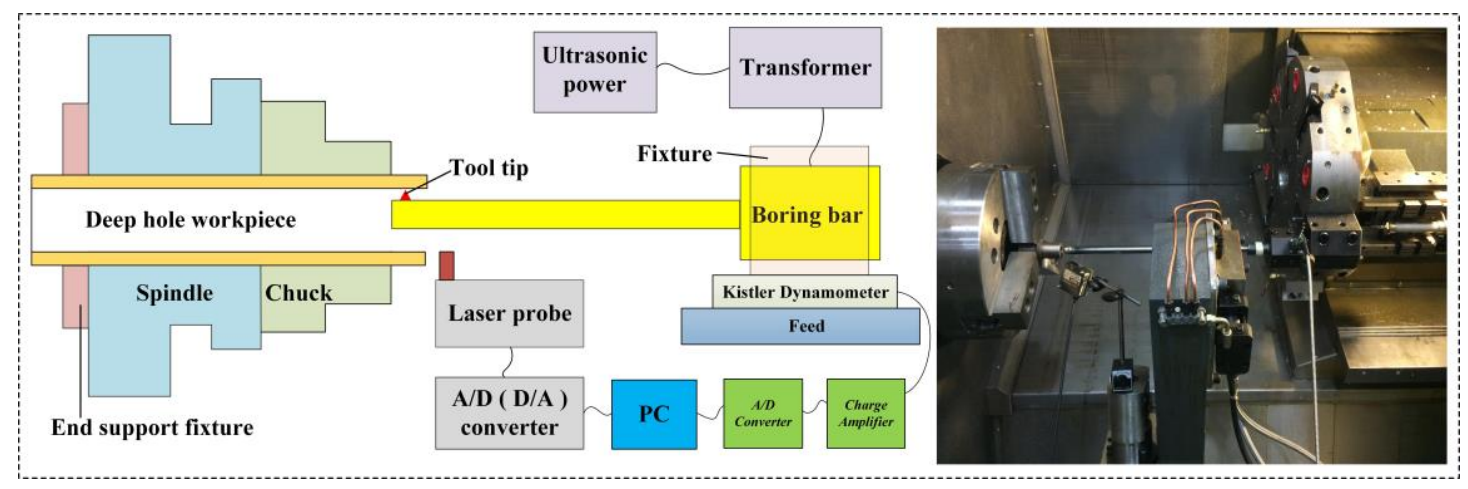

Fig. 9 Schematics of the experiment setup

The workpiece material used in this study is a typical titanium alloy Ti6Al4V. Considering its external diameter of $40 \mathrm{~mm}$, the experimental setup included the boring of three differently sized holes with inner diameters of $16 / 20 / 24 \mathrm{~mm}$. The detailed experimental parameters are listed in Table 2.

Table 2 Detailed experimental parameters

\begin{tabular}{cccccc}
\hline $\boldsymbol{F} / \mathbf{H z}$ & $\boldsymbol{A} / \boldsymbol{\mu m}$ & $\boldsymbol{a}_{\mathrm{p}} / \mathbf{m m}$ & $\boldsymbol{f} / \mathbf{m m} / \mathbf{r}$ & $\boldsymbol{n} / \mathbf{r} / \mathbf{m i n}$ & $\boldsymbol{d} / \mathbf{m m}$ \\
\hline 17768 & 7 & $0.04-0.1$ & $0.004-0.012$ & $60-120$ & $16 / 10 / 24$ \\
\hline
\end{tabular}




\section{Results and discussion}

\subsection{Reduction of boring force}

The influence of machining parameters, including rotational speed, cutting depth and feed rate on boring force, is shown in Fig. 10. The results for all of these experiments indicate that AUVB can effectively reduce the 3-dimensional boring force, as compared with CB. Fig. 10(a) shows that, with the increase of rotational speed, the main boring force $\mathrm{F}_{\mathrm{c}}$ and the radial force $F_{p}$ obviously increase, however, the growth of feed force $F_{f}$ is not distinct. This occurs as the material removal rate increases with the rotational speed, resulting in the increase of the above forces.

(a) Boring force versus rotation speed

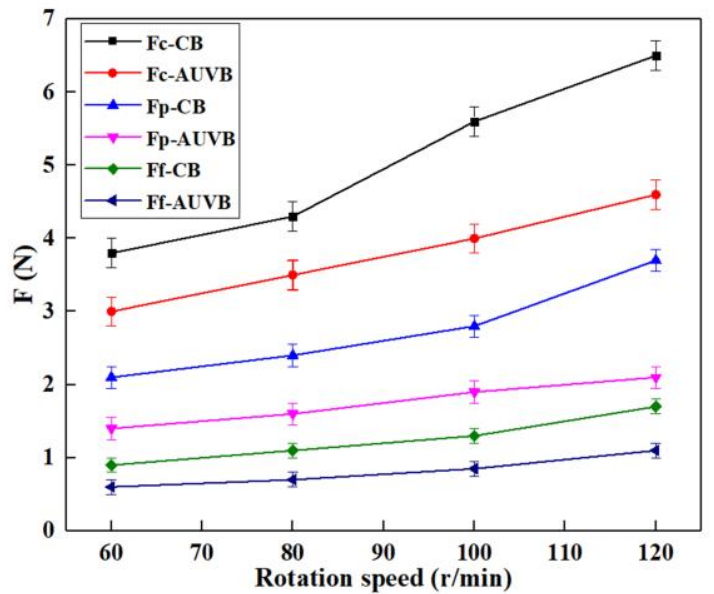

(b) Boring force versus cutting depth

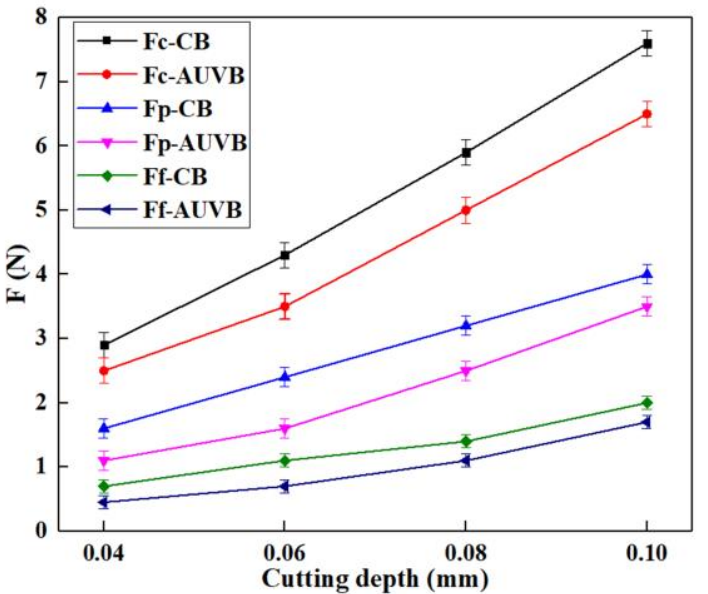

(c) Boring force versus feed rate

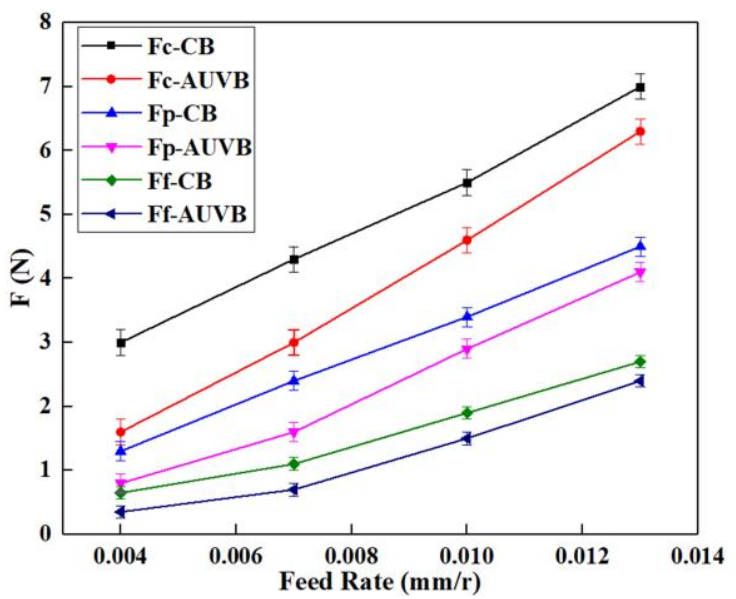

Fig. 10 Influence of machining parameters on boring force $\left(D_{l}=7473\right)$

In addition, this increase of material removal rate in CB is larger than that in AUVB. For instance, the main boring force at $100 \mathrm{r} / \mathrm{min}$ for AUVB seems identical to that at $60 \mathrm{r} / \mathrm{min}$ for 
$\mathrm{CB}$, which is a result of the separation cutting feature of AUVB, as mentioned above. Therefore, in the $\mathrm{CB}$ process, due to the lower rigidity of the boring system, a lower rotational speed should be adopted to ensure lower cutting force to avoid excessive deformation of the boring bar. In the AUVB process, however, a relatively higher rotational speed can be considered.

The influence of cutting depth and feed rate on boring force is presented in Fig. 10(b) and (c), respectively. Results indicate that the impacts of cutting depth on the main boring force $F_{c}$, radial force $F_{p}$ and feed force $F_{f}$ are all distinct. Therefore, to avoid excessive deformation, smaller cutting depth should be adopted to ensure a lower cutting force. The feed rate has a distinct impact on boring forces in the three directions. This occurs because the rise of feed rate and boring force would increase the cutting layer thickness and load on the cutting edge, thus elevating the cutting force. Moreover, the material removal rate in AUVB shows a larger increase than that in $\mathrm{CB}$, and this rate in AUVB decreases with the increase of feed rate. The reason is that with the feed rate increasing, boring gradually transforms from a separation cutting process to a continuous one, and the separation cutting feature of AUVB disappears. Therefore, the boring force in AUVB is gradually close to that in CB.

The separation cutting feature offers multiple advantages for the machining process. The first such benefit is a significant reduction of the average machining force, resulting in a prominent improvement of machining accuracy. Due to the precision machining process, the machining force should be analyzed based on the micro cutting theory and a transient separation cutting force model with four components, namely elastic recovery force, ploughing force, shearing force, and friction force, as established in the literature [26]. Therefore, the cutting force components for AUVB and their average values are displayed in Fig. 11, and compared with the average cutting force values of CB. Accordingly, it can be inferred from theory that a reduction of the average cutting force will be obtained for AUVB, which is a combined result of the no-force region for the elastic recovery, ploughing forces during non-cutting, and an offset duration for the larger shearing and friction forces during cutting. The essential factors behind the reduced average cutting force are the transient cutting characteristics and separation cutting characteristics caused by added ultrasonic vibration. 


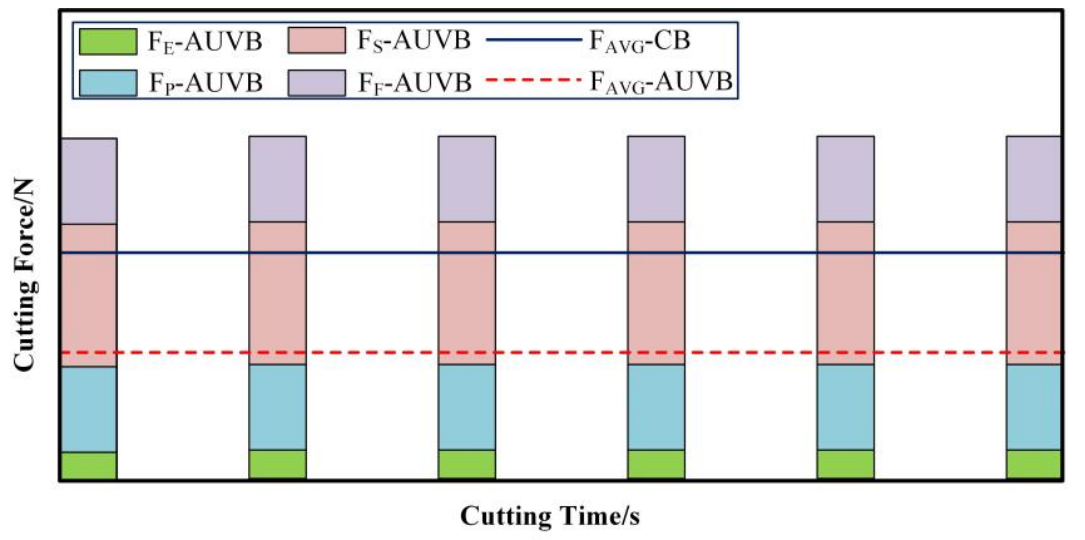

Fig. 11 Schematic of cutting force reduction principle for AUVB

The actual boring force signals measured at different rotational speeds and feed rates are shown in Fig. 12 and Fig. 13. In order to minimize the experimental error, the change of parameters was set in advance by a numerical control program. There is distinct reduction of boring force for AUVB overall; the main boring force is observed to increase with the rotational speed or feed rate, the latter having a stronger effect on the boring force. Results are highly consistent with those in Fig.10.

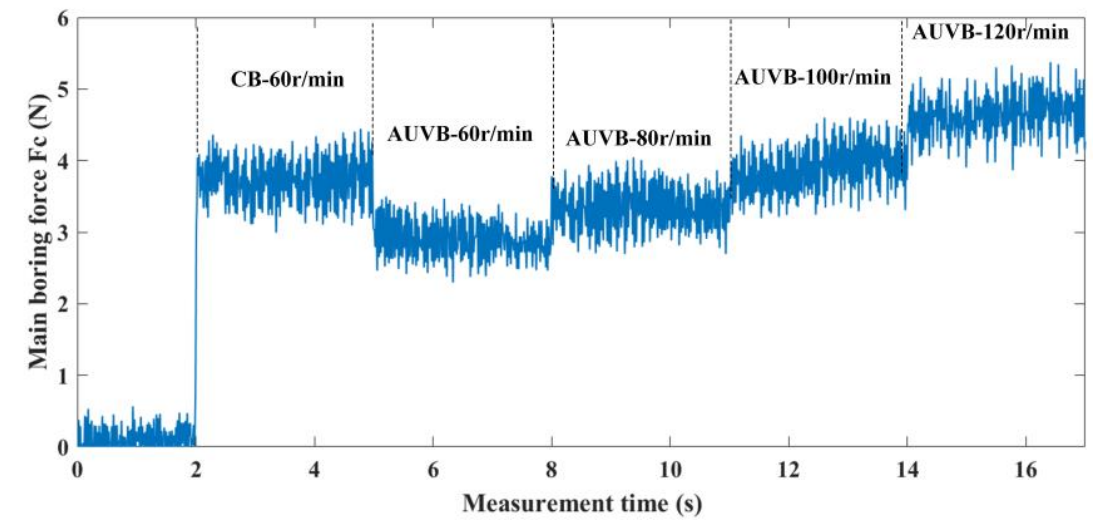

Fig. 12 Boring force signals at different rotational speeds $\left(D_{l}=7473\right)$

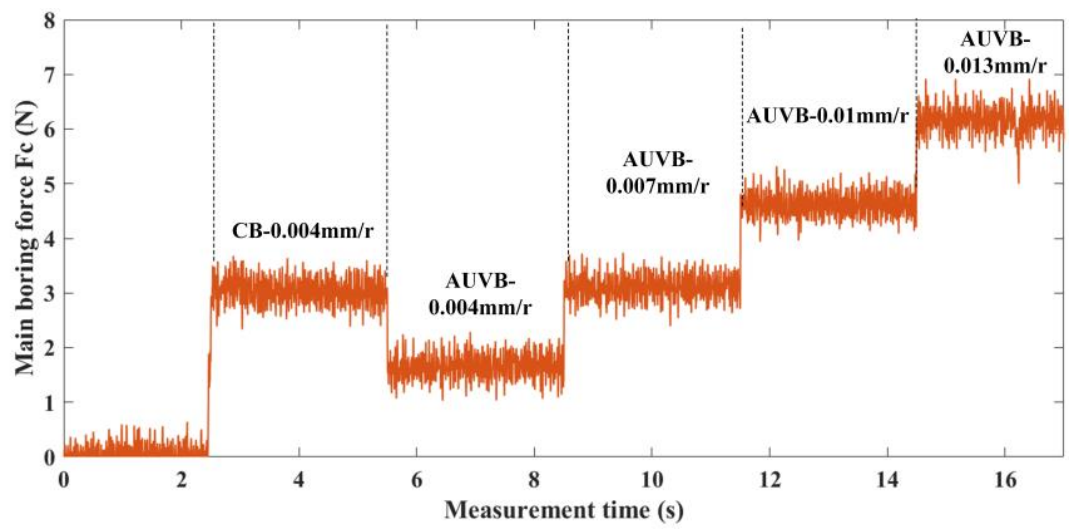

Fig. 13 Boring force signals at different feed rates $\left(D_{l}=7473\right)$ 
In a typical weak rigidity system, the size parameter of the boring bar should be considered for calculating the boring force. Herein, experiments with three boring bar sizes with different size coefficients were conducted, and the comparative results are presented in Fig. 14. As seen, the larger the size coefficient, the weaker the bar rigidity. The boring forces increase distinctly in all three directions with the decrease of size coefficient. In other words, under the same condition, the lower the bar's rigidity, the smaller the boring force. Although the nominal cutting parameter is the same, the actual cutting amount will be different. Using a bar with lower rigidity may lead to larger deformation and greater cutter relieving effect; thereby the actual cutting volume is smaller, leading to a reduction of boring force. Hence, a boring bar with better rigidity should be used for the interest of machining accuracy.

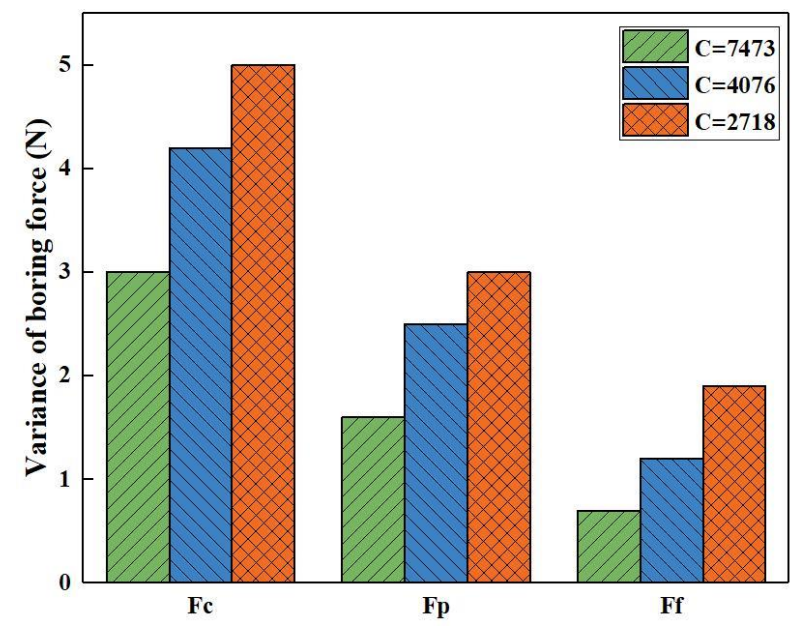

Fig. 14 Influence of size coefficient on boring force for AUVB

\subsection{Improvement of boring accuracy}

The influence of machining parameters, including rotational speed, cutting depth and feed rate, on boring accuracy is demonstrated in Fig. 15. Results for these experiments all indicate that AUVB can effectively reduce the aperture error, and improve the boring accuracy compared with CB. Fig. 15(a) shows that, with the increase of the rotational speed, the aperture error slightly increases compared with the trend shown in 15(b) and (c). The aperture error is determined by the boring force in a positively dependent manner. The boring force is also influenced by the increase of rotational speed, albeit this correlation is weaker.

Fig. 15(b) and (c) present the influence of cutting depth and feed rate, respectively, on boring accuracy. The data indicate that these influences are both distinct. This occurs because 
the increase of the cutting depth and feed rate will boost the material removal rate, resulting in a greater boring force.

(a) Aperture error versus rotation speed

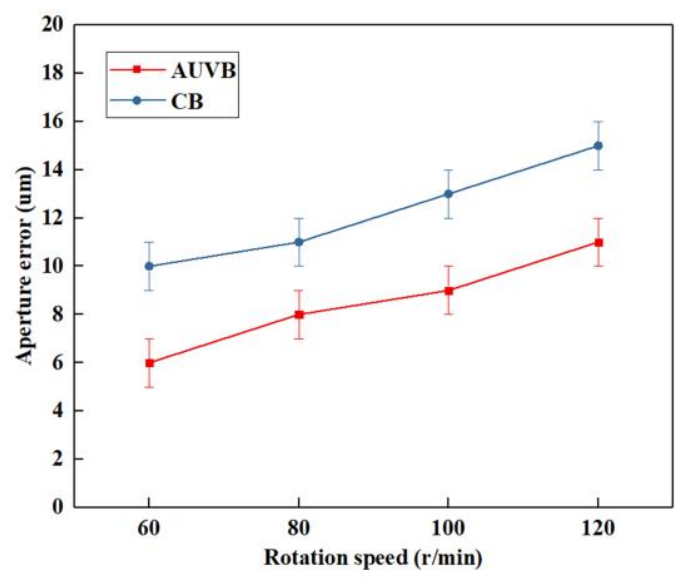

(b) Aperture error versus cutting depth

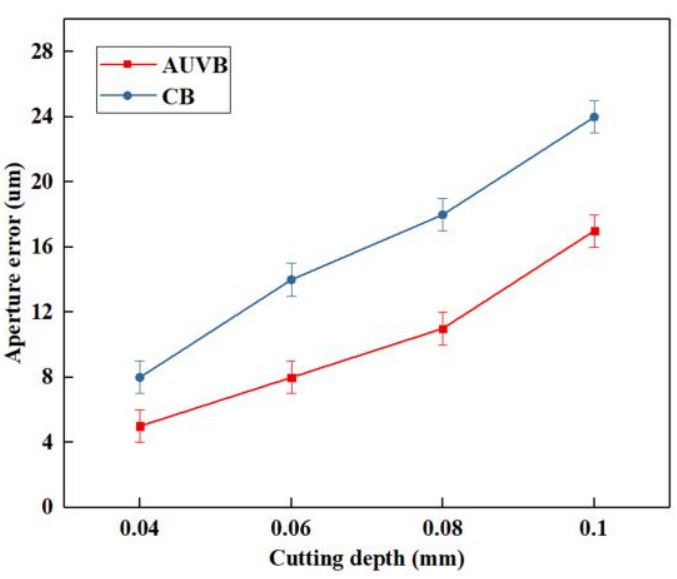

(c) Aperture error versus feed rate

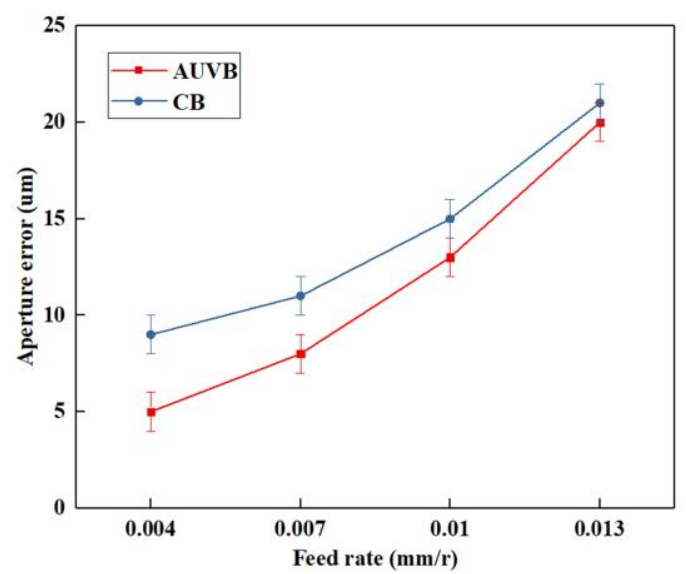

Fig. 15 Influence of machining parameters on boring accuracy $\left(D_{l}=7473\right)$

In addition, the growth rate of aperture error for $\mathrm{CB}$ is larger than that for AUVB, as seen in Fig. 15(b). For example, the aperture error at $0.1 \mathrm{~mm}$ cutting depth for AUVB seems lower than that at $0.08 \mathrm{~mm}$ for $\mathrm{CB}$. This is also the consequence of the separation cutting feature of AUVB, which results in boring force reduction. Therefore, to avoid the excessive deformation of the boring bar during the CB process, lower cutting depth should be adopted to ensure a lower cutting force. In the AUVB process, however, a relatively larger value can be considered. The growth rate of aperture error in CB is smaller compared with AUVB, as shown in Fig. 15(c), whereas the aperture error in AUVB continuously approaches that in CB with increasing feed rate. The explanation is that, with the rising feed rate, the process gradually transforms from separation cutting to a continuous one, and the separation cutting feature of AUVB 
diminishes. Thus, the boring force in AUVB will be the same as in CB, as shown in Fig.11(c). A smaller feed rate should therefore be used to improve the machining accuracy, and to sustain the separation cutting feature in the AUVB process.

The size parameters of the boring bar should also be considered for better boring accuracy; relevant comparative results are presented in Fig. 16. The larger the size coefficient, the weaker the bar rigidity. In this way, the aperture error decreases and the boring accuracy improves distinctly with the reduction of size coefficient. That is to say, under the same condition, the weaker the bar rigidity, the larger the aperture error. This phenomenon is contrary to the variation of boring force as seen in Fig.14, since rigidity is a fundamental property that determines the actual amount of cut material and further affects the boring force.

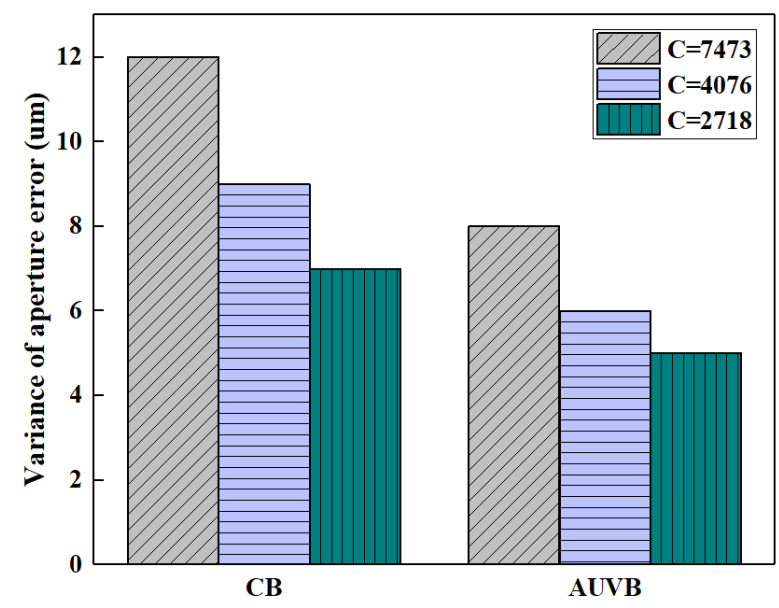

Fig. 16 Influence of size coefficient on boring accuracy

\subsection{Suppression of the vibration}

Vibration signals were measured and the power spectrum was analyzed under the condition of $\mathrm{a}_{\mathrm{p}}=0.06 \mathrm{~mm}, f=0.007 \mathrm{~mm} / \mathrm{r}, \mathrm{n}=80 \mathrm{r} / \mathrm{min}$, and $D_{l}=7473$; results are shown in Fig. 17. It is intuitively observed that, when the AUVB method is used for deep-hole boring, the vibration is successfully suppressed. The maximum vibration amplitude in the time domain exceeds about $10 \mu \mathrm{m}$ in the $\mathrm{CB}$ process, however, this value seems no higher than $5 \mu \mathrm{m}$ in the AUVB process. Furthermore, experimental results showed that vibration signals in CB seem to change vigorously compared to those in AUVB, which indicates that vibration is more radical in $\mathrm{CB}$, which is a disadvantage for the controllability of the boring process and the successful optimization of machining results. 
(a) Vibration signals in time domain

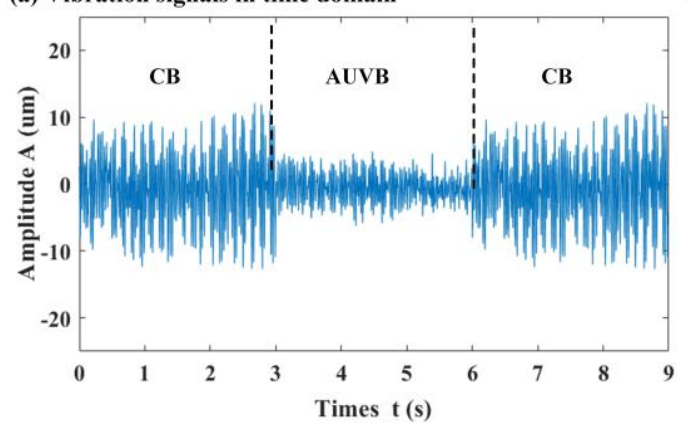

(b) Power spectrum

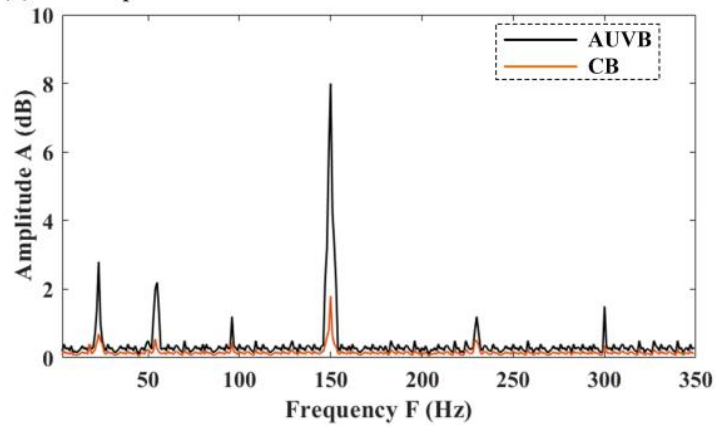

Fig. 17 Vibration signals and power spectrum analysis

The power spectrum results of vibration for both CB and AUVB, as shown in Fig. 17(b), intuitively demonstrate the advantages of AUVB in vibration suppression. The vibration amplitudes (dB) are dramatically decreased in AUVB to only $20 \%-25 \%$ of that in the CB process. For instance, the maximum vibration amplitude $(\mathrm{dB})$ is about $8 \mathrm{~dB}$ at $\approx 150 \mathrm{~Hz}$ frequency for $\mathrm{CB}$, while it is only less than $2 \mathrm{~dB}$ for the $\mathrm{AUVB}$ process. Consequently, in $\mathrm{AUVB}$, the vibration is maintained at an inferior energy input-output equilibrium state, resulting from the decrease of energy intake through the reduction of boring force. In addition, the vibration amplitudes $(\mathrm{dB})$ show a marked increase at about the frequencies of $20 \mathrm{~Hz}, 50 \mathrm{~Hz}, 90 \mathrm{~Hz}, 150 \mathrm{~Hz}$, $220 \mathrm{~Hz}$ and $300 \mathrm{~Hz}$. All these values are the resonant frequencies of the boring bar in multiple vibrational modals, which was further evidenced by the results of vibration modal analysis for the boring bar by ANSYS software, as shown in Fig. 18.

Furthermore, the vibration signals under different boring parameters were measured and analyzed by the power spectrum. For the convenience of analysis and quantitative comparison, the maximum vibration amplitude $(\mathrm{dB})$ at about $150 \mathrm{~Hz}$ in the power spectrum was chosen to represent the stability of the boring process. The influence of machining parameters including rotational speed, cutting depth and feed rate on boring stability is demonstrated in Fig. 19.

The results of all of these experiments indicate that AUVB can effectively reduce boring bar vibration and improve the stability of the boring process, as compared with $\mathrm{CB}$. It is also shown in Fig. 19, that with the increased values of machining parameters, regardless of whether it is rotational speed, cutting depth or feed rate, the vibration amplitude $(\mathrm{dB})$ markedly increases. The growth of vibration amplitude $(\mathrm{dB})$ is rather significant for rotational speed and feed rate, as rotation is the main factor influencing the stability in the CB process, and feed rate is the 
main variable influencing the separation cutting feature in the AUVB process. As a result, the vibration amplitude $(\mathrm{dB})$ seems to gradually converge between CB and AUVB, along with the increase of rotational speed and feed rate. Nonetheless, AUVB still presents clear advantages under existing experimental conditions.

(a) Vibration mode at the frequency of $18.754 \mathrm{~Hz}$

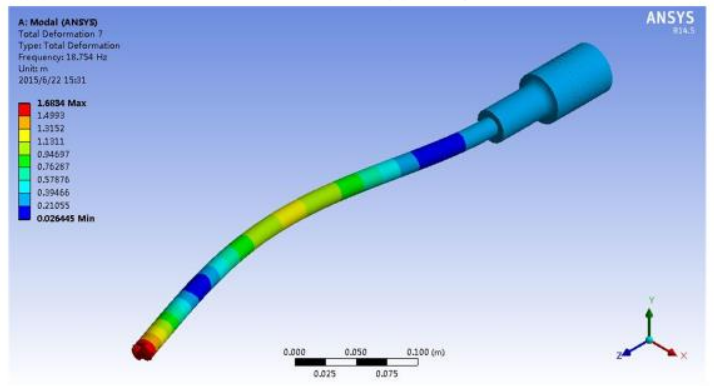

(c) Vibration mode at the frequency of $92.648 \mathrm{~Hz}$

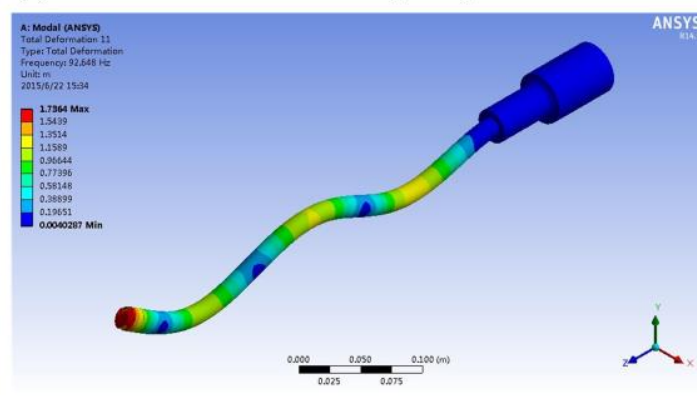

(e) Vibration mode at the frequency of $219.18 \mathrm{~Hz}$

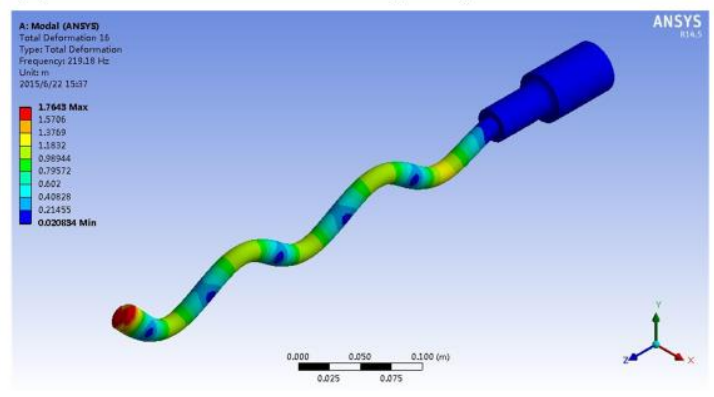

(b) Vibration mode at the frequency of $49.459 \mathrm{~Hz}$

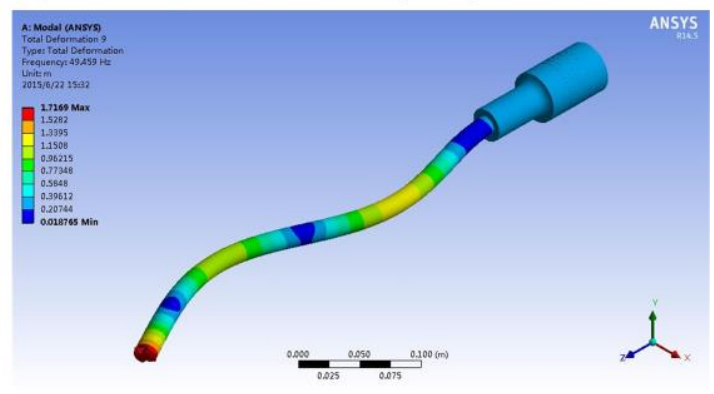

(d) Vibration mode at the frequency of $152.62 \mathrm{~Hz}$

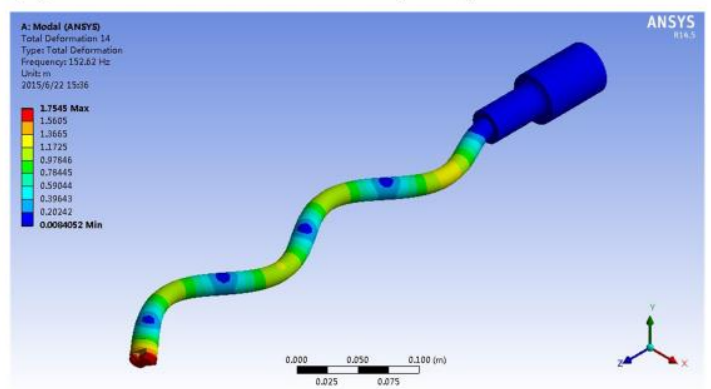

(f) Vibration mode at the frequency of $305.14 \mathrm{~Hz}$

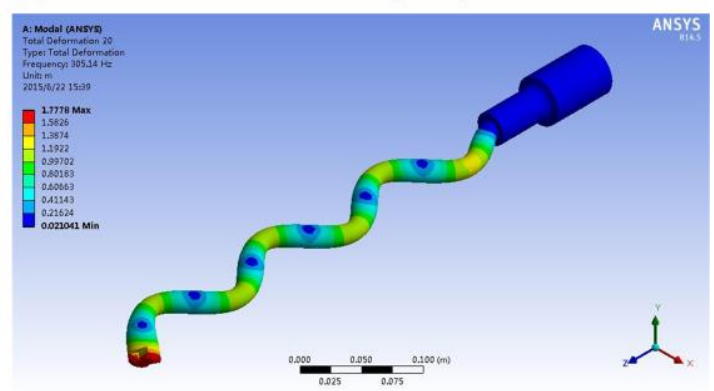

Fig. 18 Vibration modal analysis results for boring bar

The size parameters of the boring bar should also be considered. The influence of size coefficient on vibration amplitude $(\mathrm{dB})$ is demonstrated in Fig. 20; the larger the size coefficient, the weaker the bar rigidity. Therefore, the vibration amplitudes $(\mathrm{dB})$ all decrease and the boring stability enhances distinctly with the decrease of size coefficient. In other words, under the same condition, the weaker the bar rigidity, the larger the vibration amplitude $(\mathrm{dB})$. Furthermore, this decline is more pronounced for $\mathrm{CB}$, while it is only slight for AUVB. The 
reason for this phenomenon is that the vibration remains at a higher level for $\mathrm{CB}$, hence if a boring bar with better rigidity is used, the stability improvement is more significant

(a) Vibration amplitude (dB) versus rotation speed

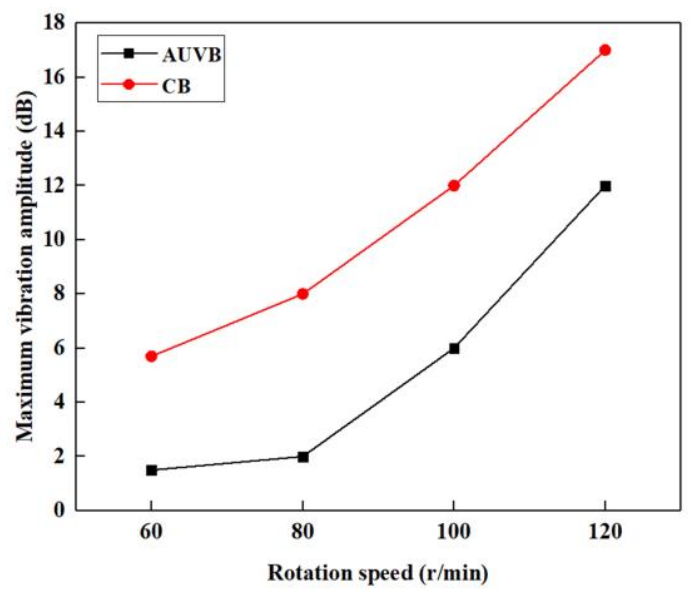

(b) Vibration amplitude (dB) versus cutting depth

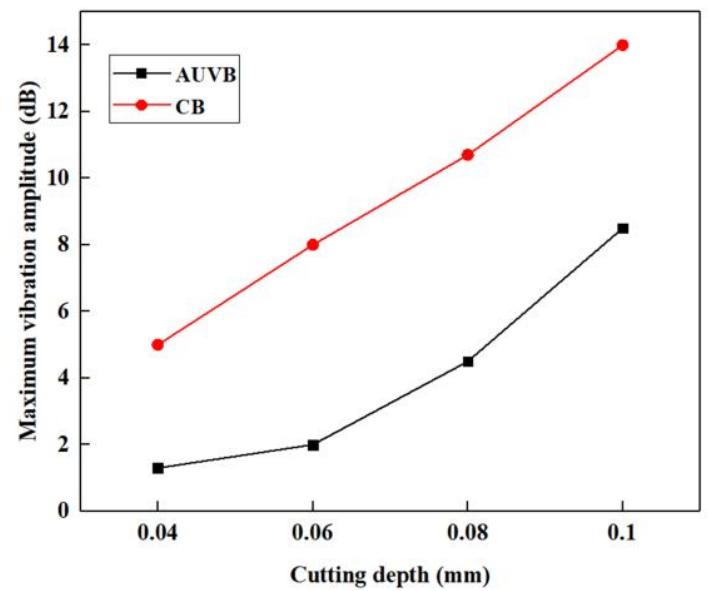

(c) Vibration amplitude (dB) versus feed rate

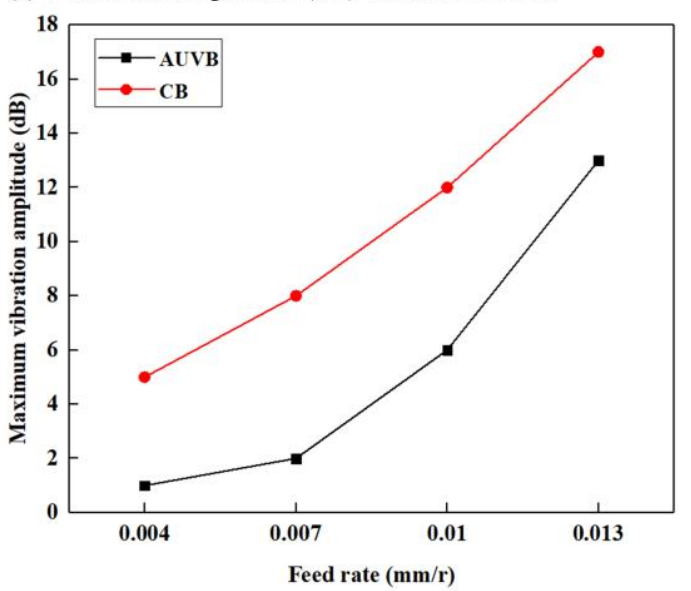

Fig. 19 Influence of machining parameters on vibration amplitude $(\mathrm{dB})\left(D_{l}=7473\right)$

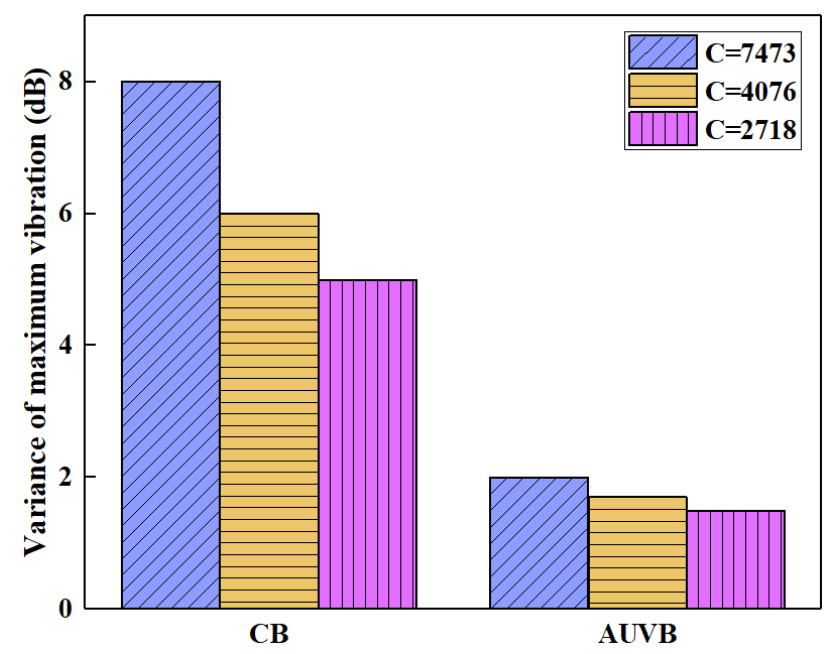

Fig. 20 Influence of size coefficient on vibration amplitude (dB) 
. For AUVB, the vibration stays at a lower level, thus the stability improvement is not significant. That is to say, the vibration level in AUVB with the weakest of the three boring bars is lower than that in $\mathrm{CB}$ with the strongest one. Consequently, AUVB can complete more difficult processing tasks with lower requirements for the boring bar.

\subsection{Promotion of surface quality}

In actual processing, more attention is paid to the overall surface quality of the deep-hole part rather than the surface quality at a specific point. The measurement result for surface roughness $R a$ along a hole of $400 \mathrm{~mm}$ length is shown in Fig. 21(a). With the increase of holedepth, the surface roughness $R a$ correspondingly enlarges, regardless of whether it is a CB process or an AUVB. Moreover, for the same measurement point in AUVB, the larger the rotational speed, the greater the surface roughness.

At the start of the boring process, the surface roughness remains at a lower level of $\mathrm{Ra}=$ 0.2-0.4 $\mu \mathrm{m}$; in this regard, the performance of CB is better than that of AUVB. At this stage, the main influencing factor on surface roughness is the geometric factor, i.e., the surface microtopography. More grooves and peaks in the surface microtopography are formed in AUVB, leading to a higher geometric value of peak height. As the process continues, the surface roughness quickly passes $\mathrm{Ra}=0.8 \mu \mathrm{m}$ with $n=100 \mathrm{r} / \mathrm{min}$ and $\mathrm{n}=120 \mathrm{r} / \mathrm{min}$ for $\mathrm{AUVB}$, and its final value nears $\mathrm{Ra}=1.6 \mu \mathrm{m}$ at the end of the hole. Under a lower rotational speed $(n=60 \mathrm{r} / \mathrm{min}$ or $n=80 \mathrm{r} / \mathrm{min}$ ), the surface roughness can remain below $\mathrm{Ra}=0.8 \mu \mathrm{m}$, which is the technical index required by an actual project. The increase of surface roughness is caused by certain physical factors, such as boring force and tool wear: the rise of boring force causes gradual tool wear, and these subsequently lead to growing surface roughness. The performance of AUVB surpasses that of $\mathrm{CB}$ at about $90 \mathrm{~mm}$ hole-depth under the same rotational speed condition of 80r/min. Therefore, AUVB has obvious advantages for surface roughness at a lower suggested rotational speed of $80 \mathrm{r} / \mathrm{min}$.

Micrographs of the bored surface at $80 \mathrm{~mm}$ and $280 \mathrm{~mm}$ depth with $80 \mathrm{r} / \mathrm{min}$ rotational speed are shown in Fig. 21(b). The difference between the surface morphologies for CB and AUVB is apparent. At $80 \mathrm{~mm}$ depth, both morphologies are inerratic and legible. At $280 \mathrm{~mm}$ depth, the boundary of each morphology begins to fade, and some surface damage starts to 
appear. However, AUVB has a stronger ability to maintain surface morphology, as surface roughness in this process rises more slowly than that in $\mathrm{CB}$.

(a) Ra of machined surface along the deep hole

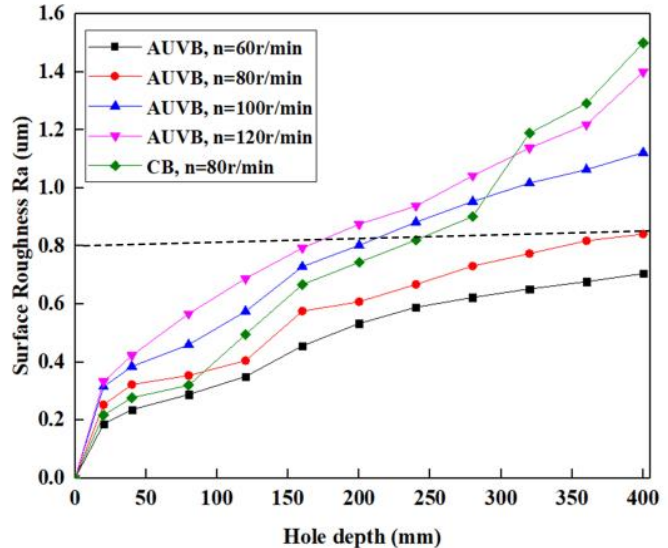

(b) Micrographs of the machined surface

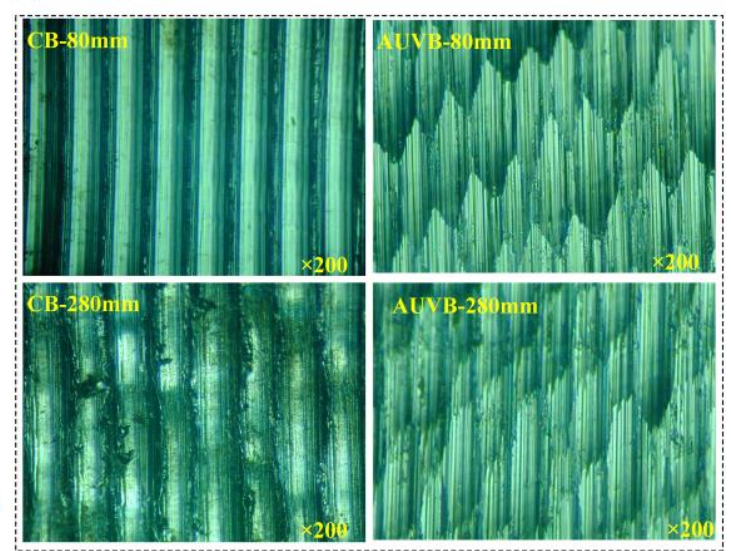

Fig. 21 Roughness $(\mathrm{Ra})$ of machined surface $\left(D_{l}=4076\right)$

Scratching by material chips is an important physical process affecting surface roughness during boring. A smaller chip size has proved to enhance the bored surface due to the narrow and enclosed processing space. Chips obtained during CB and AUVB are shown in Fig. 22. Chip forming is continuous in CB. Further amplification and analysis revealed that these are serrated chips, which is a typical chip form of titanium alloy. Chips formed by AUVB are of the interrupted type, resulting from separation between the tool and the workpiece. This also explains the better surface quality obtained by AUVB.

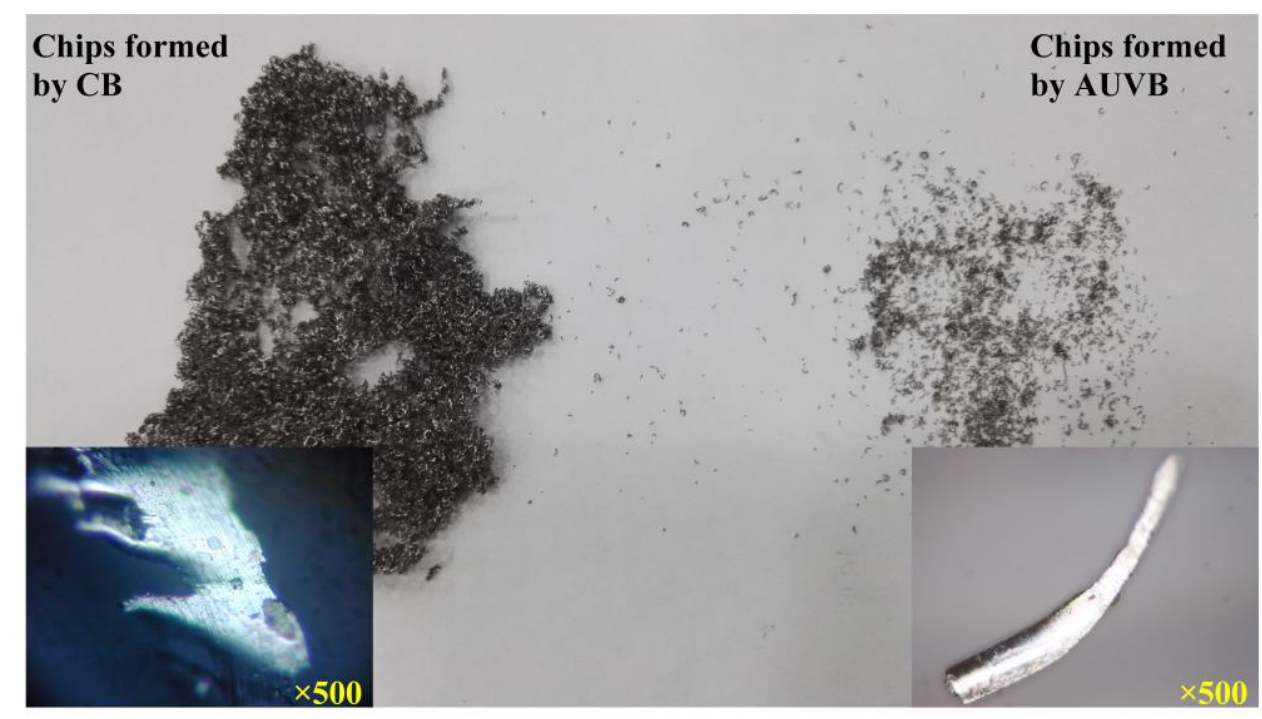

Fig.22 Chip morphologies generated by the CB and the AUVB processes 
For further comparison and analysis, the roughness of bored surface was measured at the middle of the hole $(200 \mathrm{~mm})$. The effects of rotational speed and feed rate on surface roughness are shown in Fig. 23. The increase of both the rotational speed and the feed rate leads to greater surface roughness. Increasing rotational speed may lead to declining boring process stability and rising boring force, both resulting in the degradation of surface quality. It should be noted that the gap of $R a$ value between AUVB and CB gradually increases with rotational speed, however, it decreases with the growing feed rate. Rotational speed is not the main factor influencing the ability to suppress vibration during AUVB; despite changes in rotational speed, a relatively stable vibration state can still be maintained in AUVB. However, the advantage of separation cutting is disappears with increasing feed rate, and the surface roughness gets close to that for $\mathrm{CB}$, which is an otherwise substantive characteristic of AUVB.

(a) Surface roughness versus rotation speed

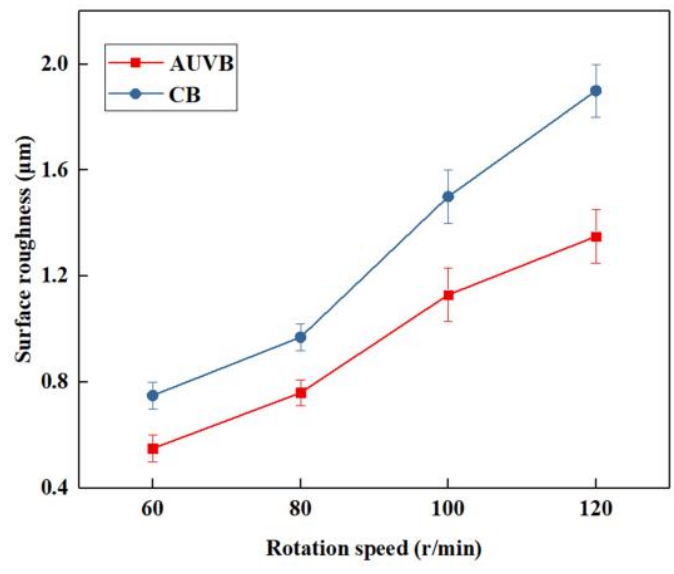

(b) Surface roughness versus feed rate

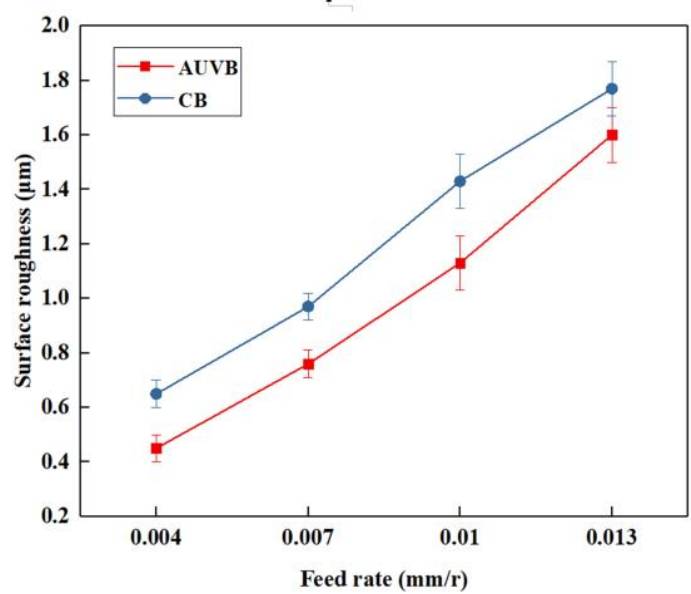

Fig. 23 Influence of rotational speed and feed rate on surface roughness for AUVB $\left(D_{l}=4076\right)$

The impact of size coefficient on surface roughness is also demonstrated in Fig. 24. Boring bar rigidity, as well as surface roughness decrease with the size coefficient. This effect is the same as that on boring force and accuracy, i.e., the size coefficient is not a direct acting factor, but affects surface roughness indirectly by influencing boring deformation and stability.

Residual stress has an important effect on fatigue life, especially of deep-hole parts. Therefore, the residual stress of the bored surface was measured, and results are shown in Fig. 25. For $\mathrm{CB}$, the residual stress is tensile, however, due to the cutting force and the temperature impact, the surface residual stress state is transferred from a tensile to a compressive one for AUVB. 


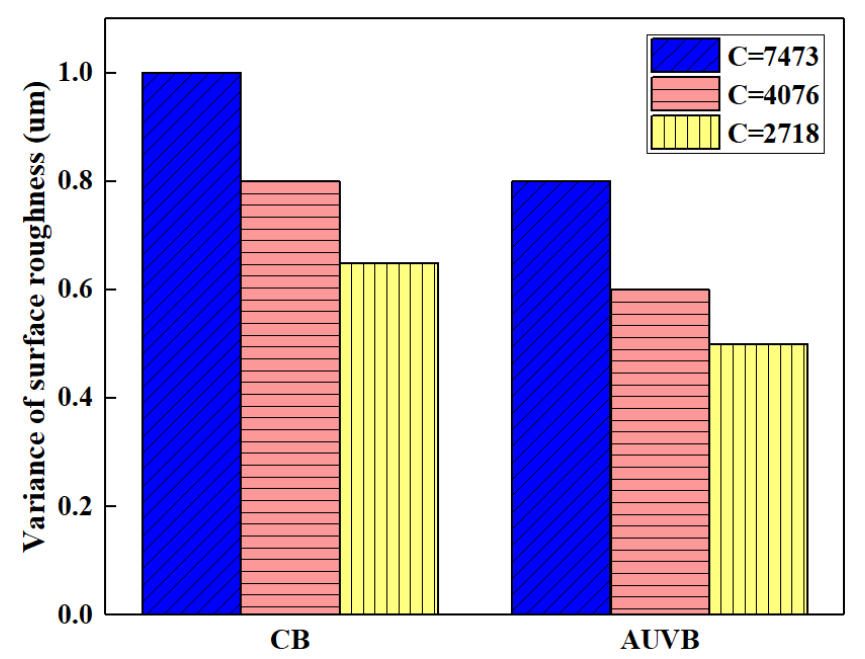

Fig. 24 Impact of size coefficient on surface roughness

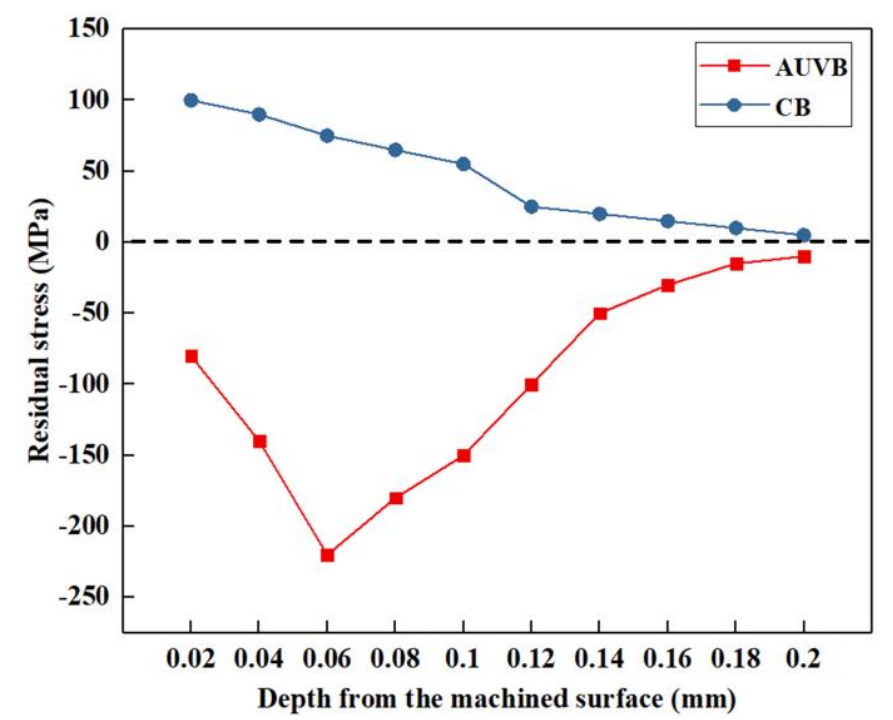

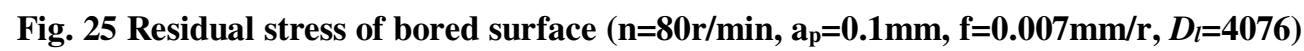

The transfer of residual stress from a tensile to a compressive state indicates a potential material fatigue promotion. Due to the higher cutting force and temperature in $\mathrm{CB}$, the residual stress of the workpiece surface is tensile and it reduces in deeper positions, whereas the residual stress in AUVB is compressive and reaches a maximum value of about 220MPa, caused by the impact when the cutting tool cuts into the workpiece. The corresponding position is $0.06 \mathrm{~mm}$ depth from the surface. As the depth increases, the influence of both cutting temperature and tool impact gradually decrease, and the residual stress decreases in both methods and tends back to a balanced state. The influence depth is $0.2 \mathrm{~mm}$, which is about twice the cutting depth of $0.1 \mathrm{~mm}$. As a result, the AUVB method not only can provide a better surface finish, but also achieves enhanced surface fatigue properties. 


\section{Conclusions}

The present study comprises an investigation into machining a super-dimensioned titanium alloy Ti6Al4V aviation deep-hole part by the axial ultrasonic vibration-assisted boring (AUVB) method. First, the kinetics of the AUVB process were analyzed and a retrospective of its separation cutting feature was provided. Next, the boring bar modal was established as a multi-step cantilever beam, and its static rigidity and dynamic stability were analyzed. In particular, the reason for the improvement of static rigidity and dynamic stability in AUVB was theoretically revealed. Finally, experiments were conducted to verify the advantages of AUVB in boring force reduction, boring accuracy improvement, vibration suppression and promotion of surface quality. The final conclusions are as follows:

- AUVB has a separation cutting feature resulting from the vibration performed along the axial direction. Due to the transient and separation cutting feature caused by the added ultrasonic vibration, a reduction of boring force for AUVB was also obtained through experiments. The boring force was demonstrated to elevate with the increase of machining parameters and size parameters.

- The boring bar can be simplified to a multi-step cantilever beam. Deformation caused by the boring force leads to cutter relieving, which in turn results in aperture error. The latter is mainly determined by the diameter of the basic hole, cutting depth, cutting force, length and diameter, elastic modulus, and the moment of inertia of each step. The size coefficient is more suitable to represent the static rigidity of the boring bar than aspect ratio, and is proportional to the third power of the diameter and inversely proportional to the fourth power of the diameter. The process of AUVB can decrease the aperture error up to $50 \%$ by offering a lower boring force.

- Two different vibration cases have been considered, namely model-coupling vibration in the $(X, Y)$ plane, and regenerative vibration in the $Z$-axis. The dynamic elastic coefficient for both of these models was deduced. The actual dynamic elastic coefficient for modelcoupling vibration is lower in AUVB, resulting from the lower actual cutting force and larger actual cutting depth. In addition, the vibration amplitude in the $Z$-axis was established while considering regenerative vibration, which is directly proportional to the dynamic elastic coefficient and feed rate, and inversely proportional to the static elastic coefficient. 
Due to the separation cutting feature, the dynamic elastic coefficient is lower in AUVB. As a whole, AUVB has better processing stability, with vibration amplitudes of only $20 \%-25 \%$ of those in the $\mathrm{CB}$ process.

- The overall surface quality of the deep-hole part was enhanced by AUVB, especially with lower machining parameter settings. The surface roughness can remain below $\mathrm{Ra}=0.8 \mu \mathrm{m}$ with the rotational speed at $60 \mathrm{r} / \mathrm{min}$ and $80 \mathrm{r} / \mathrm{min}$ in the AUVB process, however, it reaches about $\mathrm{Ra}=1.6 \mu \mathrm{m}$ in $\mathrm{CB}$. Moreover, smaller-sized interrupted chips formed in AUVB constitute an important physical factor enhancing surface quality.

- In AUVB, the surface residual stress state is transferred from the tensile to the compressive one due to the impact of cutting force and temperature, and reaches the maximum value of about $220 \mathrm{MPa}$ at the depth of $0.06 \mathrm{~mm}$ below the bored surface. The maximum influence depth is $0.2 \mathrm{~mm}$, which is about twice the cutting depth. Consequently, AUVB not only provides a better surface finish, but also results in improved surface fatigue properties.

\section{Ethical Approval}

Not applicable.

\section{Consent to Participate}

Not applicable.

\section{Consent to Publish}

Not applicable.

\section{Authors Contributions}

Author He Sui carried out theoretical and experimental study of this paper, and was a major contributor in writing the manuscript. Author Lifeng Zhang contributed to the conception of the study, and helped perform the theoretical analysis part with constructive discussions. Author Shuang Wang performed the data analyses and wrote the manuscript. Author Zhaojun Gu contributed significantly to analysis and manuscript preparation.

\section{Funding}

This work was supported by the Fundamental Research Funds for the Central Universities of Civil Aviation University of China (grant no. 3122019072). 


\section{Competing Interests}

We declare that we have no financial and personal relationships with other people or organizations that can inappropriately influence our work, there is no professional or other personal interest of any nature or kind in any product, service and/or company that could be construed as influencing the position presented in, or the review of, the manuscript entitled.

\section{Availability of data and materials}

All data generated or analyzed during this study are included in this published article, and further request can be contacted with the corresponding author.

\section{References}

[1] Chern GL, Liang JM (2007) Study on boring and drilling with vibration cutting. Int. J. Mach. Tools Manuf. 47: 133-140. https://doi.org/10.1016/j.ijmachtools.2006.02.017

[2] Li XB, Zheng JM, Li Y, Xiao JM, Guo B, Liu C (2020) Modeling and experimental investigation of drilling force for low-frequency axial vibration-assisted BTA deep hole drilling. Int. J. Adv. Manuf. Technol. 111: 1721-1733. https://doi.org/10.1007/s00170$\underline{020-06162-4}$

[3] Zhang H, Shen X, Bo A, Li Y, Zhan H, Gu Y (2017) A multiscale evaluation of the surface integrity in boring trepanning association deep hole drilling. Int. J. Mach. Tools Manuf. 123: 48-56. http://dx.doi.org/10.1016/j.ijmachtools.2017.07.005

[4] Dai GL, Hui YH, Jin KK (2003) Design and manufacture of a carbon fiber epoxyrotating boring bar. Compos. Struct. 60(1): 115-124. https://doi.org/10.1016/S0263$\underline{8223(02) 00287-8}$

[5] Zhou X, Jiang P (2017) Variation source identification for deep hole boring process of cutting-hard workpiece based on multisource information fusion using evidence theory. J. Intell. Manuf. 28(2): 255-270. https://doi.org/10.1007/s10845-014-0975-7

[6] Zhang CJ, Ren YS, Ji SJ, Zhang JF (2020) Analysis of the vibration and chatter stability of a tapered composite boring bar. Shock and Vibration. 2020, 1-11. https://doi.org/10.1155/2020/4190806 
[7] Ghorbani S, Rogov VA, Carluccio A, Belov PS (2019) The effect of composite boring bars on vibration in machining process. Int. J. Adv. Manuf. Technol. 105: 1157-1174. https://doi.org/10.1007/s00170-019-04298-6

[8] Sastry CC, Hariharan P, Kumar MP, Manickam MAM (2019) Experimental investigation on boring of HSLA ASTM A36 steel under dry, wet, and cryogenic environments. Mater. Manuf. Process. 34: 1352-1379. https://doi.org/10.1080/10426914.2019.1643477

[9] Song QH, Shi JH, Liu ZQ, Wan Y, Xia F (2016) Boring bar with constrained layer damper for improving process stability. Int. J. Adv. Manuf. Technol. 83: 1951-1966. https://doi.org/10.1007/s00170-015-7670-5

[10] Chen F, Lu X, Altintas Y (2014) A novel magnetic actuator design for active damping of machining tools. Int. J. Mach. Tools. Manuf. 85: 58-69. https://doi.org/10.1016/j.ijmachtools.2014.05.004

[11] Matsubara A, Maeda M, Yamaji I (2014) Vibration suppression of boring bar by piezoelectric actuators and LR circuit. CIRP Annals-Manuf. Technol. 63(1): 373-376. https://doi.org/10.1016/j.cirp.2014.03.132

[12] Chen F, Hanifzadegan M, Altintas Y, Lu XD (2015) Active damping of boring bar vibration with a magnetic actuator. IEEE-ASME T. Mech. 20: 2783-2794. https://doi.org/10.1109/TMECH.2015.2393364

[13] Som A, Kim DH, Son HS (2015) Semiactive magnetorheological damper for high aspect ratio boring process. IEEE-ASME T. Mech. 20: 2575-2582. https://doi.org/10.1109/TMECH.2015.2388861

[14] Vashisht RK, Peng QJ (2020) Efficient active chatter mitigation for boring operation by electromagnetic actuator using optimal fractional order PD lambda controller. J. Mater. Process Technol. 276: 116423. https://doi.org/10.1016/j.jmatprotec.2019.116423

[15] Fallah M, Moetakef-Imani B (2019) Design, analysis, and implementation of a new adaptive chatter control system in internal turning. Int. J. Mach. Tools Manuf. 104: 16371659. https://doi.org/10.1007/s00170-019-03808-w

[16] Ma CX, Ma J, Shamoto E, Moriwaki T (2011) Analysis of regenerative chatter suppression with adding the ultrasonic elliptical vibration on the cutting tool. Precision Engineering. 35: 329-338. https://doi.org/10.1016/j.precisioneng.2010.12.004 
[17] Gao J, Altintas Y (2020) Chatter stability of synchronized elliptical vibration assisted $\begin{array}{llll}\text { milling. } & \text { CIRP } & \text { Annals-Manuf. } & \text { Technol. }\end{array}$ https://doi.org/10.1016/j.cirpj.2019.11.006

[18] Gao Y, Sun R, Leopold J (2015) Analysis of cutting stability in vibration assisted machining using an analytical predictive force model. Procedia CIRP. 31: 515-520. https://doi.org/10.1016/j.procir.2015.03.014

[19] Dong G, Lang C, Li C, Zhang L (2020) Formation mechanism and modelling of exit edgechipping during ultrasonic vibration grinding of deep-small holes of microcrystalline-mica ceramics. Ceram. Int. 46(8): 12458-12469. https://doi.org/10.1016/j.ceramint.2020.02.008

[20] Sui H, Zhang DY, Chen HW, Zhang XY (2016) Influence of ultrasonic vibration cutting on mode-coupling chatter. Acta aeronautica et astronautica sinica. 37(5): 1696-1704. (in Chinese) https://doi.org/10.7527/s1000-6893.2015.0230

[21] Zhang XY, Sui H, Zhang DY, Wu RB (2017) The improvement of deep-hole boring machining quality assisted with ultrasonic vibration. Journal of mechanical engineering. 53(19): 143-148. ( in Chinese) https://doi.org/10.3901/JME.2017.19.143

[22] Dong GJ, Wang L, Li C, Yu YF (2020) Investigation on ultrasonic elliptical vibration boring of deep holes with large depth-diameter ratio for high-strength steel 18Cr2Ni4WA. Int. J. Adv. Manuf. Technol. 108: 1527-1539. https://doi.org/10.1007/s00170-020-05531$\underline{3}$

[23] Saoubi RM, Axinte D, Soo SL, Nobel C, Attia H, Kappmeyer G, Engin S, Sim W (2015) High performance cutting of advanced aerospace alloys and composite materials. CIRP Ann. 64 (2): 557-580. https://10.1016/j.cirp.2015.05.002

[24] Zheng K, Liao W, Dong Q, Sun L (2018) Friction and wear on titanium alloy surface machined by ultrasonic vibration-assisted milling. J. Braz. Soc. Mech. Sci. Eng. 40, 411. https://doi.org/10.1007/s40430-018-1336-9

[25] Sui H, Zhang XY, Zhang DY, Jiang XG, Wu RB (2017) Feasibility study of high-speed ultrasonic vibration cutting titanium alloy. J. Mater. Process. Tech. 247: 111-120. https:// doi.org/10.1016/ j. jmatprotec.2017.03.017 
[26] Sui H, Zhang LF, Wang S, Gu ZJ (2020) Transient separation cutting characteristic of axial ultrasonic vibration-assisted cutting. Int. J. Adv. Manuf. Tech. 110: 2407-2425. https://doi.org/10.1007/s00170-020-06020-3

[27] Zhang XY, Sui H, Zhang DY, Jiang XG (2018a) Study on the separation effect of highspeed ultrasonic vibration cutting. Ultrasonics. 87: 166-181. https://doi.org/10.1016/j.ultras. 2018.02.016

[28] Zhang XY, Sui H, Zhang DY, Jiang XG (2018b) An analytical transient cutting force model of high-speed ultrasonic vibration cutting, Int. J. Adv. Manuf. Tech. 95: 3929-3941. https://doi.org/10.1007/s00170-017-1499-Z

[29] Liu JJ, Jiang XG, Han X, Gao Z, Zhang DY (2019a) Effects of rotary ultrasonic elliptical machining for side milling on the surface integrity of Ti-6Al-4V. Int. J. Adv. Manuf. Tech. 1: 1451-1465. https://doi.org/10.1007/s00170-018-2847-3

[30] Liu JJ, Jiang XG, Han X, Zhang DY (2019b) Influence of parameter matching on performance of high-speed rotary ultrasonic elliptical vibration-assisted machining for side milling of titanium alloys. Int. J. Adv. Manuf. Tech. 101: 1333-1348. https://doi.org/10.1007/s00170-018-3006-6

[31] Li J, Geng DX, Zhang DY, Qin W, Jiang YG (2018) Ultrasonic vibration mill-grinding of single-crystal silicon carbide for pressure sensor diaphragms. Ceram. Int. 44(3): 31073112. https://doi.org/10.1016/j.ceramint.2017.11.077

[32] Geng DX, Teng YD, Liu YH, Shao ZY, Jiang XG, Zhang DY (20190 Experimental study on drilling load and hole quality during rotary ultrasonic helical machining of smalldiameter CFRP holes. J. Mater. Process Technol. 270: 195-205. https://doi.org/10.1016/j.jmatprotec.2019.03.001

[33] Ma CX, Shamoto E, Moriwaki T, Wang LJ (2004) Study of machining accuracy in ultrasonic elliptical vibration cutting. Int. J. Mach. Tools. Manuf. 44(12-13): 1305-1310. https://doi.org/10.1016/j.ijmachtools.2004.04.014

[34] Shamoto E, Moriwaki T (1994) Study on Elliptical Vibration Cutting. CIRP Annuals. 43(1): 35-38. https://doi.org/10.1016/S0007-8506(07)62158-1 
[35] Sui H, Zhang XY, Zhang DY (2021) Surface modeling and analysis of high-speed ultrasonic vibration cutting. Machining Science and Technology. 25:1, 100-117. https://doi.org/10.1080/10910344.2020.1815046 
Figures

(a) Deep hole boring operation

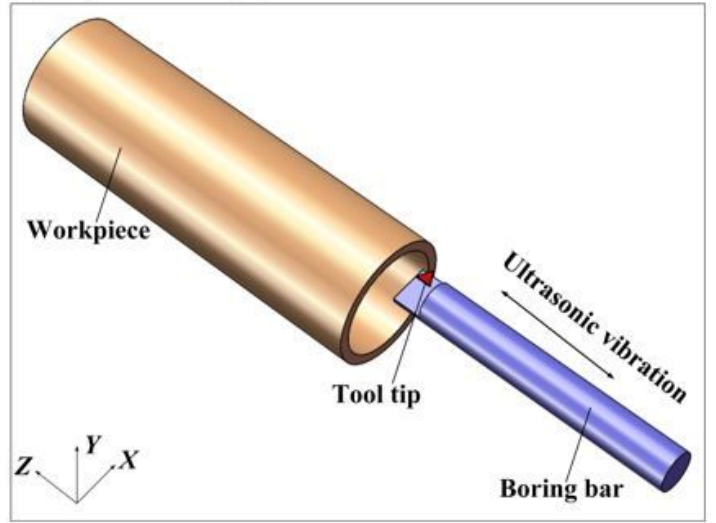

(b) The trajectory of the tool tip

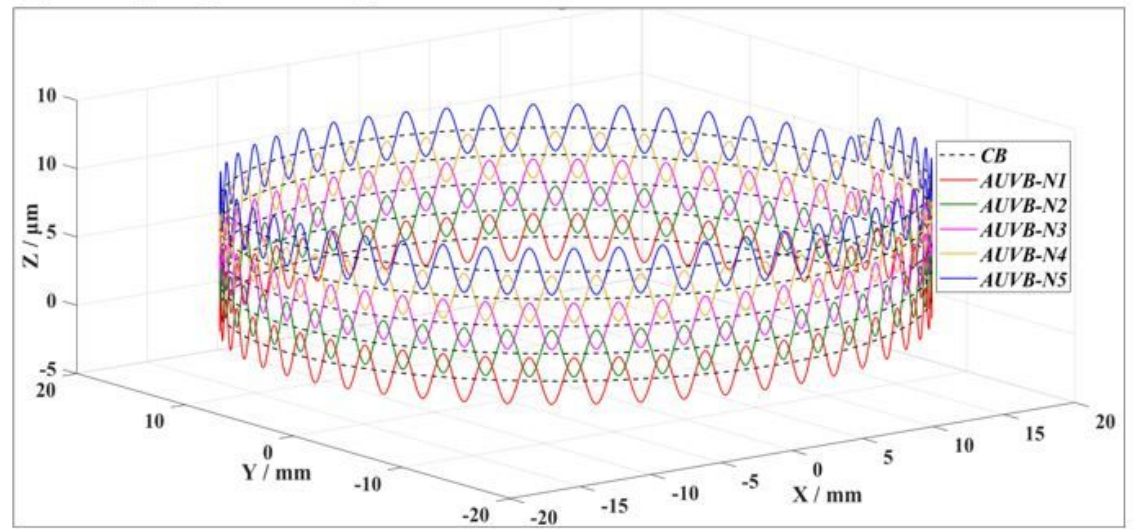

\section{Figure 1}

Schematic of axial ultrasonic vibration-assisted boring

(a) The extended plane of the workpiece

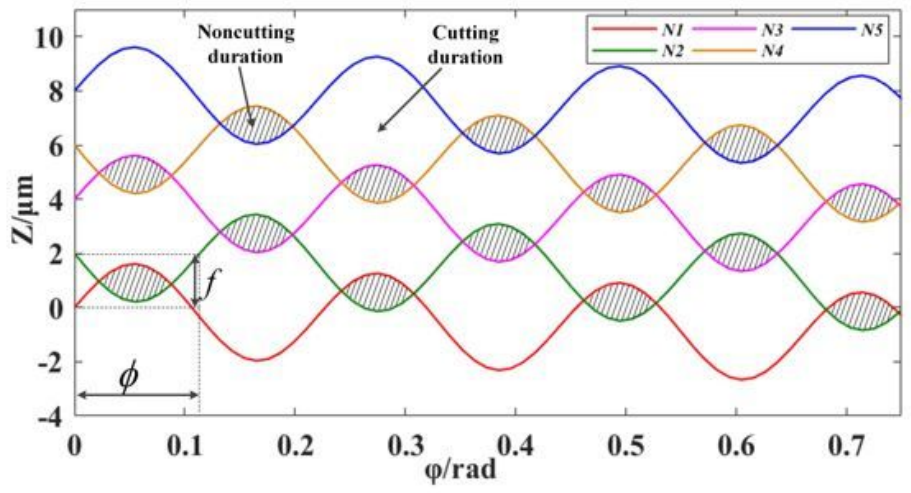

(b) The critical condition of separating cutting

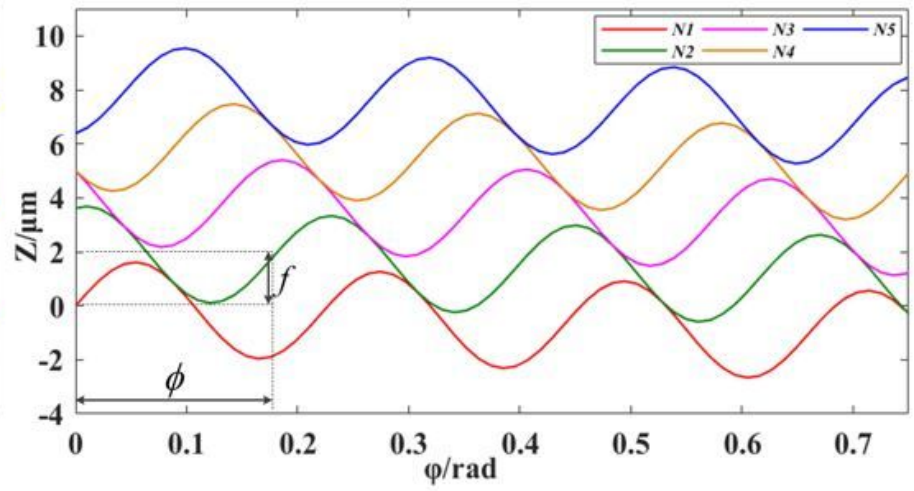

Figure 2

Separation cutting feature of axial ultrasonic vibration-assisted boring 
(a) The boring bar model

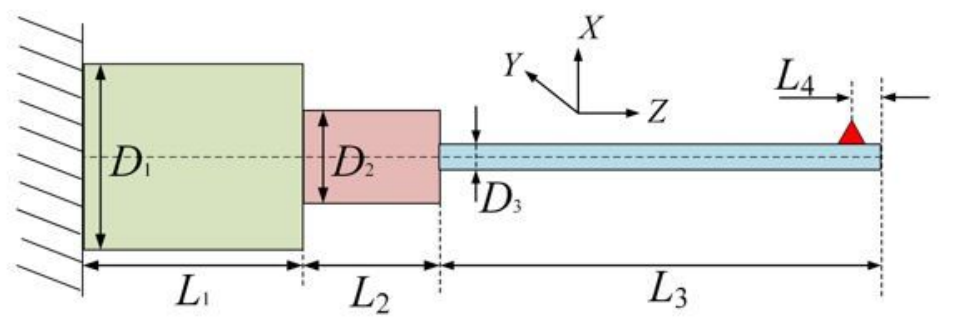

(c) The hole diameter error

(b) Ladder rod stiffness model of the boring bar
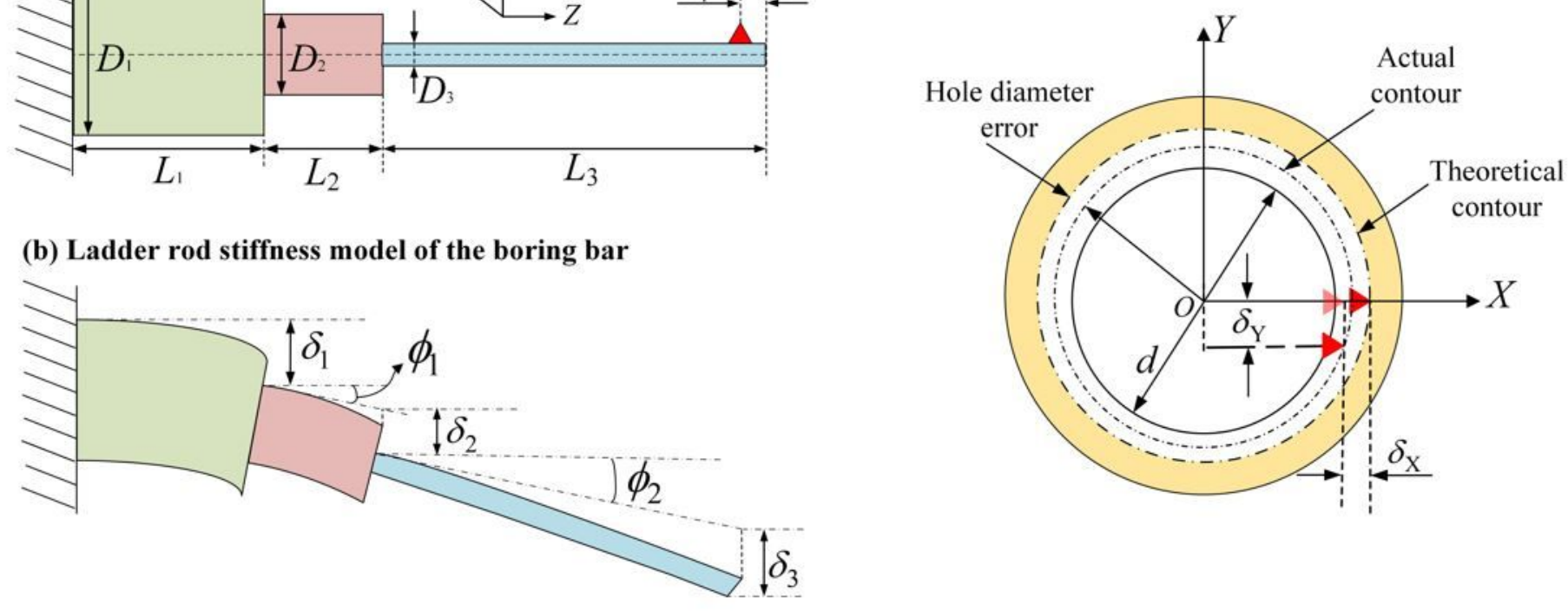

\section{Figure 3}

Static rigidity model and aperture error of ultrasonic vibration-assisted boring bar

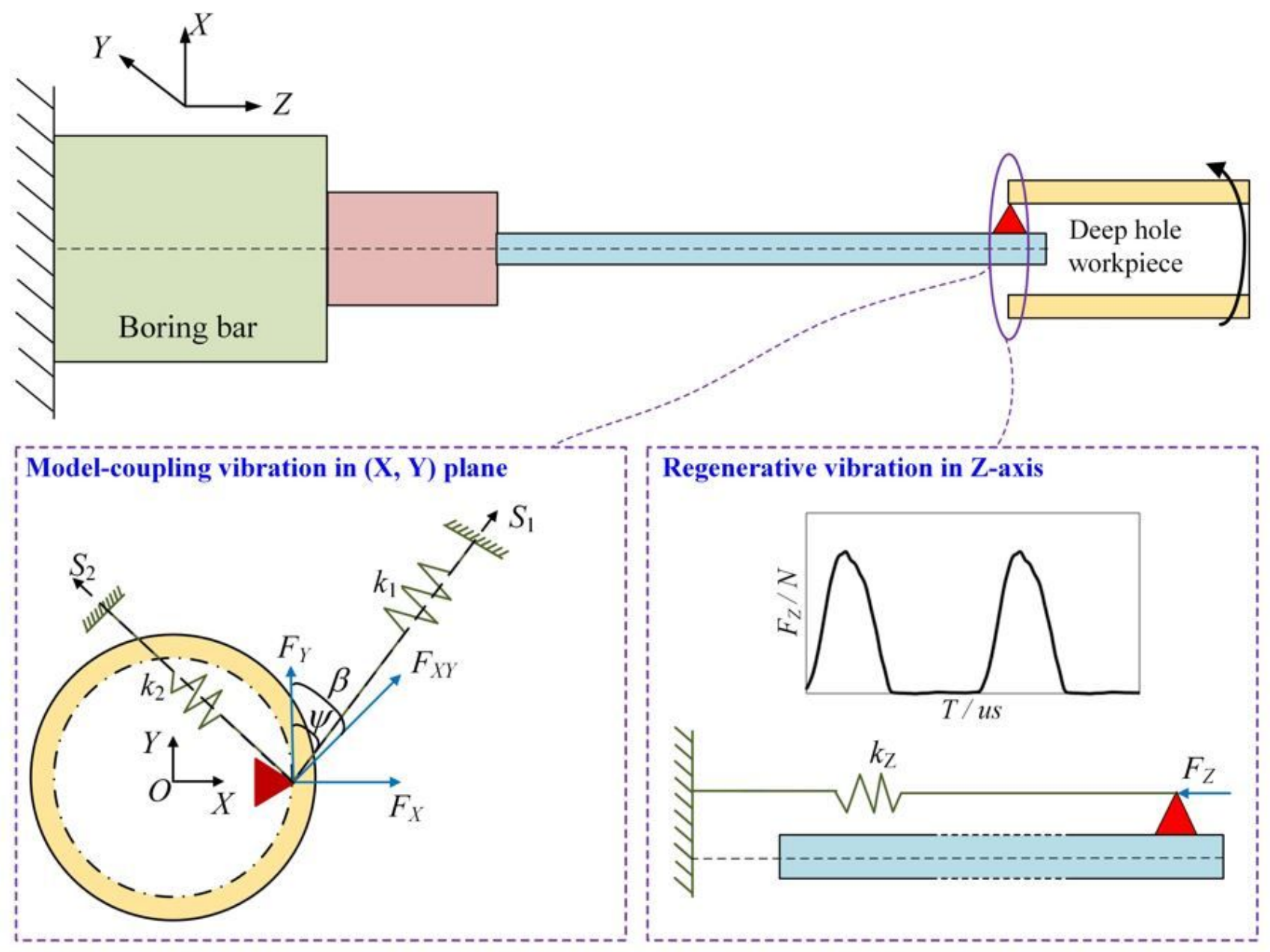


Figure 4

Vibration model in deep-hole boring

(a) Separation cutting

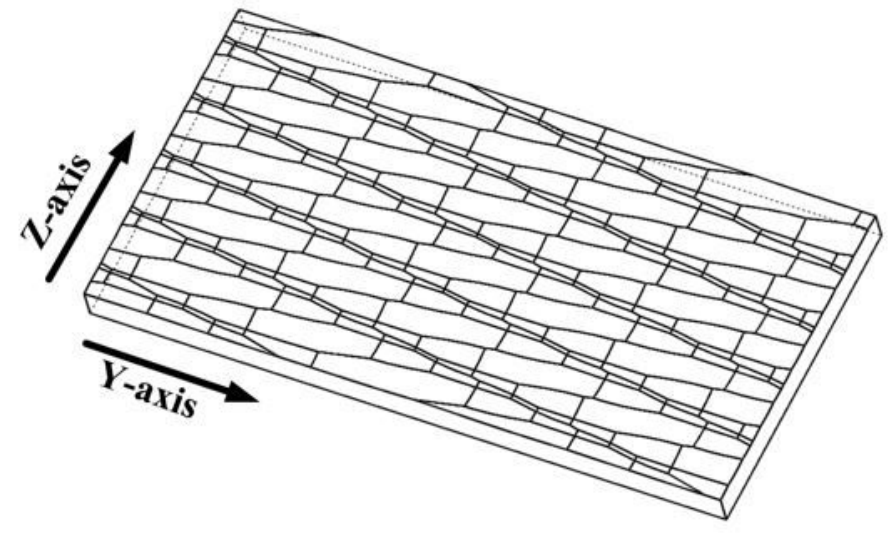

(b) Continuous cutting

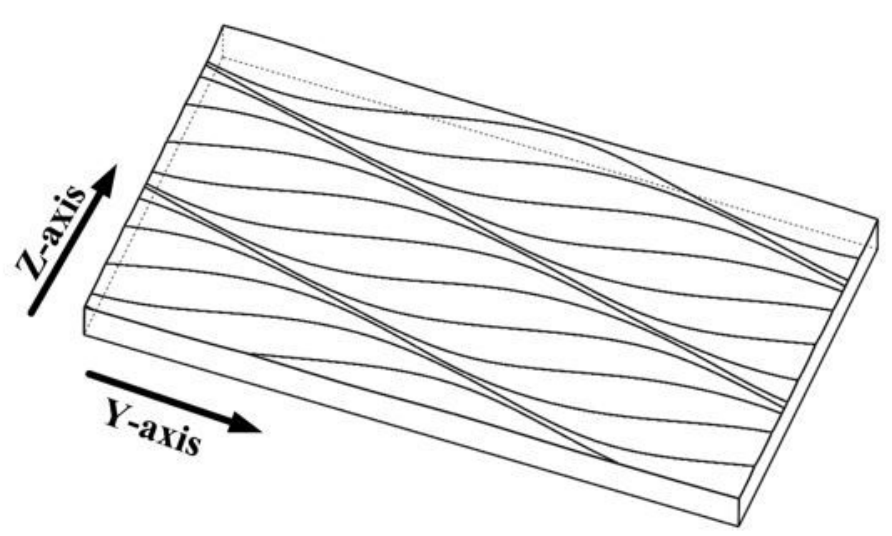

Figure 5

Simulation results of surface micromorphology in AUVB

(a) Formation of micromorphology in a separation AUVB process

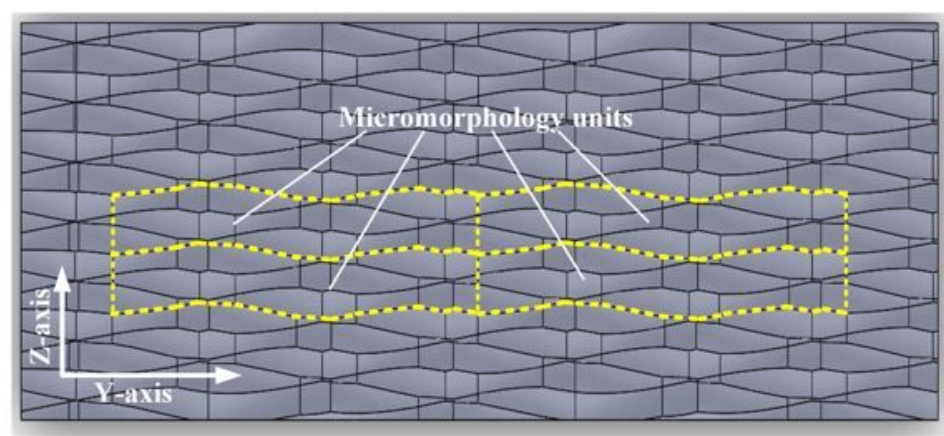

(b) Formation of the ridges and peaks in the micromorphology unit

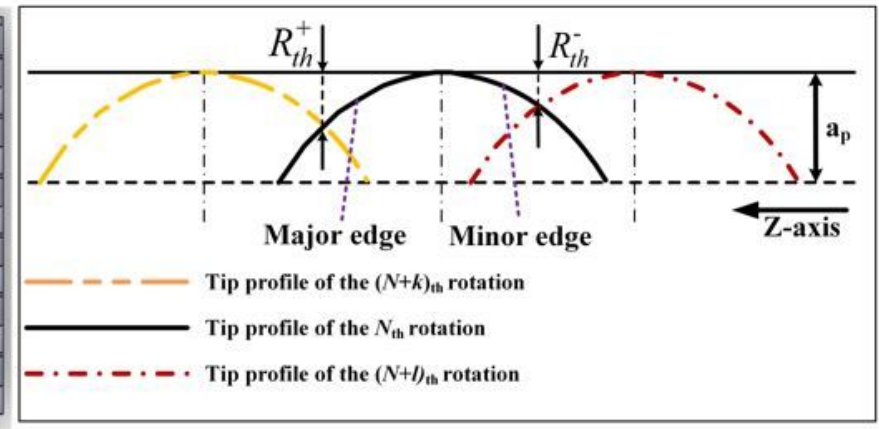

\section{Figure 6}

Schematics of the formation of ridges and peaks formed in a separation AUVB process 


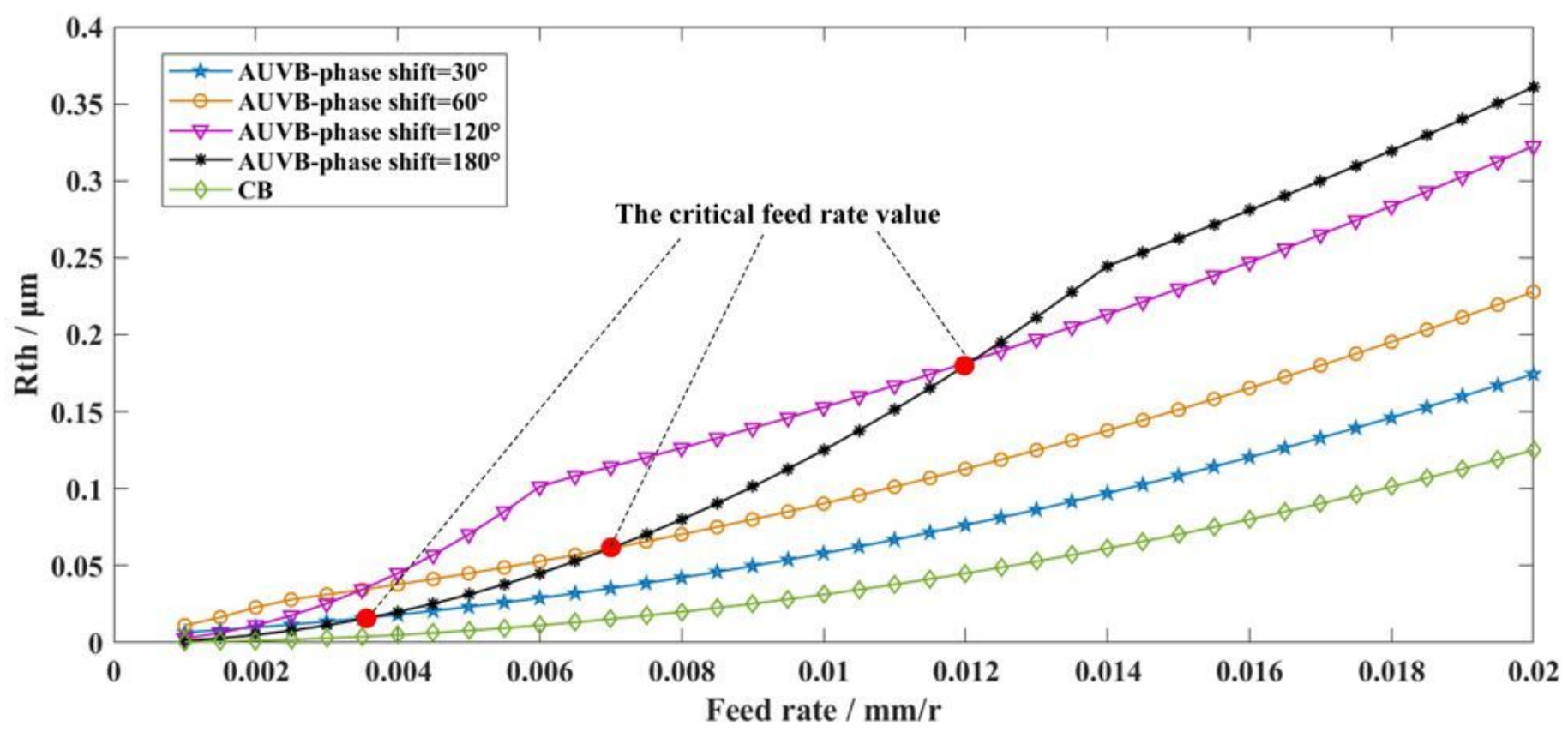

Figure 7

The height of peaks as formed in the AUVB and the CB process

(a) Design of the boring bar

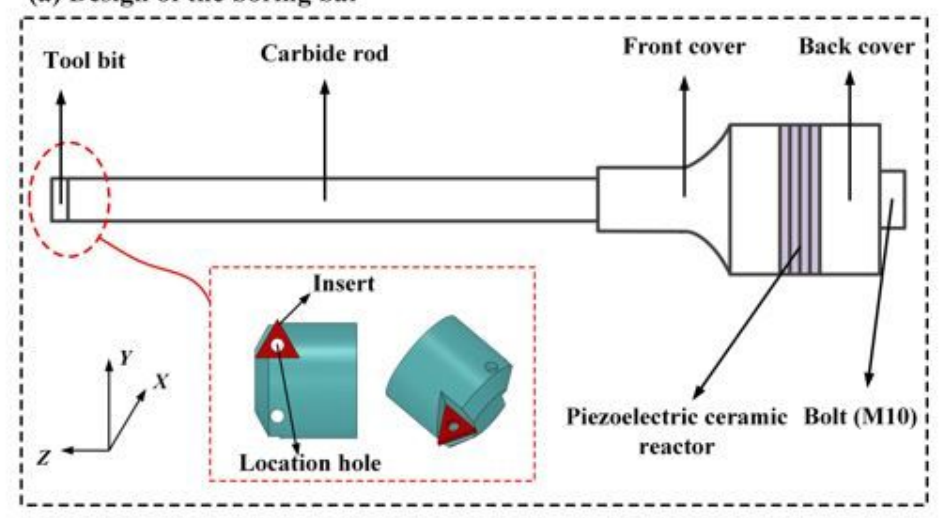

(b) Product of the boring bar

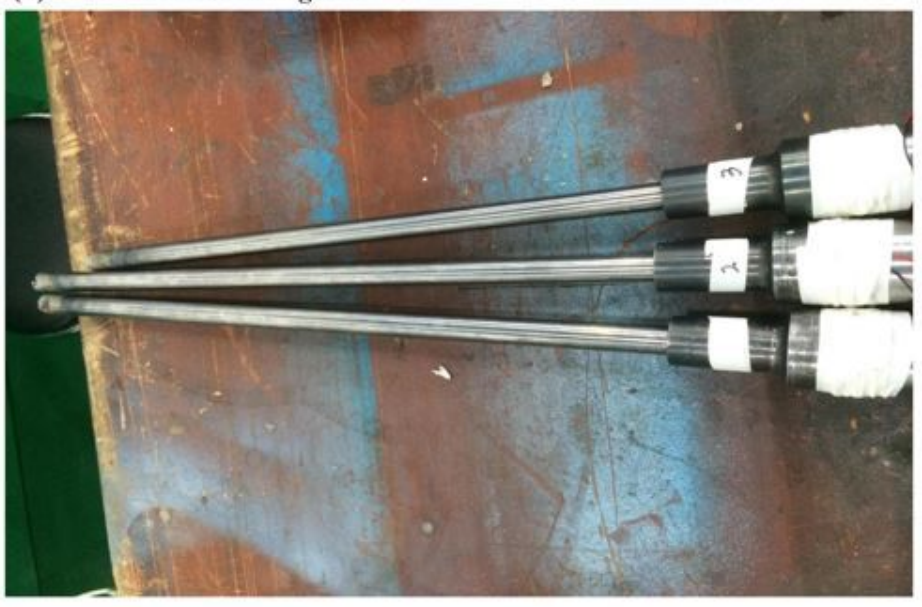

(c) Resonant frequency of the boring bar

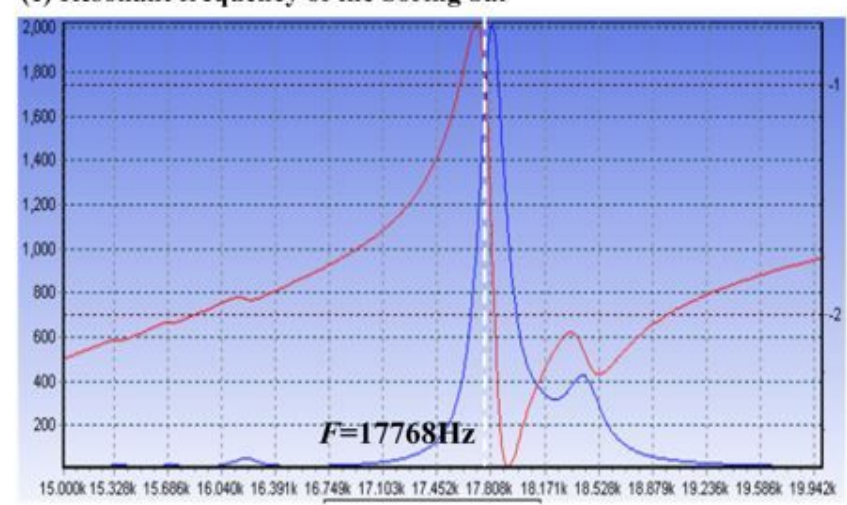

(d) Amplitude of the boring bar

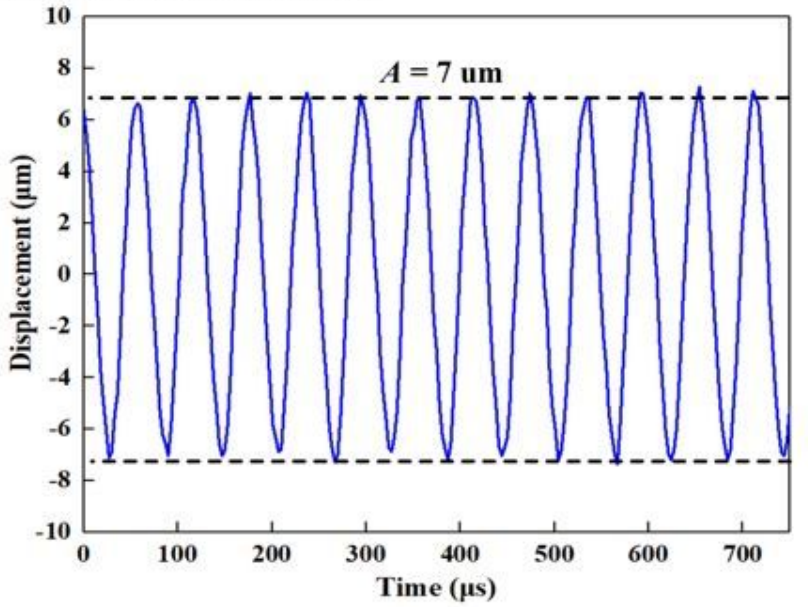


Design and implementation of the boring bar

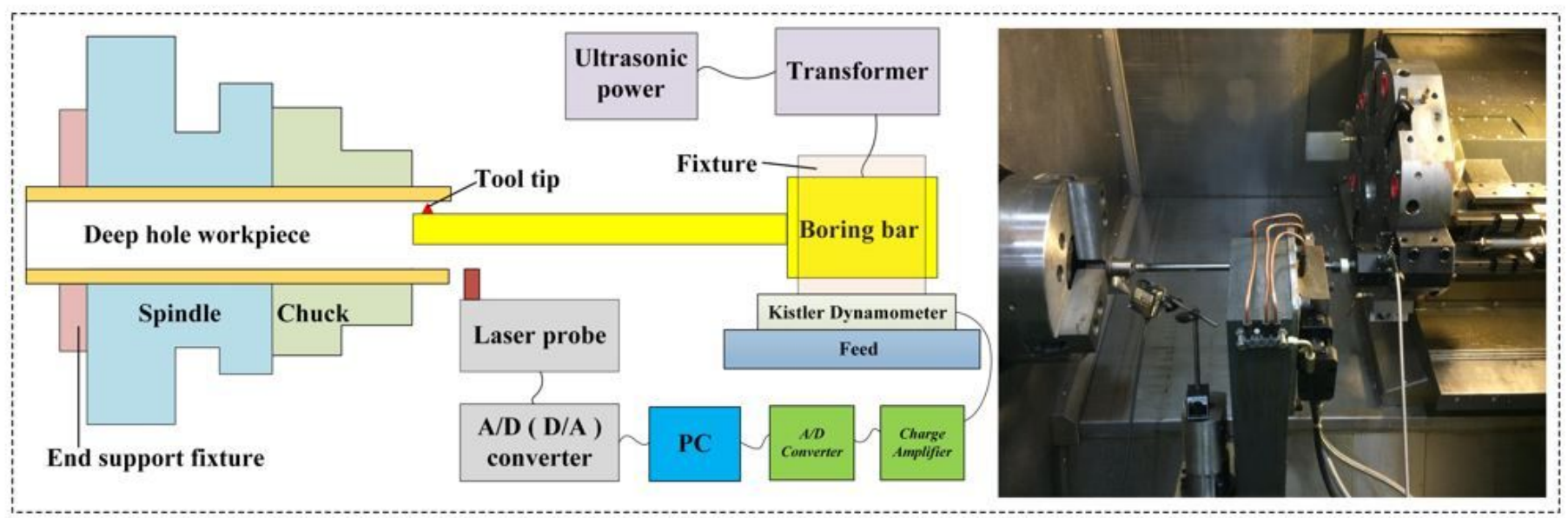

\section{Figure 9}

Schematics of the experiment setup 
(a) Boring force versus rotation speed

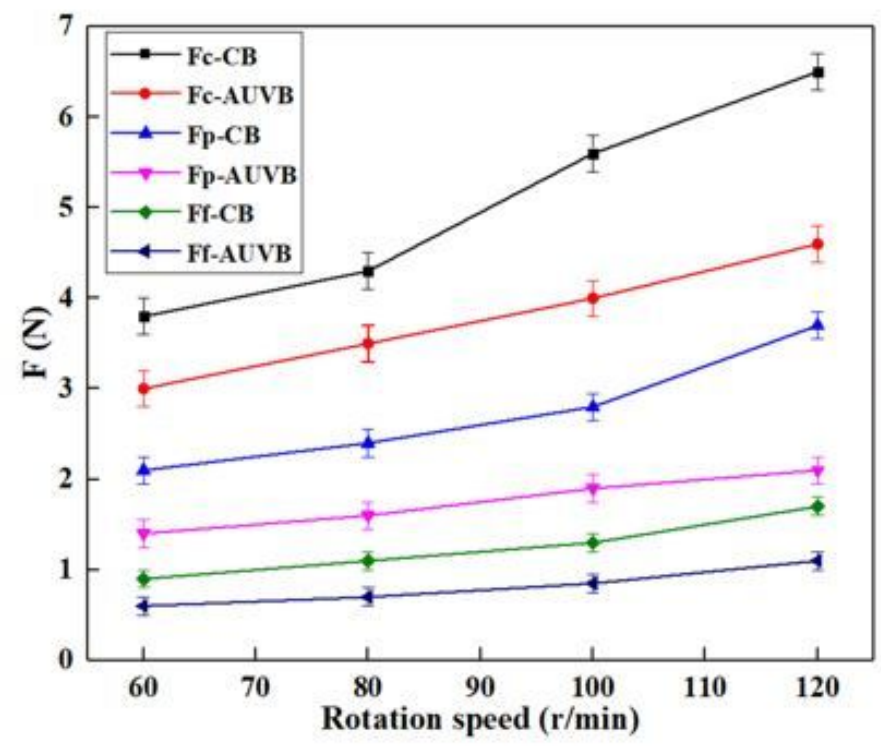

(b) Boring force versus cutting depth

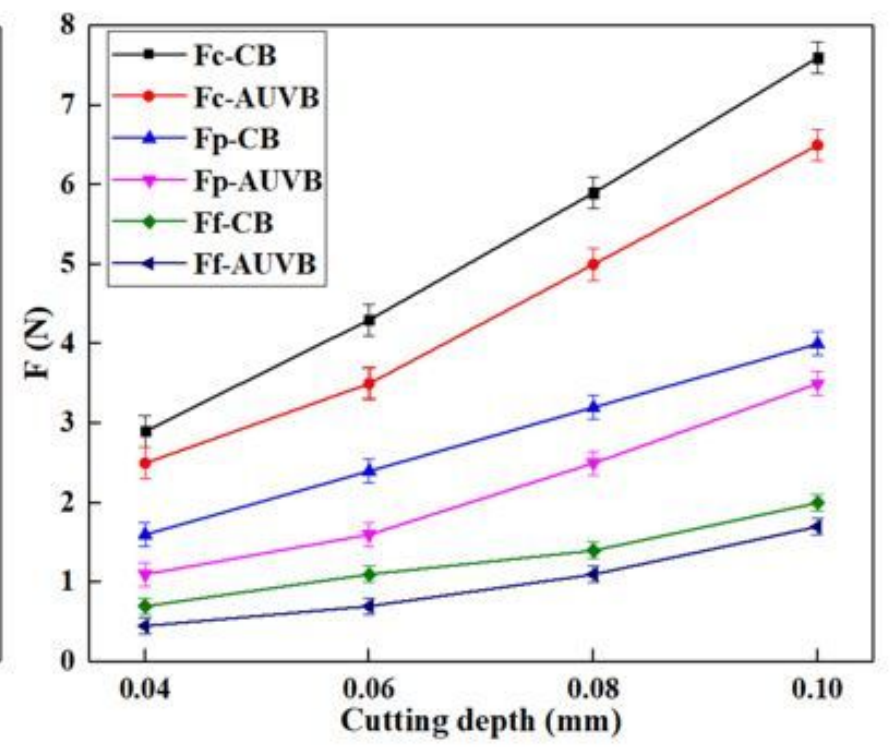

(c) Boring force versus feed rate

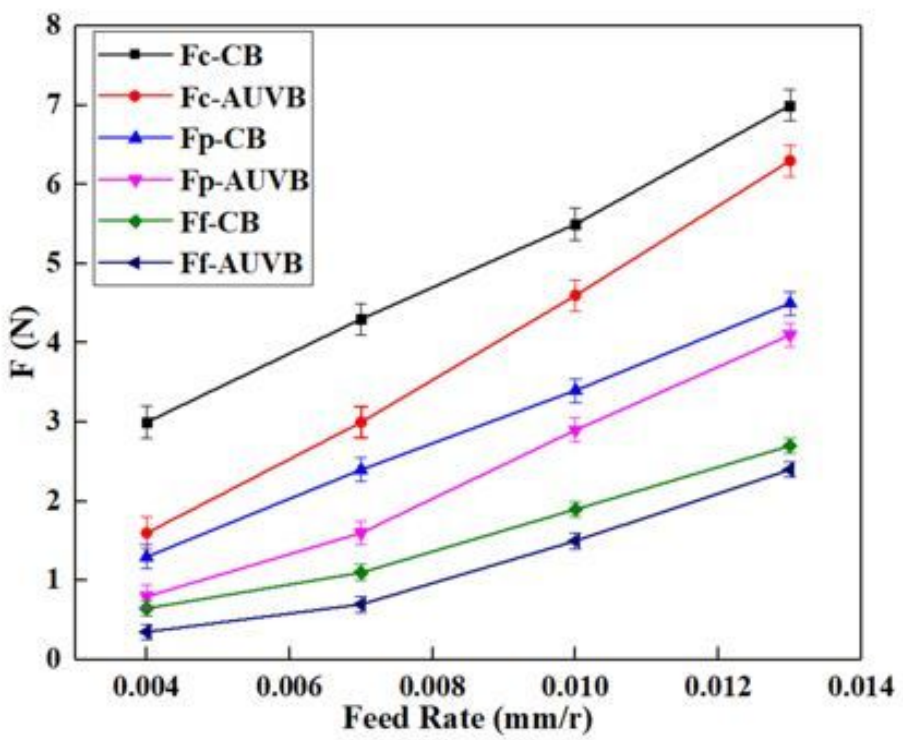

Figure 10

Influence of machining parameters on boring force (DI =7473) 


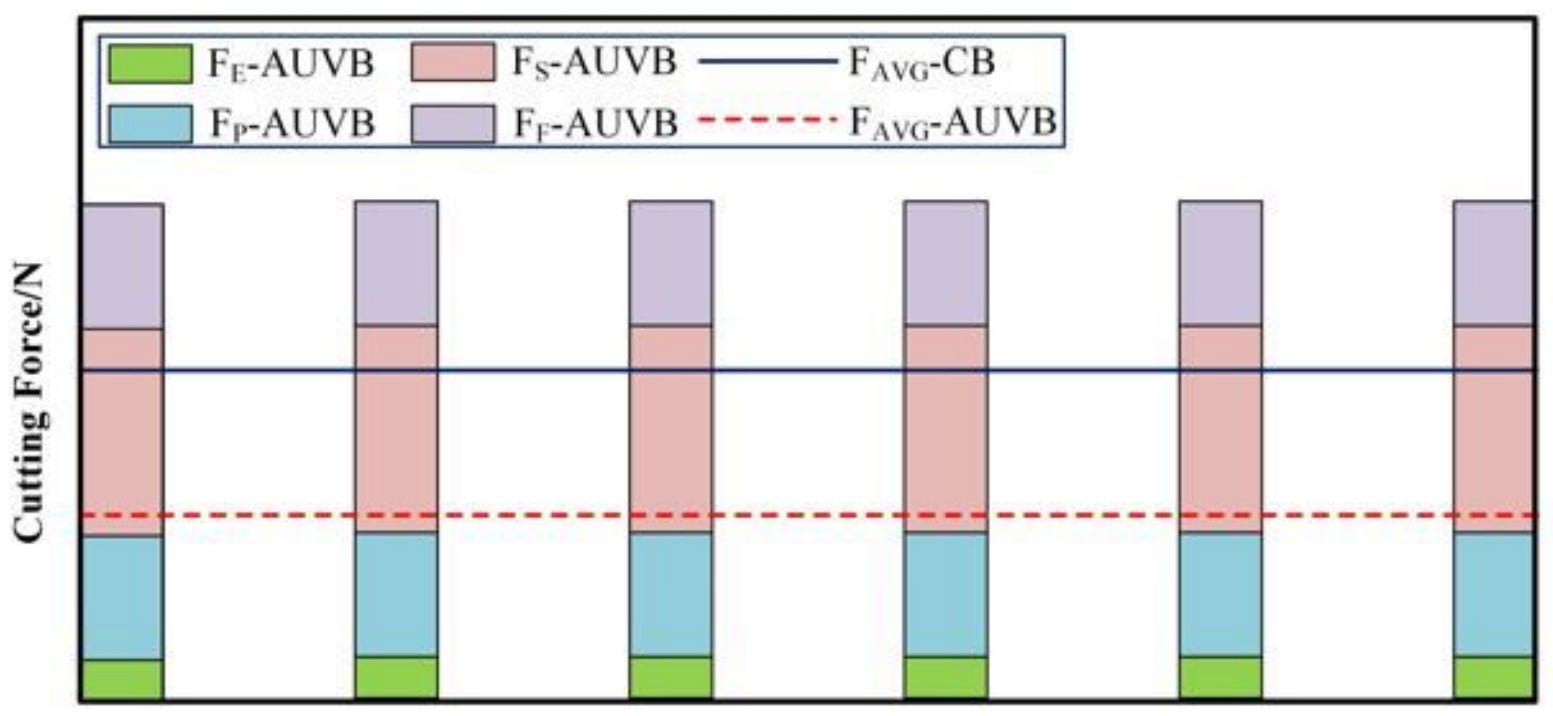

Cutting Time/s

Figure 11

Schematic of cutting force reduction principle for AUVB

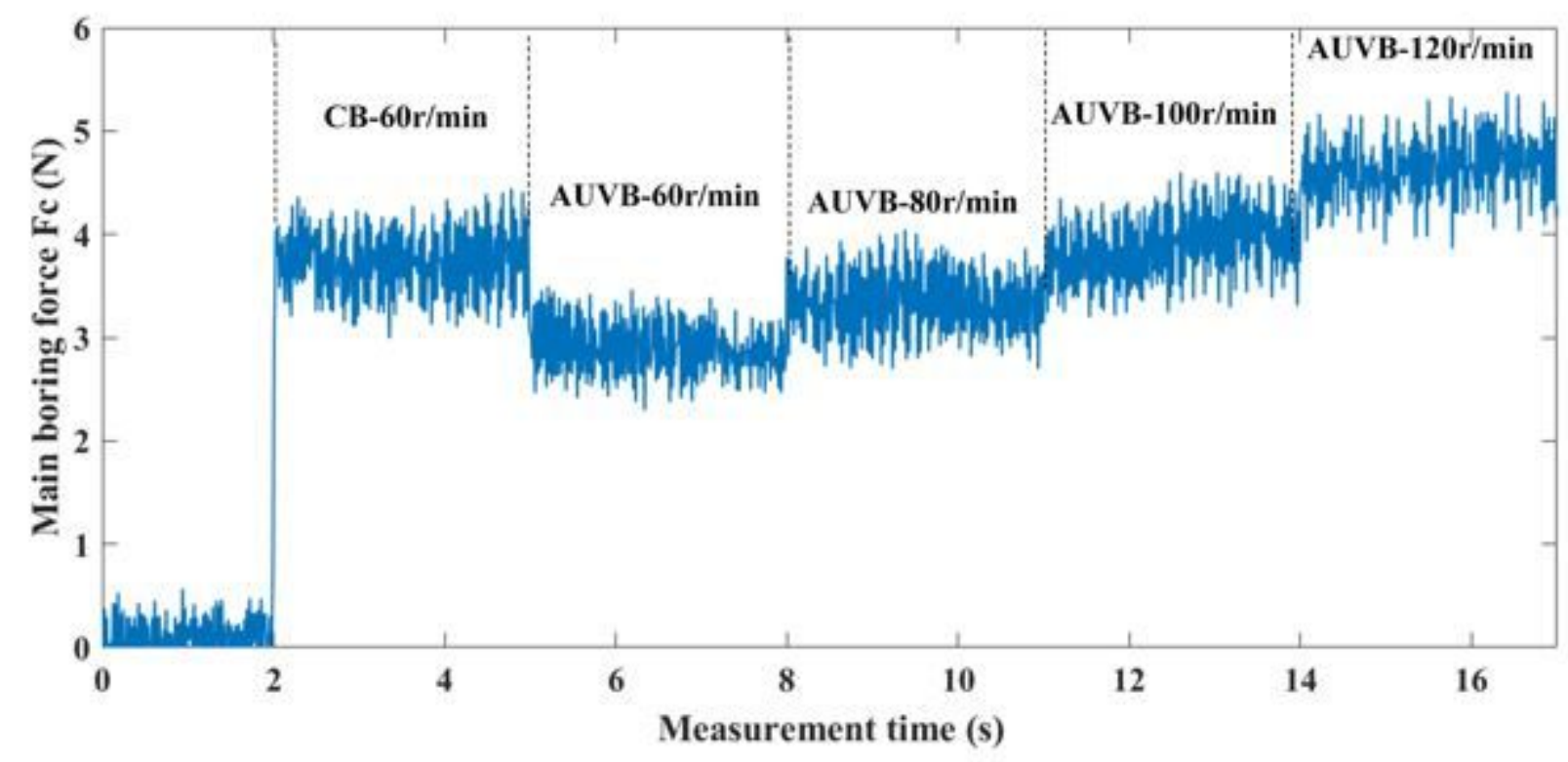

Figure 12

Boring force signals at different rotational speeds $(\mathrm{DI}=7473$ ) 


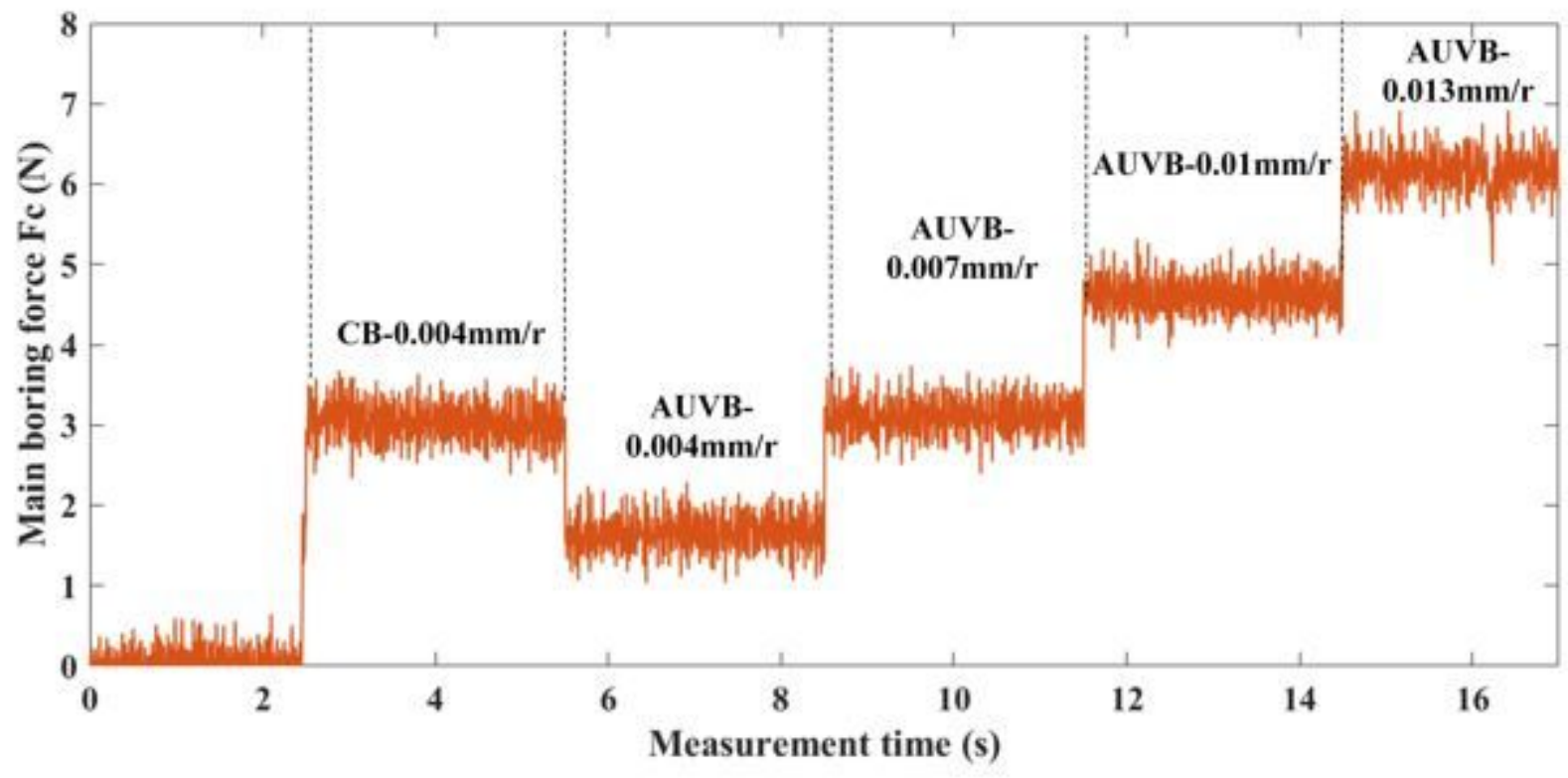

Figure 13

Boring force signals at different feed rates ( $D I=7473$ )

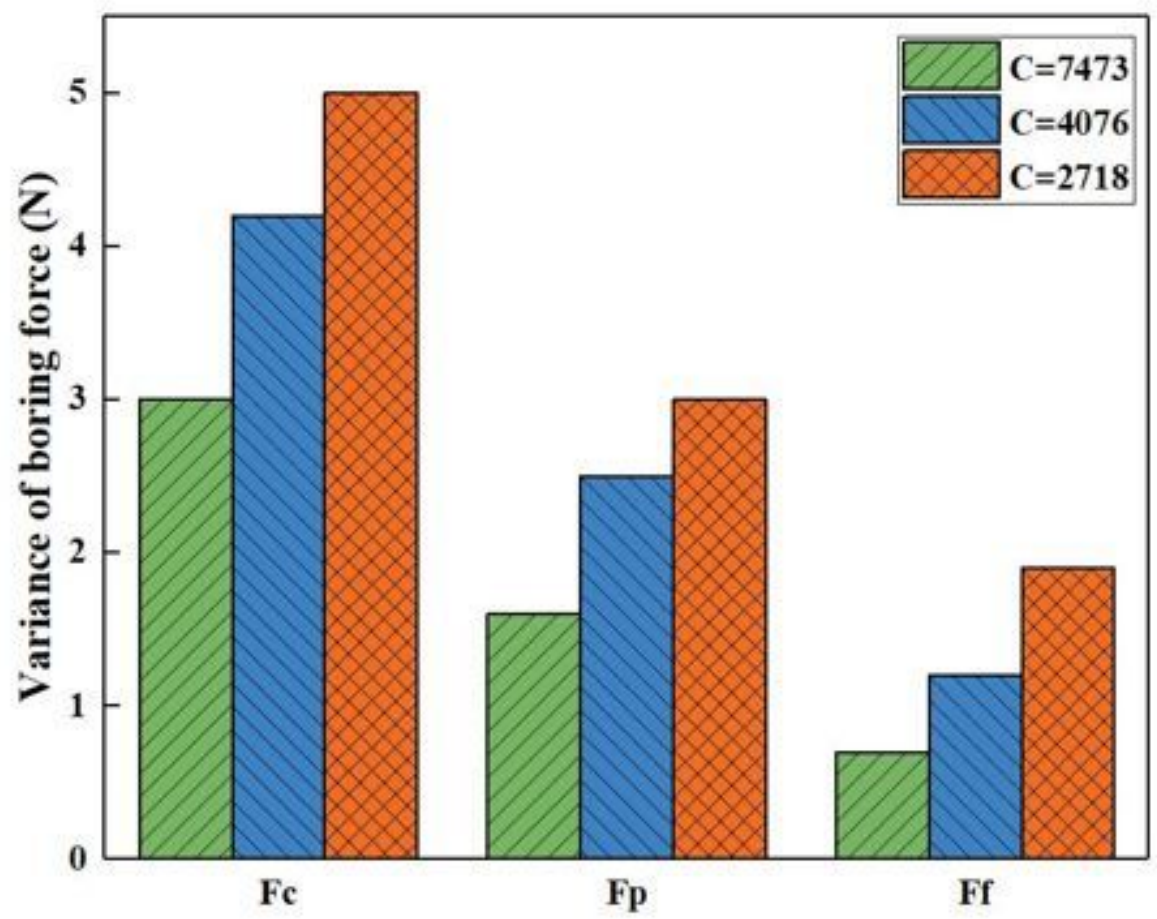

Figure 14

Influence of size coefficient on boring force for AUVB 
(a) Aperture error versus rotation speed

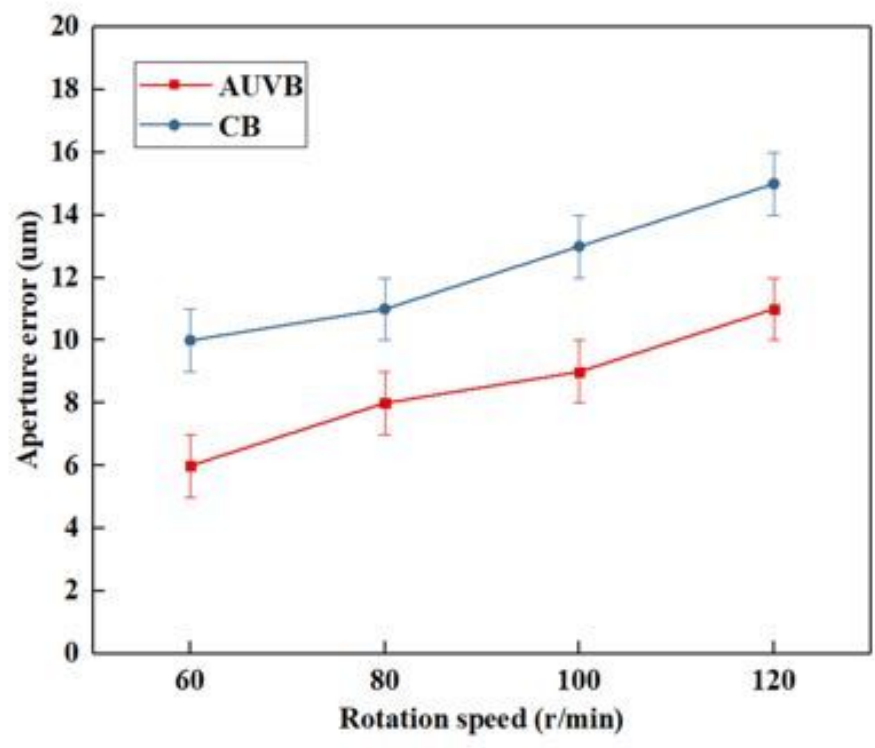

(b) Aperture error versus cutting depth

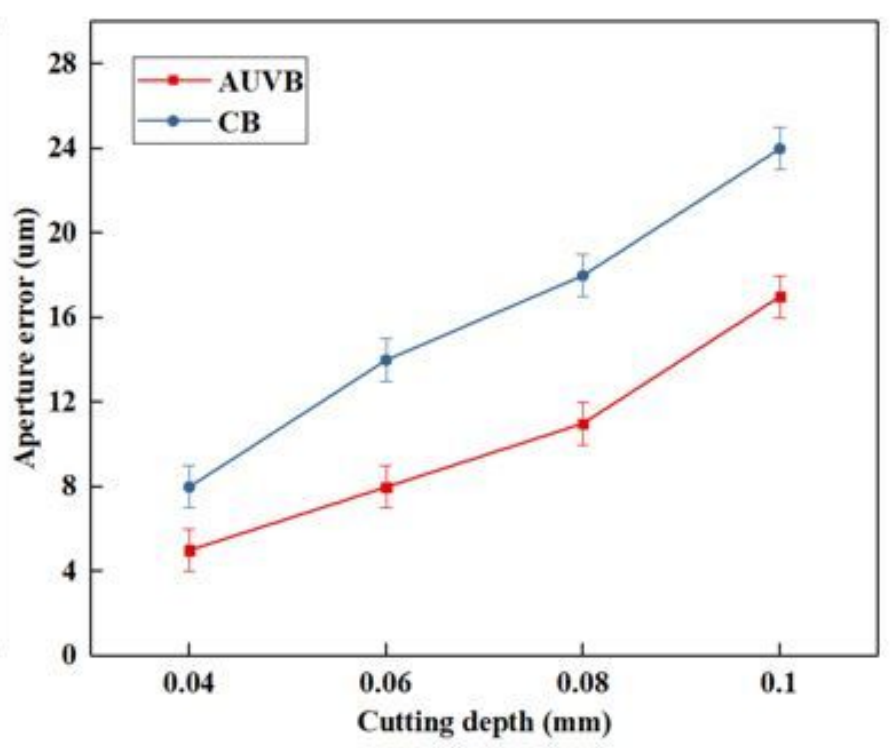

(c) Aperture error versus feed rate

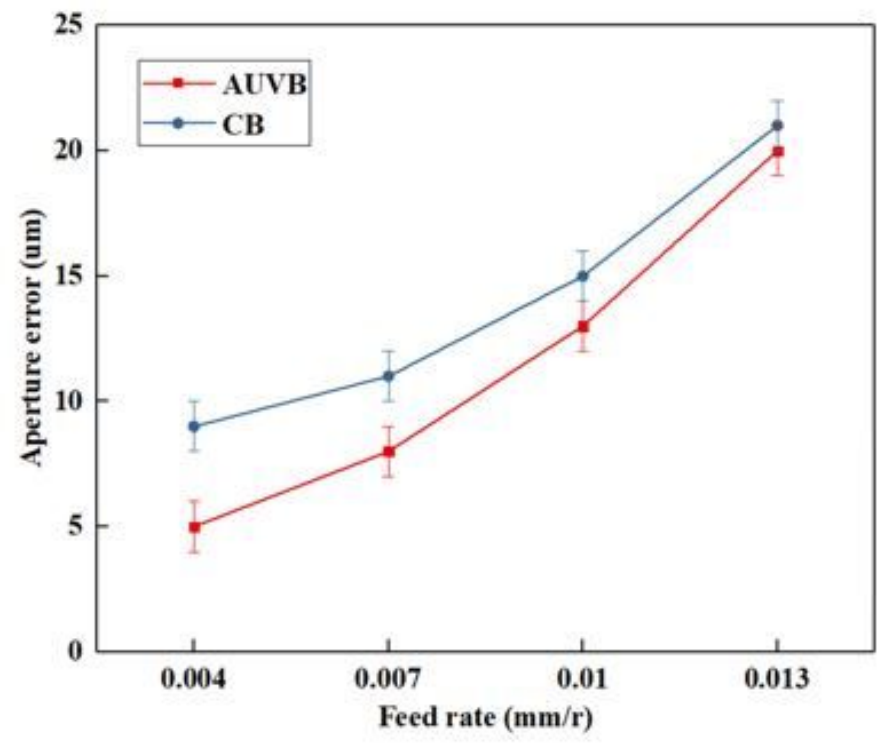

Figure 15

Influence of machining parameters on boring accuracy (DI =7473) 


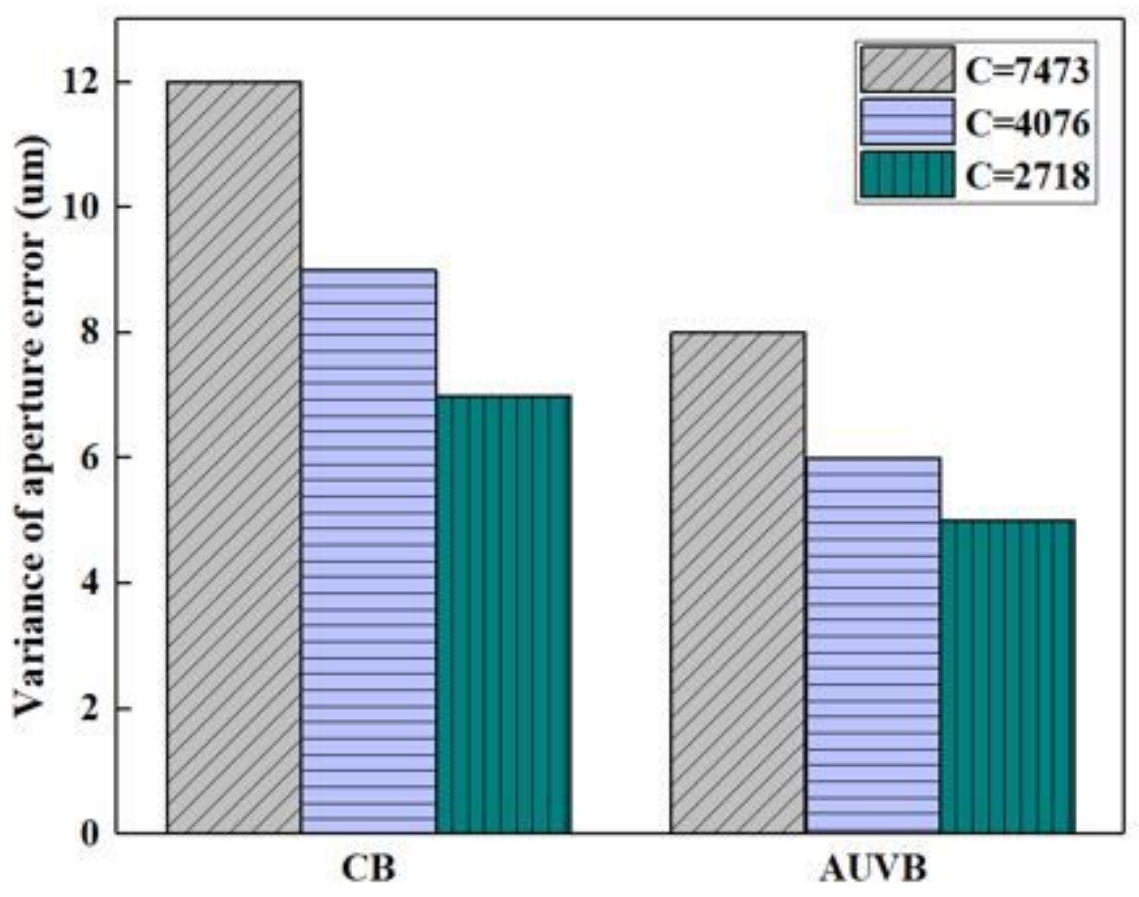

Figure 16

Influence of size coefficient on boring accuracy

(a) Vibration signals in time domain

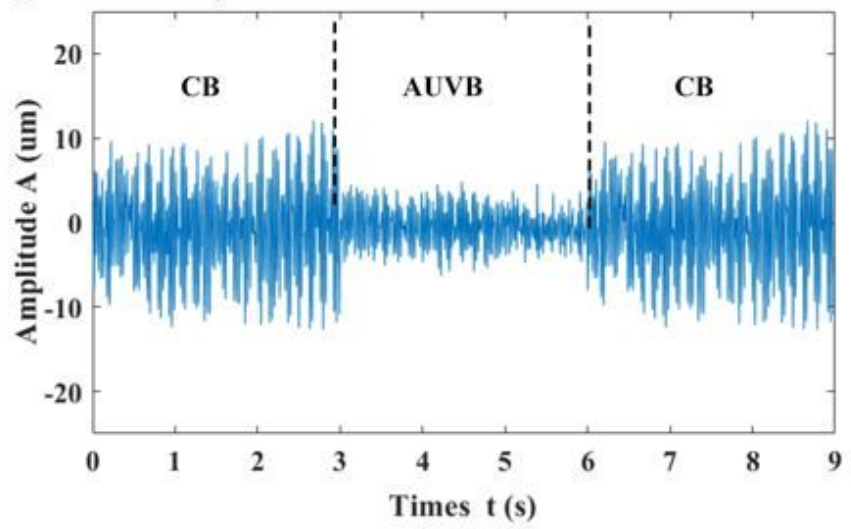

(b) Power spectrum

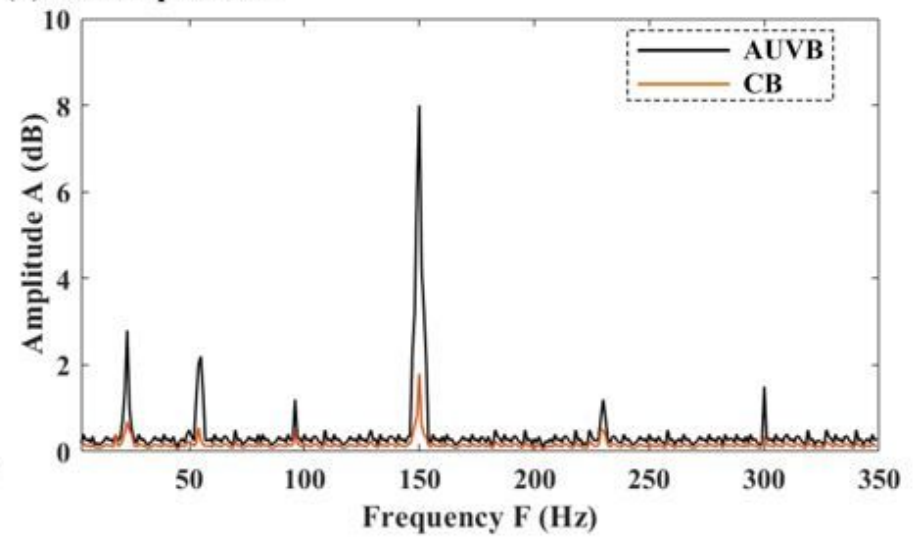

Figure 17

Vibration signals and power spectrum analysis 
(a) Vibration mode at the frequency of $18.754 \mathrm{~Hz}$

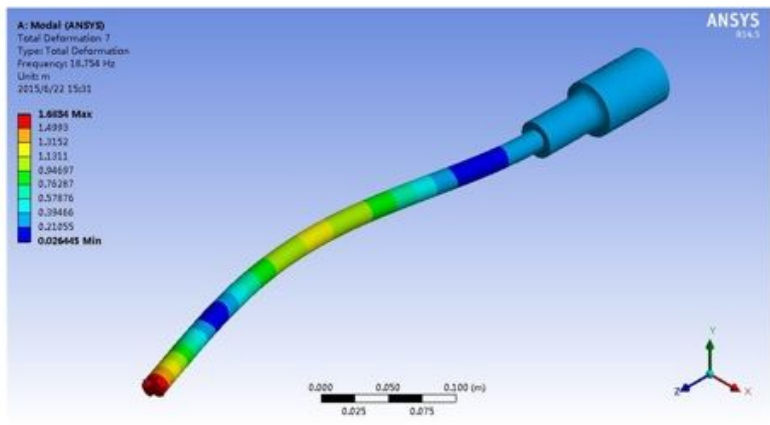

(c) Vibration mode at the frequency of $92.648 \mathrm{~Hz}$

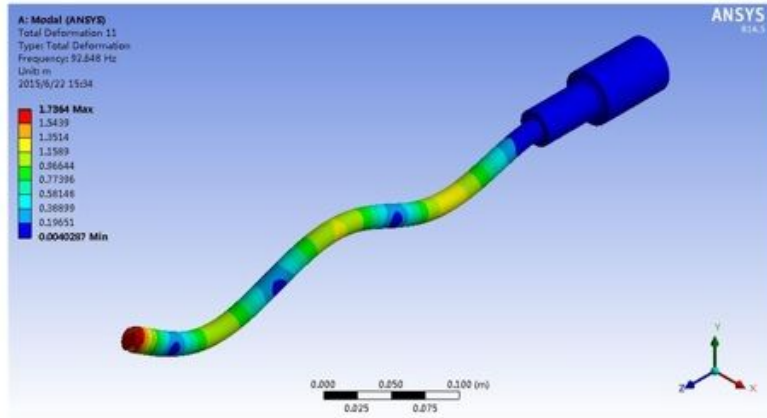

(e) Vibration mode at the frequency of $219.18 \mathrm{~Hz}$

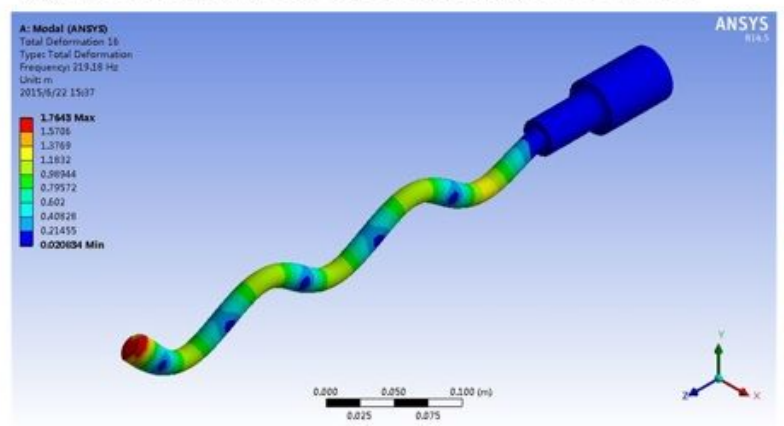

(b) Vibration mode at the frequency of $49.459 \mathrm{~Hz}$

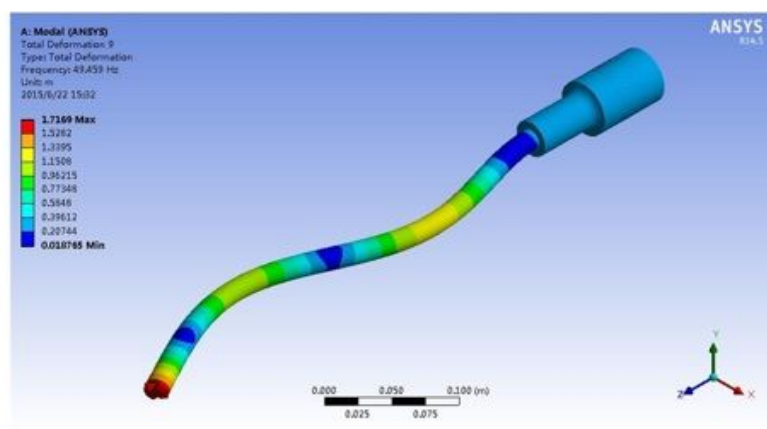

(d) Vibration mode at the frequency of $152.62 \mathrm{~Hz}$

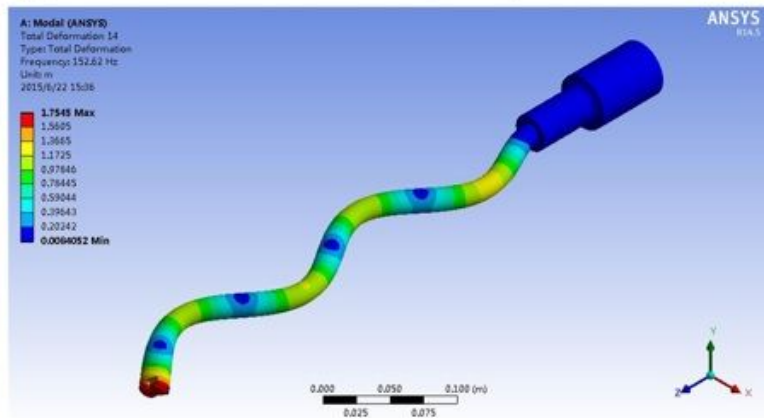

(f) Vibration mode at the frequency of $305.14 \mathrm{~Hz}$

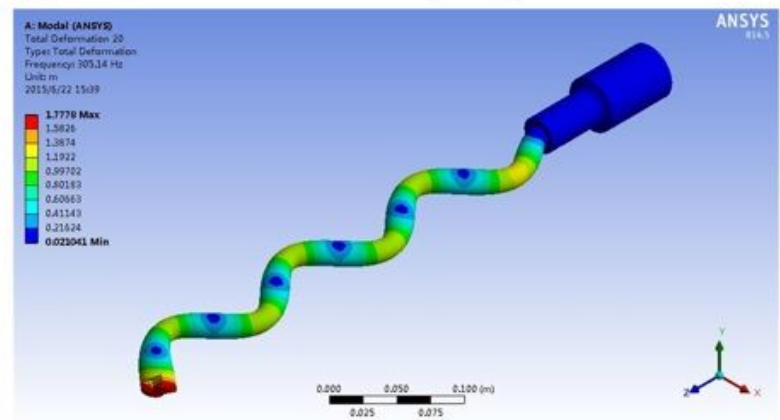

Figure 18

Vibration modal analysis results for boring bar 

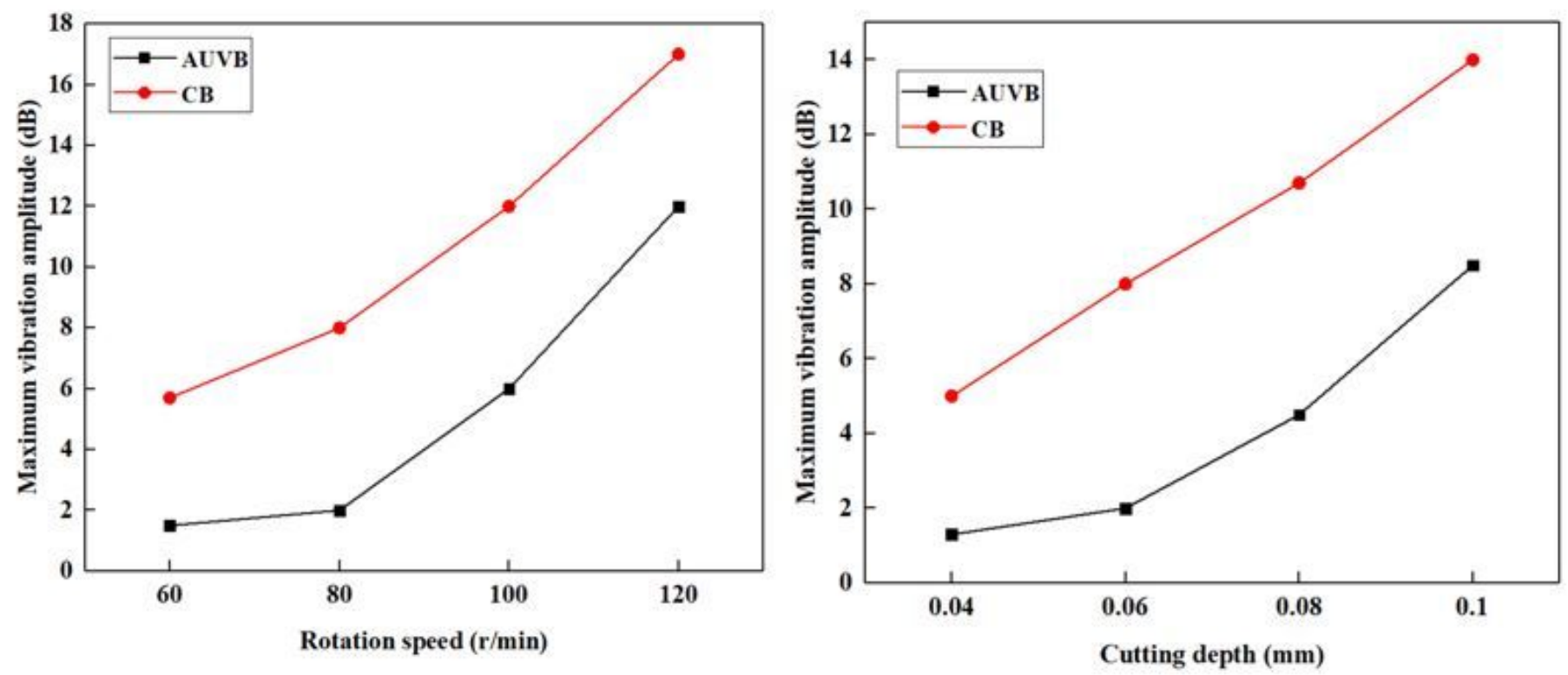

(c) Vibration amplitude (dB) versus feed rate

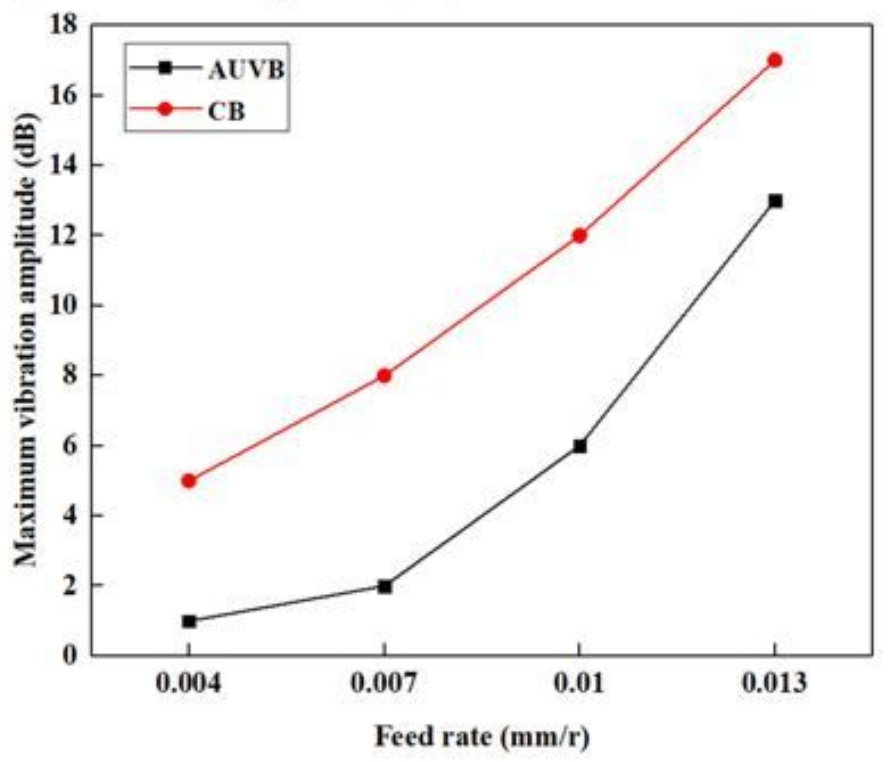

Figure 19

Influence of machining parameters on vibration amplitude (dB) (DI =7473) 


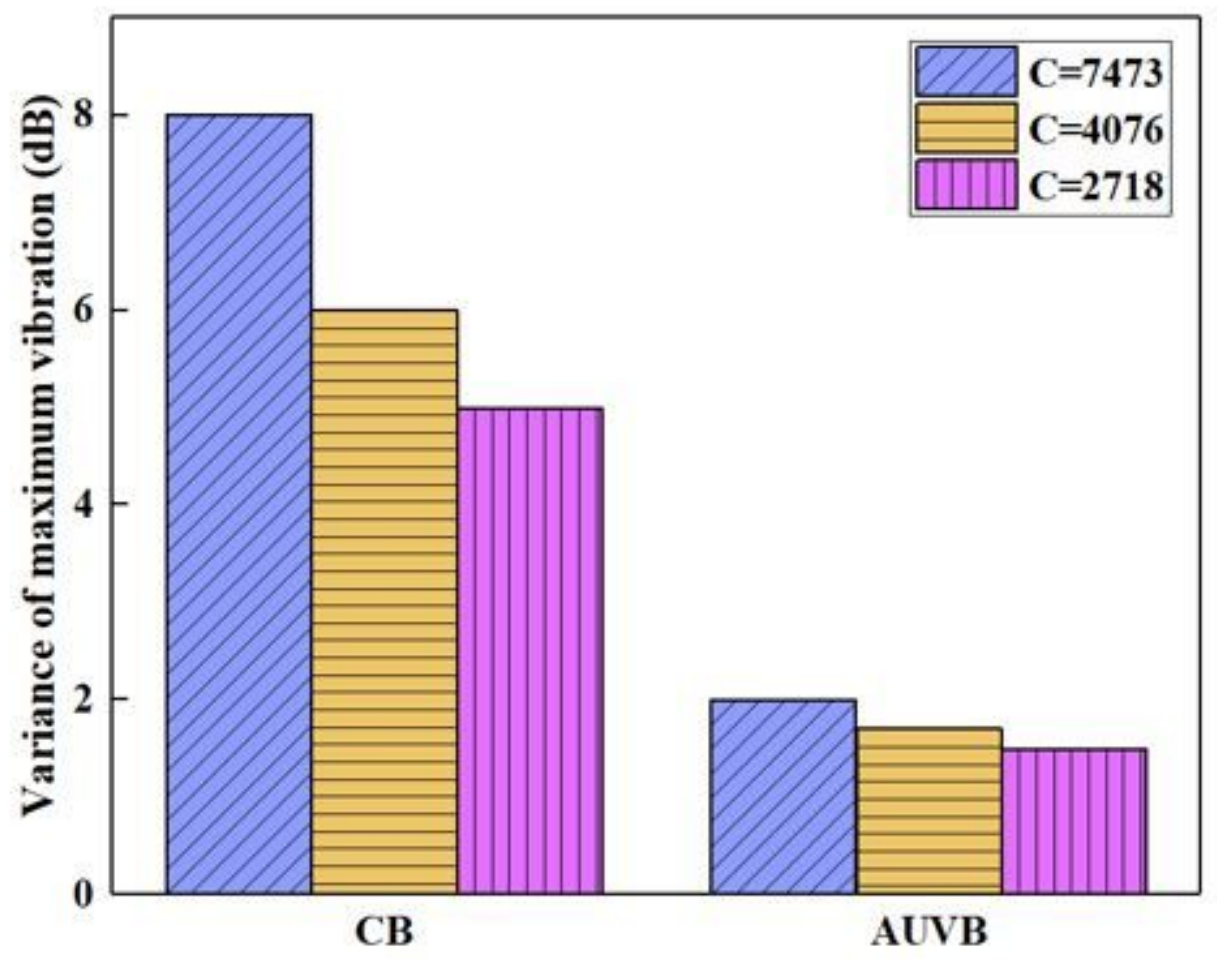

Figure 20

Influence of size coefficient on vibration amplitude $(\mathrm{dB})$

(a) Ra of machined surface along the deep hole

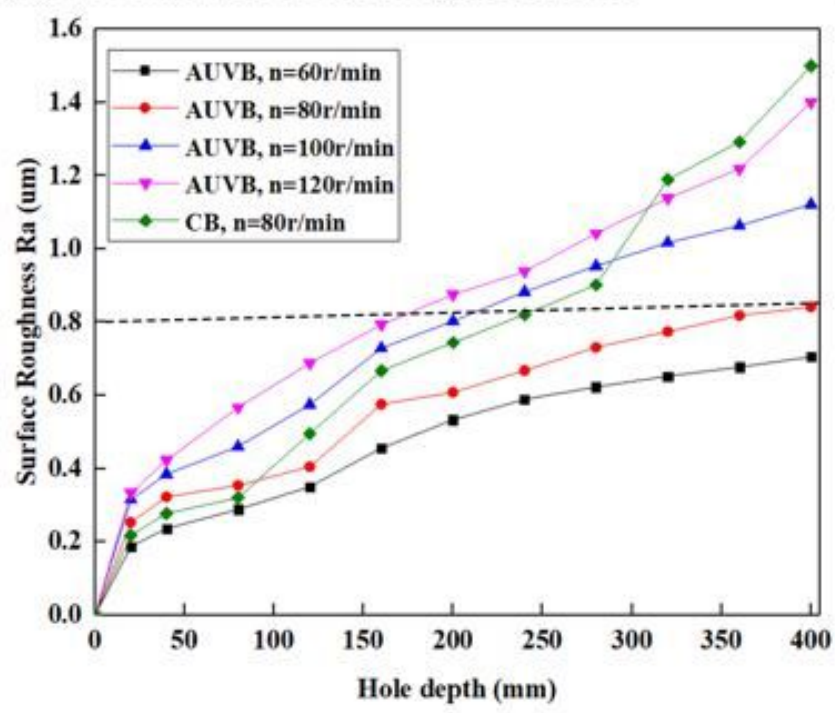

(b) Micrographs of the machined surface

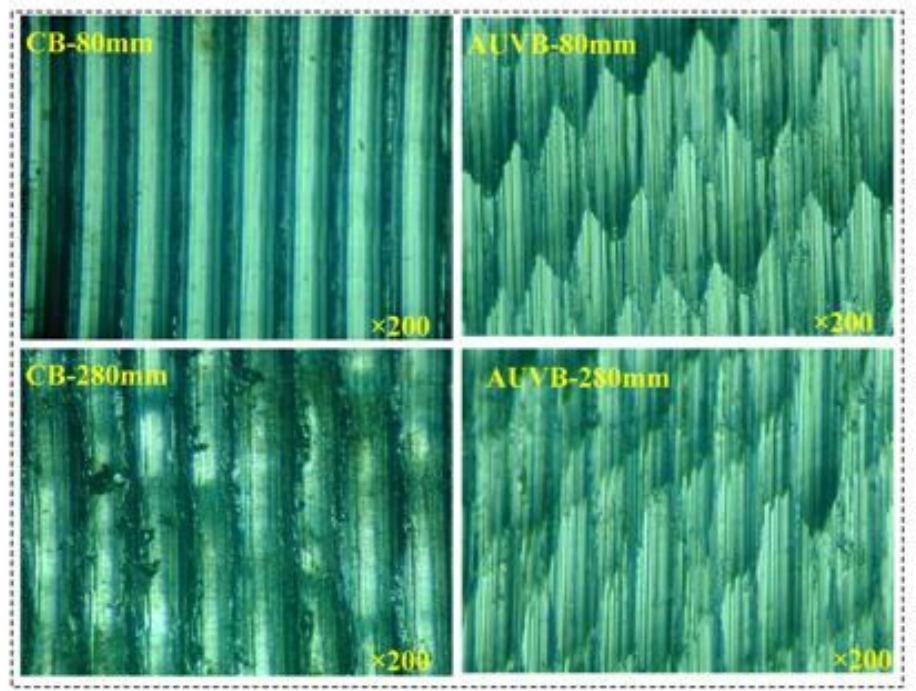

Figure 21

Roughness $(\mathrm{Ra})$ of machined surface $(\mathrm{DI}=4076)$ 


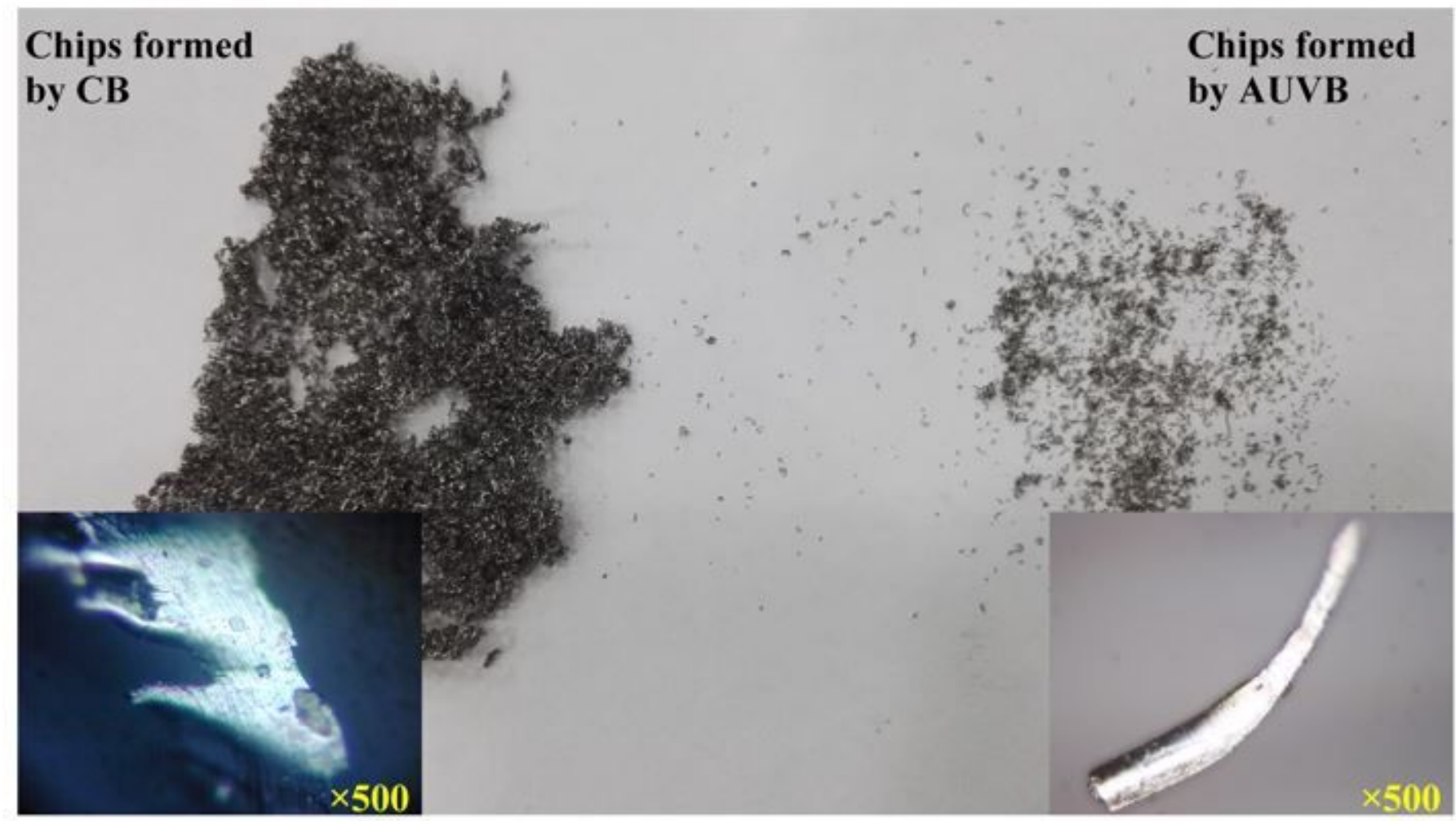

Figure 22

Chip morphologies generated by the CB and the AUVB processes

(a) Surface roughness versus rotation speed

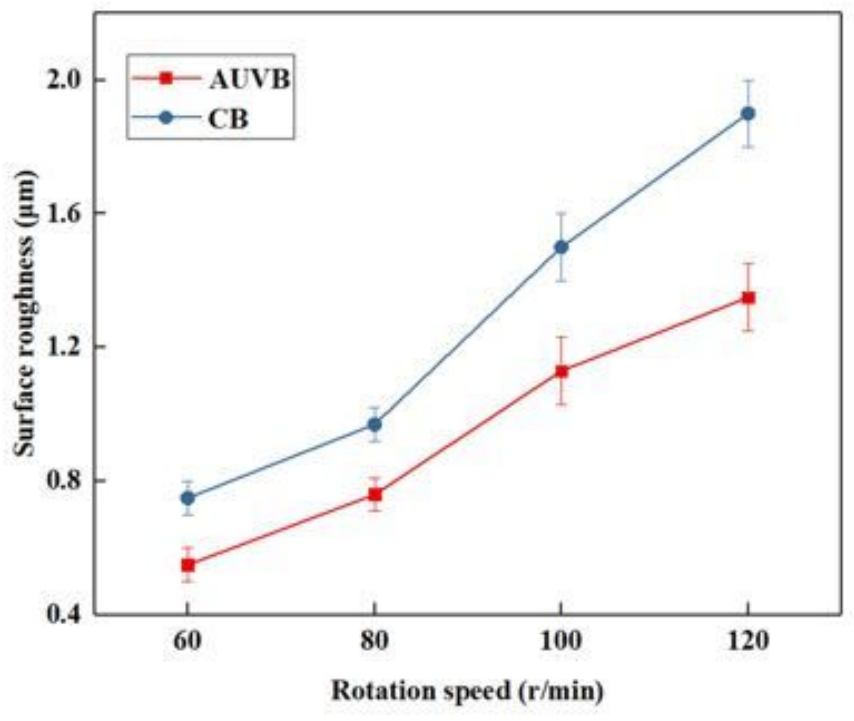

(b) Surface roughness versus feed rate

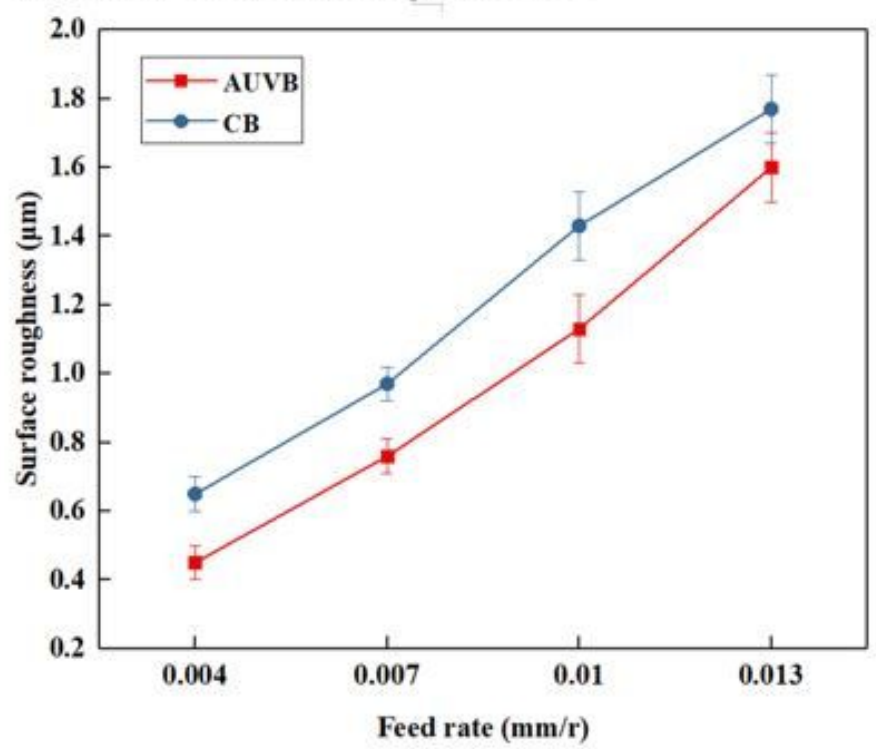

Figure 23

Influence of rotational speed and feed rate on surface roughness for AUVB (DI=4076) 


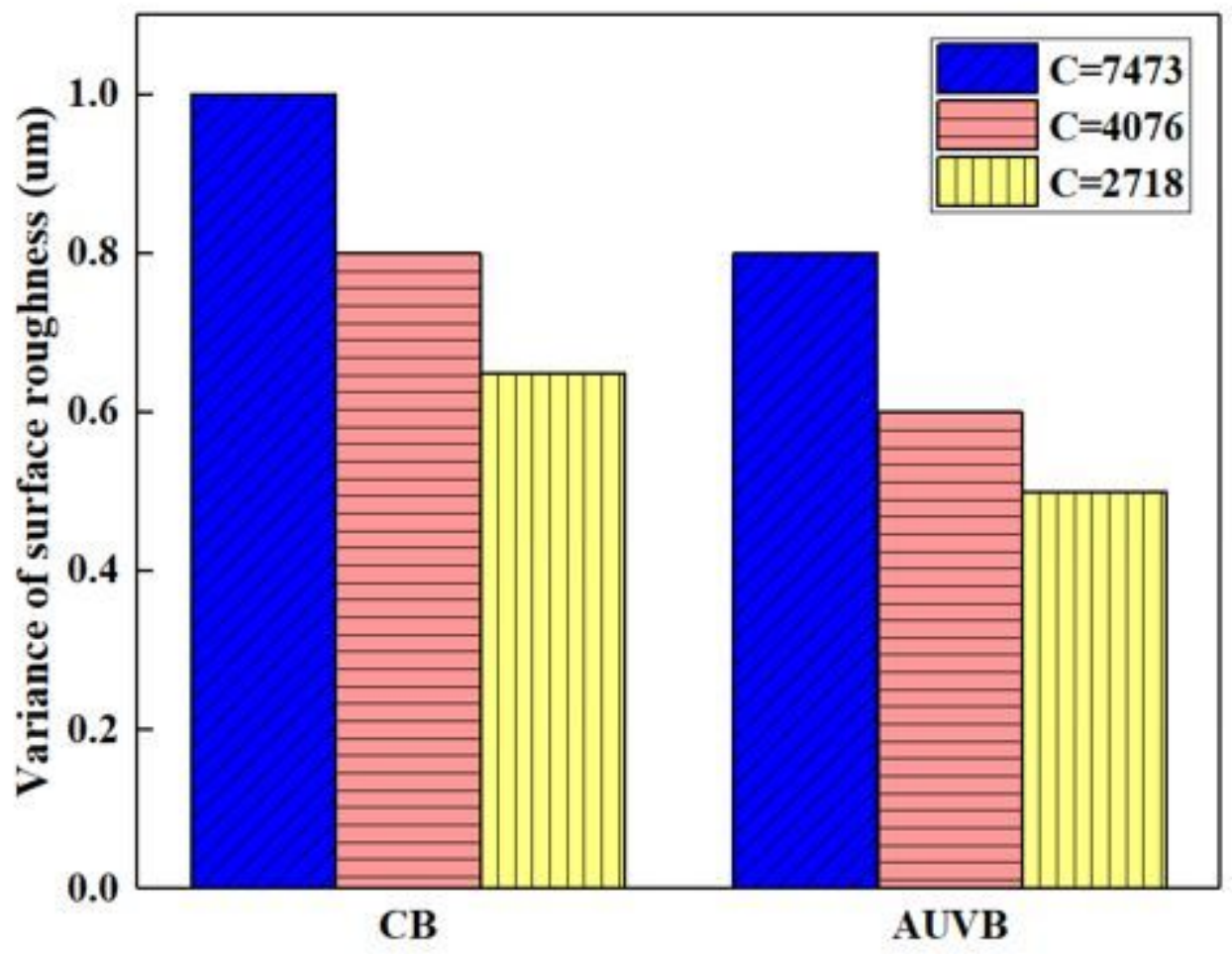

Figure 24

Impact of size coefficient on surface roughness

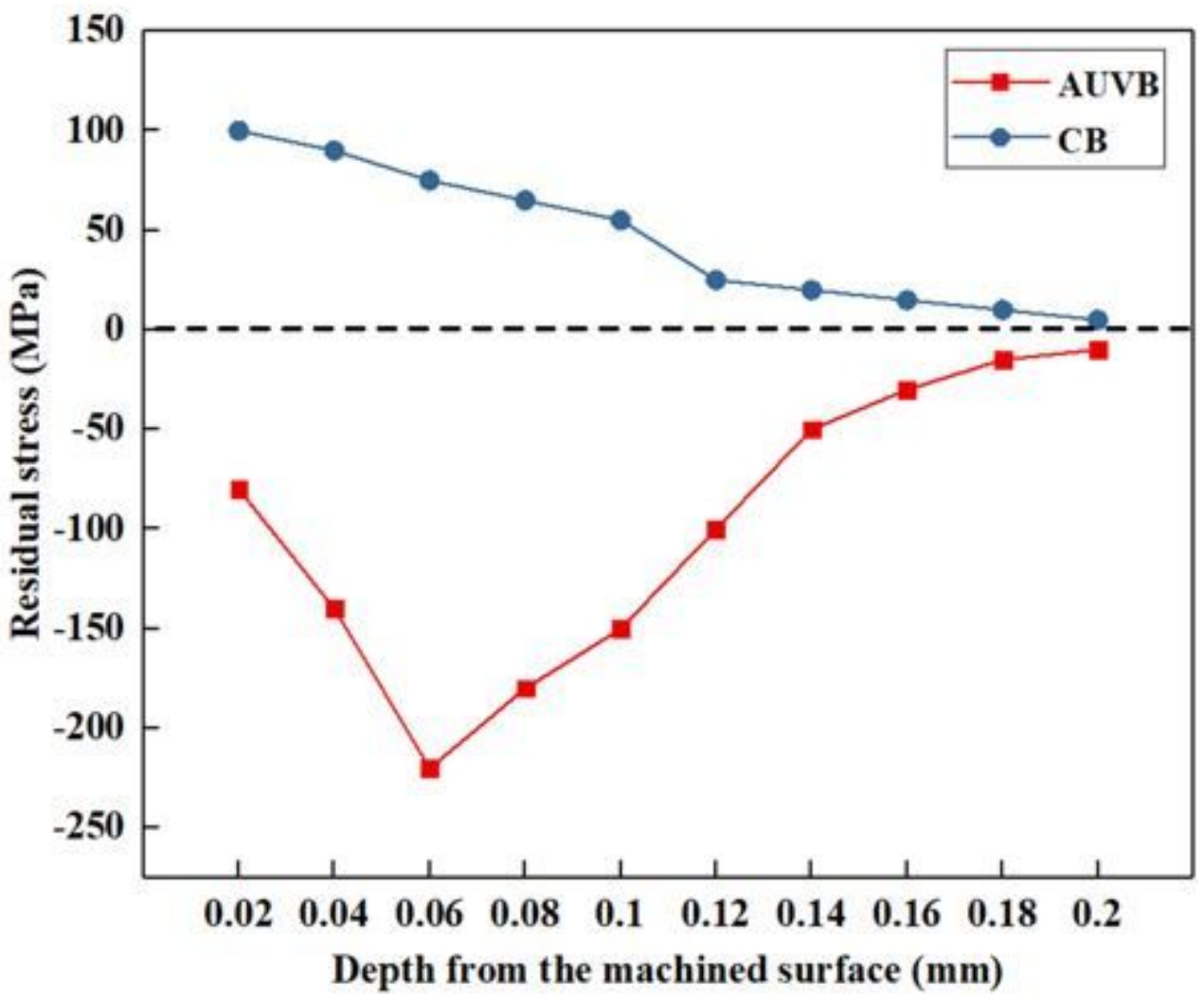


Figure 25

Residual stress of bored surface $(n=80 r / m i n, a p=0.1 \mathrm{~mm}, f=0.007 \mathrm{~mm} / \mathrm{r}, \mathrm{Dl}=4076)$ 